Florida International University

FIU Digital Commons

FIU Electronic Theses and Dissertations

University Graduate School

$7-3-2013$

\title{
Assessment of the Occurrence and Potential Risks of Antibiotics and their Metabolites in South Florida Waters Using Liquid Chromatography Tandem Mass Spectrometry
}

Venkata Reddy Panditi

vpand001@fiu.edu

DOI: $10.25148 /$ etd.FI13080706

Follow this and additional works at: https://digitalcommons.fiu.edu/etd

Part of the Analytical Chemistry Commons, Environmental Chemistry Commons, Environmental Indicators and Impact Assessment Commons, and the Environmental Monitoring $\underline{\text { Commons }}$

\section{Recommended Citation}

Panditi, Venkata Reddy, "Assessment of the Occurrence and Potential Risks of Antibiotics and their Metabolites in South Florida Waters Using Liquid Chromatography Tandem Mass Spectrometry" (2013). FIU Electronic Theses and Dissertations. 916.

https://digitalcommons.fiu.edu/etd/916 


\section{FLORIDA INTERNATIONAL UNIVERSITY}

Miami, Florida

ASSESSMENT OF THE OCCURRENCE AND POTENTIAL RISKS OF

ANTIBIOTICS AND THEIR METABOLITES

IN SOUTH FLORIDA WATERS USING LIQUID CHROMATOGRAPHY TANDEM

MASS SPECTROMETRY

A dissertation submitted in partial fulfillment of

the requirements for the degree of

DOCTOR OF PHILOSOPHY

in

CHEMISTRY

by

Venkata Reddy Panditi 
To: Dean Kenneth G. Furton

College of Arts and Sciences

This dissertation, written by Venkata Reddy Panditi, and entitled Assessment of the occurrence and potential risks of antibiotics and their metabolites in South Florida waters using liquid chromatography tandem mass spectrometry, having been approved in respect to style and intellectual content, is referred to you for judgment.

We have read this dissertation and recommend that it be approved.

Rudolf Jaffe

Yong Cai

Berrin Tansel

Jeffrey Joens

Piero R. Gardinali, Major Professor

Date of Defense: July $3^{\text {rd }}, 2013$

The dissertation of Venkata Reddy Panditi is approved.

Dean Kenneth G. Furton

College of Arts and Sciences

Dean Lakshmi N. Reddi

University Graduate School

Florida International University, 2013

ii 
(C) Copyright 2013 by Venkata Reddy Panditi

All rights reserved. 


\section{DEDICATION}

This thesis is dedicated to the memory of my beloved mother, Samrajyam. She inspired me through her pain and suffering. I would also like to dedicate this thesis to my wife,

Sudha Rani and loving daughter, Hasini, for their understanding, support and unconditional love. 


\section{ACKNOWLEDGEMENTS}

I would like to express the deepest appreciation to my major professor, Piero Gardinali for being such an inspiring mentor, who has the attitude and the substance of genius. Every conversation with him made me to question my propositions and think critically to find the answer that led me to become a better scientist. Without his guidance and persistent support this dissertation would not been possible.

I would like to thank my committee members Dr. Rudolf Jaffe, Dr. Yong Cai, Dr. Jeffrey Joenes and Dr. Berring Tansel for sharing their ideas and constructive comments that helped as check points during the course of my research study. I would also like to thank Professor Dr. Kati Migliaccio and her research crew from University of Florida, Tropical Research and Education Center (TREC), Homestead, for helping me in ground water sample collection.

My special thanks to one of my best friends Natalia. She was always helpful and guided me during difficult times.

I also would like to thank my loving brother, Sridhara Reddy for his moral support. I feel he is always with me. Finally, I wish to thank all my co-workers, fellow students and friends for leaving me such a memorable time in college. 


\author{
ABSTRACT OF THE DISSERTATION \\ ASSESSMENT OF THE OCCURRENCE AND POTENTIAL RISKS OF \\ ANTIBIOTICS AND THEIR METABOLITES \\ IN SOUTH FLORIDA WATERS USING LIQUID CHROMATOGRAPHY TANDEM \\ MASS SPECTROMETRY \\ by \\ Venkata Reddy Panditi
}

Florida International University, 2013

Miami, Florida

Professor Piero R. Gardinali, Major Professor

An automated on-line SPE-LC-MS/MS method was developed for the quantitation of multiple classes of antibiotics in environmental waters. High sensitivity in the low ng/L range was accomplished by using large volume injections with $10-\mathrm{mL}$ of sample. Positive confirmation of analytes was achieved using two selected reaction monitoring (SRM) transitions per antibiotic and quantitation was performed using an internal standard approach. Samples were extracted using online solid phase extraction, then using column switching technique; extracted samples were immediately passed through liquid chromatography and analyzed by tandem mass spectrometry. The total run time per each sample was $20 \mathrm{~min}$. The statistically calculated method detection limits for various environmental samples were between 1.2 and $63 \mathrm{ng} / \mathrm{L}$. Furthermore, the method was validated in terms of precision, accuracy and linearity.

The developed analytical methodology was used to measure the occurrence of antibiotics in reclaimed waters $(n=56)$, surface waters $(n=53)$, ground waters $(n=8)$ and drinking 
waters $(\mathrm{n}=54)$ collected from different parts of South Florida. In reclaimed waters, the most frequently detected antibiotics were nalidixic acid, erythromycin, clarithromycin, azithromycin trimethoprim, sulfamethoxazole and ofloxacin (19.3-604.9 ng/L). Detection of antibiotics in reclaimed waters indicates that they can't be completely removed by conventional wastewater treatment process. Furthermore, the average mass loads of antibiotics released into the local environment through reclaimed water were estimated as $0.248 \mathrm{Kg} /$ day. Among the surface waters samples, Miami River (reaching up to 580 ng/L) and Black Creek canal (up to $124 \mathrm{ng} / \mathrm{L}$ ) showed highest concentrations of antibiotics. No traces of antibiotics were found in ground waters. On the other hand, erythromycin (monitored as anhydro erythromycin) was detected in $82 \%$ of the drinking water samples (n.d-66 ng/L). The developed approach is suitable for both research and monitoring applications.

Major metabolites of antibiotics in reclaimed wates were identified and quantified using high resolution benchtop Q-Exactive orbitrap mass spectrometer. A phase I metabolite of erythromycin was tentatively identified in full scan based on accurate mass measurement. Using extracted ion chromatogram (XIC), high resolution data-dependent MS/MS spectra and metabolic profiling software the metabolite was identified as desmethyl anhydro erythromycin with molecular formula $\mathrm{C}_{36} \mathrm{H}_{63} \mathrm{NO}_{12}$ and $\mathrm{m} / \mathrm{z}$ 702.4423. The molar concentration of the metabolite to erythromycin was in the order of $13 \%$. To my knowledge, this is the first known report on this metabolite in reclaimed water. Another compound acetyl-sulfamethoxazole, a phase II metabolite of sulfamethoxazole was also identified in reclaimed water and mole fraction of the metabolite represent $36 \%$, of the vii 
cumulative sulfamethoxazole concentration. The results were illustrating the importance to include metabolites also in the routine analysis to obtain a mass balance for better understanding of the occurrence, fate and distribution of antibiotics in the environment.

Finally, all the antibiotics detected in reclaimed and surface waters were investigated to assess the potential risk to the aquatic organisms. The surface water antibiotic concentrations that represented the real time exposure conditions revealed that the macrolide antibiotics, erythromycin, clarithromycin and tylosin along with quinolone antibiotic, ciprofloxacin were suspected to induce high toxicity to aquatic biota. Preliminary results showing that, among the antibiotic groups tested, macrolides posed the highest ecological threat, and therefore, they may need to be further evaluated with, long-term exposure studies considering bioaccumulation factors and more number of species selected. Overall, the occurrence of antibiotics in aquatic environment is posing an ecological health concern. 


\section{TABLE OF CONTENTS}

\section{CHAPTER}

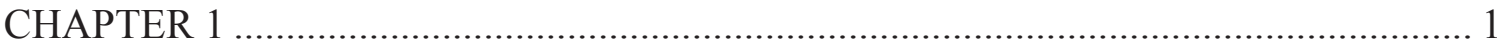

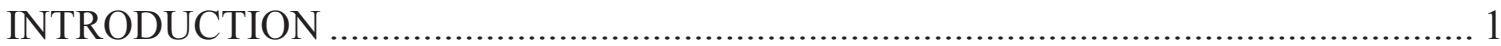

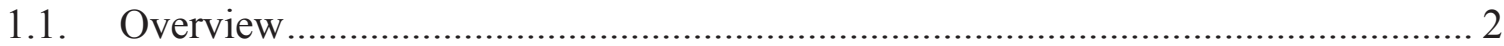

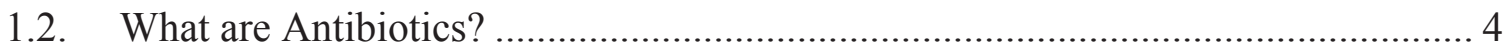

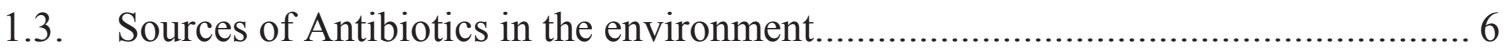

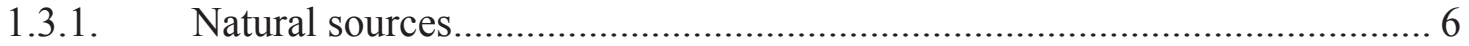

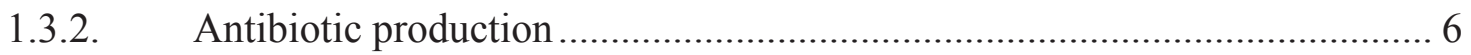

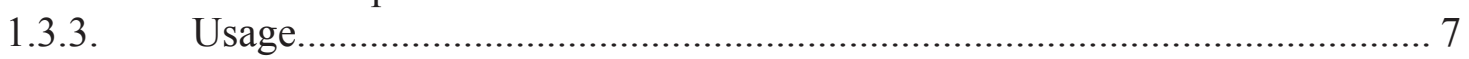

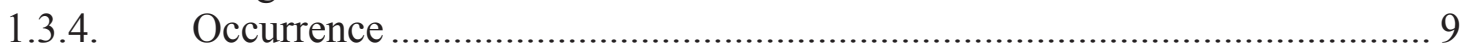

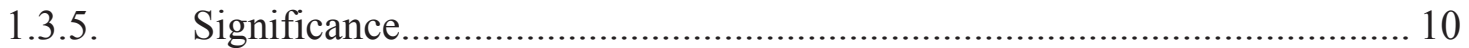

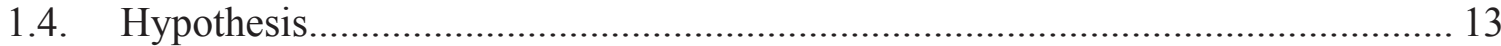

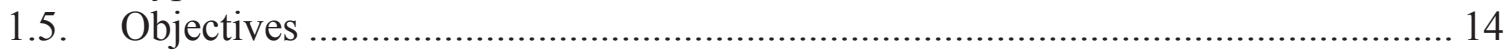

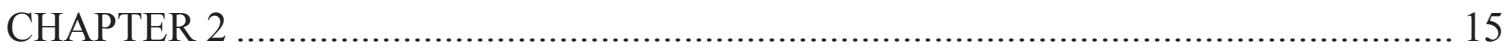

Online solid-phase extraction-liquid chromatography-electrospray-tandem mass spectrometry method for determination of multiple classes of antibiotics ....................... 15

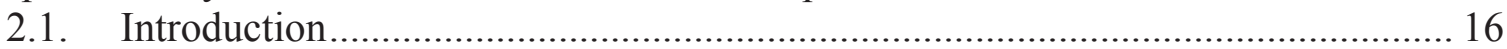

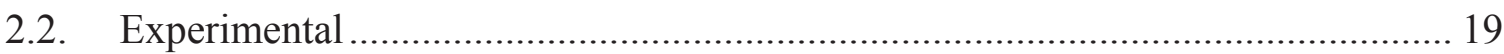

2.2.1. Standards, reagents, and solutions …………....................................... 19

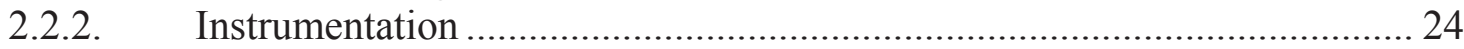

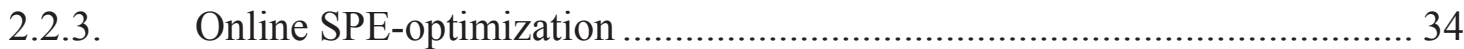

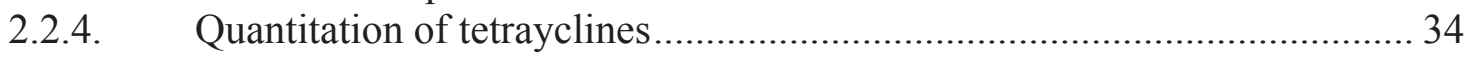

2.2.5. Matrix effect............................................................................. 35

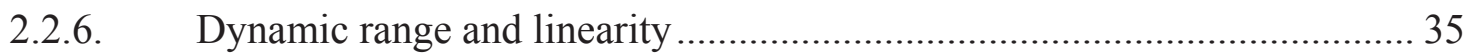

2.2.7. Method accuracy and detection limits ....................................................... 37

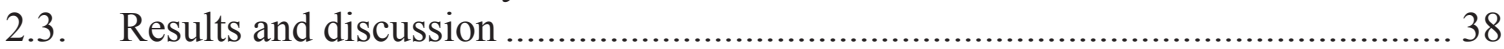

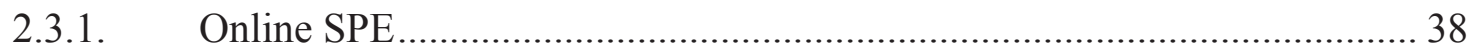

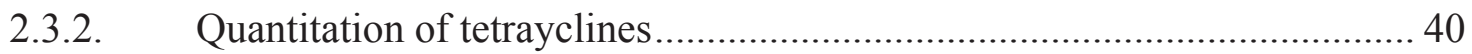

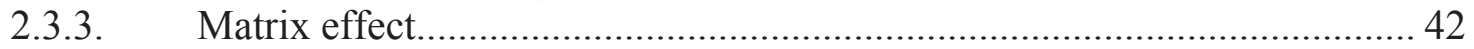

2.3.4. Method accuracy and detection limits .................................................... 45

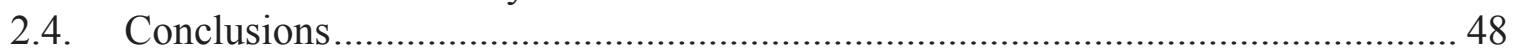

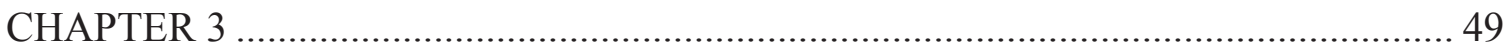

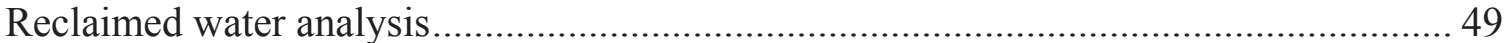

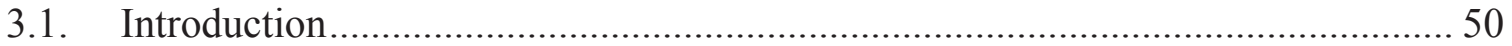

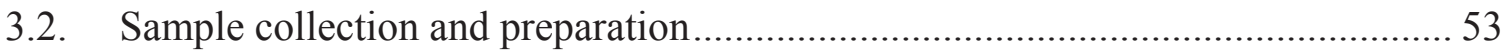

3.3. Applicability of the method to reclaimed water samples....................................... 54

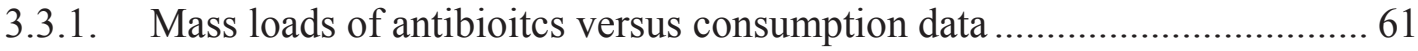

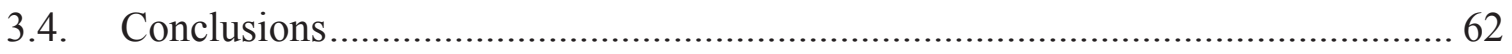




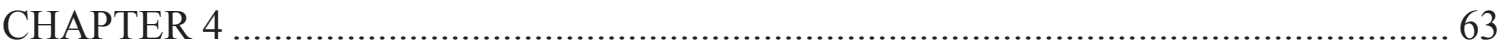

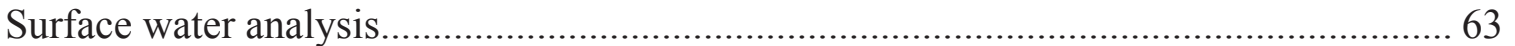

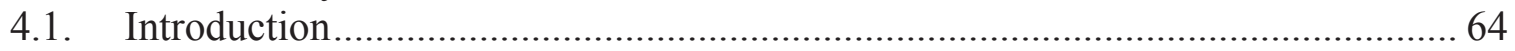

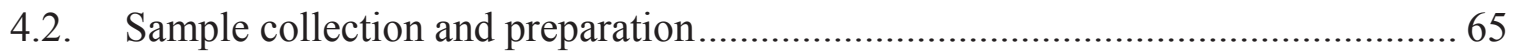

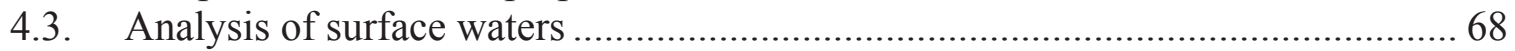

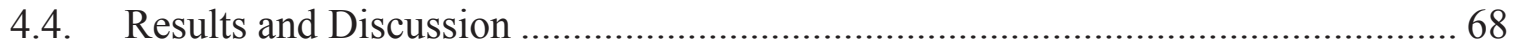

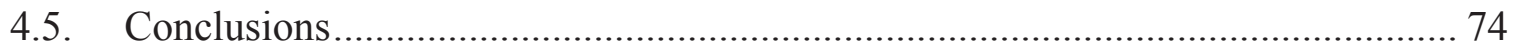

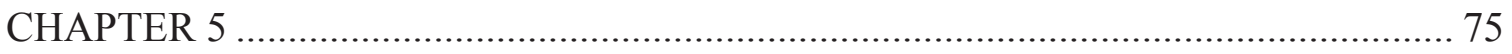

Drinking water and Ground water analysis .............................................................. 75

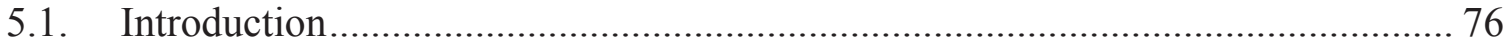

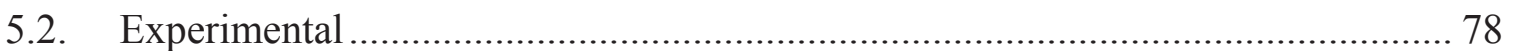

5.2.1. Sample collection and preparation........................................................ 78

5.2.2. Optimization of analytical methodology ................................................. 79

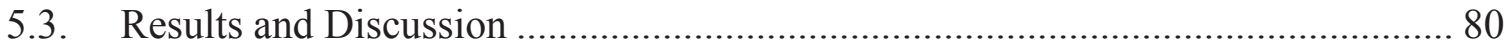

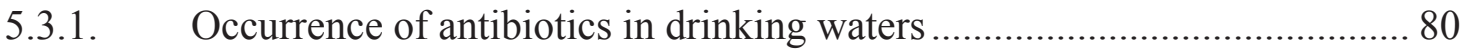

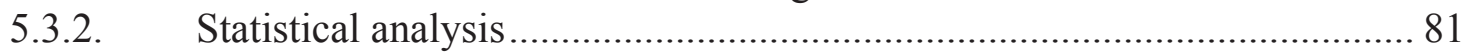

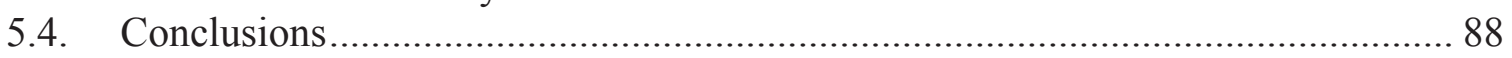

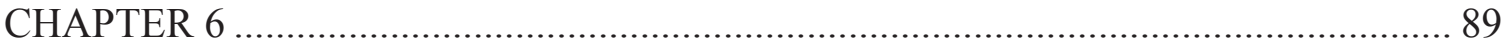

Identification of antibiotic metabolites and their transformation products in reclaimed water using high resolution benchtop Orbitrap mass spectrometry ................................. 89

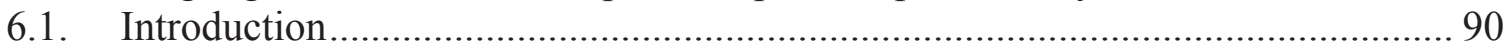

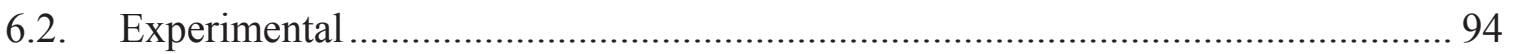

6.2.1. Chemicals and Standards .................................................................... 94

6.2.2. Sample collection, extraction and preparation........................................... 95

6.2.3. Liquid Chromatography and High Resolution Mass Spectrometry............ 95

6.2.4. Data processing and Interpretation ........................................................... 97

6.2.4.1. Tentative identification of potential metabolites and transformation products in reclaimed water .................................................................................... 99

6.2.5. Identification of Desmethyl-anhydroerythromycin .................................. 104

6.2.6. Identification of acetyl-sulfamethoxazole............................................. 109

6.2.7. Determination of erythromycin, sulfamethoxazole and their metabolites in

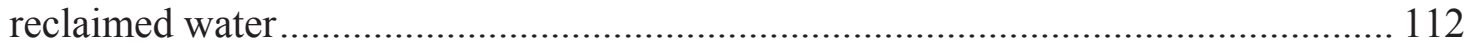

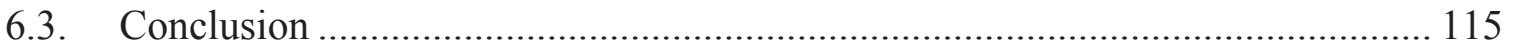

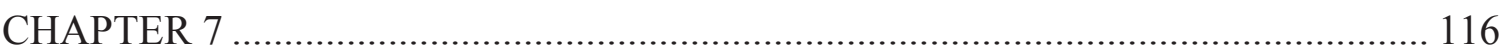

Environmental risk assessment of antibiotic residues in reclaimed and surface waters. 116

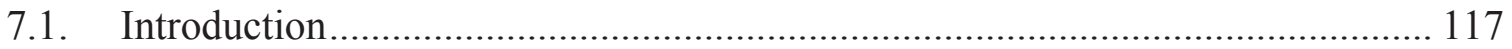

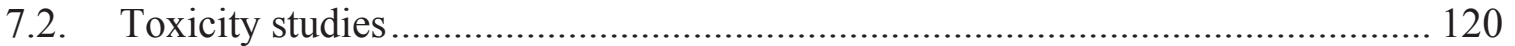

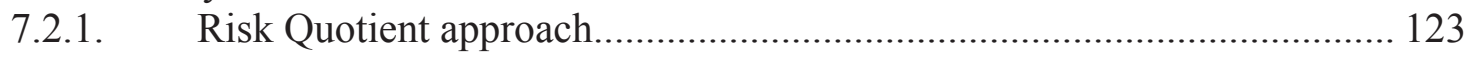

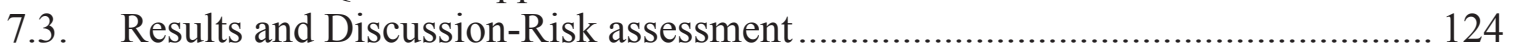

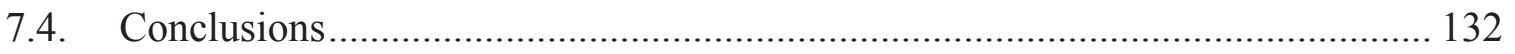


CONCLUSION..

REFERENCES . 


\section{LIST OF TABLES}

TABLE

PAGE

Table 1. Target antibiotics and their classification

Table 2. Nationwide antibacterial drug use in humans and food producing animals in the U.S. 8

Table 3. Structures of the selected antibiotics 21

Table 4. Optimized parameters for the detection of all analytes and internal standards in MS/MS SRM mode. 28

Table 5. Mobile phase program for the load pumps (top) and analytical (bottom) ......... 40

Table 6. Signal suppression/enhancement values of tetrayclines in reclaimed waters using sulfamethoxazole-d5 as internal standard.

Table 7. Signal suppression/enhancement values in reclaimed water sample matrix ...... 43

Table 8. Intra- and inter- day precision for all analytes expressed as \%RSD 44

Table 9. Method detection limits of target analytes in deionized, river and reclaimed water matrices 46

Table 10. Reclaimed water statistics for the target analytes $(n=56)$. 56

Table 11. Estimated mass loads ( $\mu \mathrm{g} / \mathrm{day} /$ person) of targeted analytes in reclaimed waters 60

Table 12. Surface waters sampling site, latitude and longitude details 65

Table 13. Method detection limits of target analytes in salt waters. 68

Table 14. Distribution of antibiotics in the selected sample locations in ng/L... 73

Table 15. Results of an ANOVA test using the samples from three major drinking water treatment plants 84 
Table 16. Mass accuracy of selected antibiotics based on exact mass and observed mass

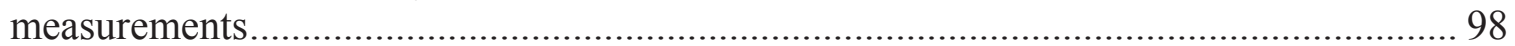

Table 17. Antibiotics and corresponding tentatively identified metabolites .................. 100

Table 18. Antibiotics detected in reclaimed water and their toxicology data from

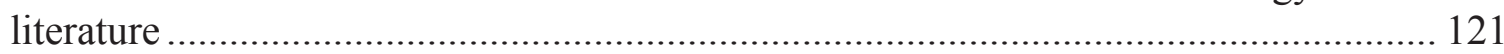

Table 19. PNEC and risk quotients for antibiotics in reclaimed waters using mean

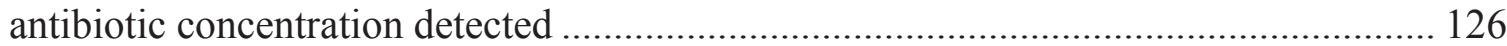

Table 20. PNEC and risk quotients for antibiotics in surface waters using mean antibiotic concentration detected 127

Table 21. PNEC and risk quotients for antibiotics in reclaimed waters using maximum

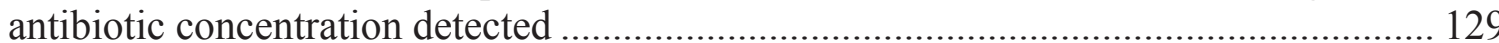

Table 22. PNEC and risk quotients for antibiotics in surface waters using maximum antibiotic concentration detected 130 


\section{LIST OF FIGURES}

FIGURE

PAGE

Figure 1. Possible sources and pathways for the environmental occurrence of antibiotics, modified from Anderson et al., 2011. 10

Figure 2. Schematic of online solid phase extraction using Thermo Fisher EQuan system

Figure 3. SPE-LC-MS/MS chromatograms of a reclaimed water sample fortified with antibiotics at a concentration equivalent to calibration 5 (CS5), 23-301 ng/L 31

Figure 4. SPE-LC-MS/MS chromatograms of an unfortified reclaimed water sample. Analytes with concentration above MDL include sulfadiazine, trimethoprim, ofloxacin, doxycycline, sulfamethoxazole, meclocycline, azithromycin, tylosin, erythromycin, nalidixic acid and clarithromycin. 33

Figure 5. Comparison of loading columns tested for the current study $(n=3)$ Sulfamethoxazole-d4 was used for quantification of tetracyclines instead of

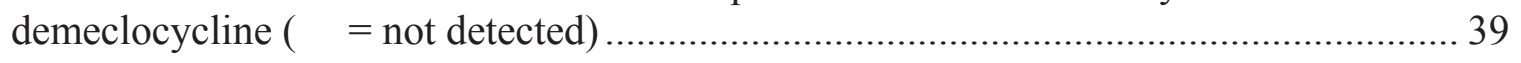

Figure 6. Recovery studies for 31 antibiotics in river and reclaimed water matrices $(n=7$ for all classes of antibiotics except tetracyclines $(n=4)$ 45

Figure 7. Comparison of MDLs in deionized water, river water and reclaimed water $(\mathrm{n}=7)$ 46

Figure 8. The amount of water used for potable and nonpotable applications on a global scale. 51

Figure 9. Existing North District Wastewater Treatment plant (circled in orange) and Florida International University reclaimed water facilities (circled in yellow) 53

Figure 10. Distribution of antibiotics in reclaimed waters (frequency of detection shown in parenthesis). The boundaries of box plot cover 25th-75th percentile, the center line indicates median of the sample population, error bars (whiskers) above and below the box refer to 90th and 10th percentiles. The dotted line in each box plot indicates mean annual concentration $(n=56)$. 
Figure 11. Month wise mass loads (mg/day) distribution of antibiotics in reclaimed waters 59

Figure 12. A plot of antibiotics sales in 2010 and their estimated mass loads from the present study 61

Figure 13. Canals sampled during the study a) from Miami-Dade County b) from Broward County

Figure 14. Distribution of antibiotics in major canals from Miami-Dade and Broward counties presented as the total concentration detected. ()- indicate the number of antibiotics detected in the selected sampling location 70

Figure 15. Distribution of antibiotics in surface waters; values in parenthesis indicate

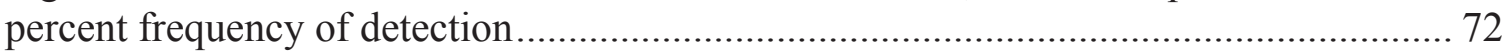

Figure 16. Distribution of total concentration of antibiotics in Miami-Dade County drinking waters 82

Figure 17. Comparison of samples from the three drinking water treatment plants........ 83

Figure 18. Distribution of samples collected from Hialeah and John E. Preston drinking water treatment plant as a function of sampling location distance from treatment plant . 85

Figure 19. Distribution of samples collected from The Alexander Orr, Jr. drinking water treatment plant as a function of sampling location distance from treatment plant ........... 86

Figure 20. Drinking water and Ground water sampling locations................................... 87

Figure 21. Extracted ion chromatograms of anhydroerythromycin and its metabolite desmethyl-anhydroerythromycin in reclaimed water (Peak settings of mass tolerance 5 ppm, and mass precision 4 decimal places) 102

Figure 22. Extracted ion chromatograms of sulfamethoxazole and its metabolite acetylsulfamethoxazole in reclaimed water (Peak detection settings of mass tolerance $5 \mathrm{ppm}$, and mass precision 4 decimal places) 103

Figure 23. High resolution MS/MS spectra and major fragments for a) erythromycin standard, b) anhydroerythromycin in reclaimed water, and c) desmethylanhydroerythromycin in reclaimed water. 107 
Figure 24. Major MS/MS fragments for erythromycin and its metabolites. 108

Figure 25. High resolution MS/MS spectra and major fragments for a) sulfamethoxazole standard, b) sulfamethoxazole in reclaimed water, and c) acetyl-sulfamethoxazole in reclaimed water. 111

Figure 26. Occurrence of erythromycin and its metabolite desmethyl-erythromycin in reclaimed water (both were measured as anhydro- forms). 114

Figure 27. Occurrence of sulfamethoxazole and its metabolite acetyl-sulfamethoxazole in reclaimed water. 115

Figure 28. Risk quotients for antibiotics using mean antibiotic concentration detected in reclaimed waters (left) and in surface waters (right). Note that absence of a symbol in the graph indicates lack of ecotoxicological data for the specific antibiotic in the given taxonomic group. 128

Figure 29. Risk quotients for antibiotics using maximum antibiotic concentration detected in reclaimed waters (left) and in surface waters (right). Note that absence of a symbol in the graph indicates lack of ecotoxicological data for the specific antibiotic in the given taxonomic group. 131 


\section{LIST OF ABBREVIATIONS AND ACRONYMS}

ABBREVIATION

$\mathrm{AF}$

ANOVA

AP

APCI

$\mathrm{BBC}$

CAS

CDDEP

CE

CEC

$\mathrm{CH}_{2} \mathrm{Cl}_{2}$

$\mathrm{CH}_{3} \mathrm{CN}$

$\mathrm{CH}_{3} \mathrm{OH}$

CID

DWTP

$\mathrm{EC}_{50}$

EDTA

ESI

FDA

FISh
FULL NAME

assessment factor

analysis of variance

American Press

atmospheric pressure chemical ionization

Biscayne Bay Campus

chemical abstract service

Center for Disease Dynamics, Economics and Policy

collision energy

contaminants of emerging concern

dichloromethane

acetonitrile

methanol

collision induced dissociation

drinking water treatment plant

median effective concentration

Ethylenediaminetetraacetic acid

electrospray ionization

Food and Drug Administration

fragment ion search

xvii 
QqQ

RPLC

RQ

RSD

SPE-LC-MS/MS

SPME

SRM

STPs

UPLC

WWTP

XIC
Triple quadrupole

Reversed-phase liquid chromatography risk quotient

relative standard deviation solid phase liquid chromatography tandem mass spectrometry solid-phase microextraction selected reaction monitoring sewage treatment plants ultra pressure liquid chromatography wastewater treatment plant extracted ion chromatograms 
CHAPTER 1

Introduction 


\subsection{Overview}

In the recent years, public awareness of the long-term effects of chemical contaminants such as pharmaceutical and personal care products (PPCPs), pesticides, perfluorinated compounds and polychlorinated biphenyls has tremendously increased due to the anticipation of adverse human and ecological health effects. Previously, most of these chemicals were undetected as their environmental occurrence and/or concentrations are usually very low (micrograms down to sub nanogram per liter) and hence were not historically considered as contaminants (Kolpin. 2013). However, the advances in environmental analytical chemistry have resulted in an information explosion regarding these chemicals (Templeton et al., 2009). Moreover, toxicologists and environmental risk assessment experts advise that some contaminants like antibiotics and hormones even at very low levels can show significant and widespread adverse environmental and human health consequences (Purdom et al., 1994; Levy, 1997; Martinez, 2008; Caliman and Gavrilescu, 2009). These chemicals were commonly referred as contaminants of emerging concern (CECs).

Contaminants of emerging concern, such as, pharmaceuticals (e.g. antibiotics, hormones, steroids), personal care products (PCPs) (e.g. cosmetics, moisturizers, antacids, caffeine, fragrances), perfluorinated compounds, and household chemicals (e.g. detergents, deodorizers, degreasers), are continuously released into septic systems all over the world. As a result of constant production and usage, CECs enter the environment, disperse to various compartments, and persist for much longer than originally expected (Kolpin et al., 2002). 
Most of the CECs are not regulated in any way and their potential health effects and acute toxicities to the environment are not known (Halling-Sorensen et al., 1998). In the previous years' diluting the contaminated water by releasing it into streams, rivers, or out to sea was considered as a good choice (Osenga, 2013). However, the continued growth in the human population created a huge demand for the Earth's limited supply of fresh water (Kolpin et al., 2002). Thus, protecting the integrity of our water resources is very essential for the present and future needs of human population. With more contaminants being released into fresh water every year, the world has started to think about the longterm effects of this action.

Among several groups of emerging chemical contaminants, pharmaceuticals, and in particular antibiotics, had received lot of attention in the media in the last several years due to the increasing number of diseases becoming resistant to traditional treatments. Previous research showed the widespread occurrence of residual antibiotics in various water ways, such as surface water (river streams, lakes, ponds), sewage effluents, ground water, ocean outfall, and drinking water (Watkinson et al., 2009). Antibiotics were recently classified as a priority risk group due to their high toxicity to algae and bacteria at low concentrations, and their potential to cause resistance among natural bacterial population (Hernando et al., 2006) and therefore, identified for future monitoring studies (Zuccato et al., 2005). 


\subsection{What are Antibiotics?}

Antibiotics are the chemotherapeutic agents that inhibit or abolish the growth of microorganisms, such as bacteria, fungi, or protozoa; they are widely used to treat infectious diseases in human and veterinary medicine, and also in agricultural practices (Kummerer, 2009). The first antibiotics used in human medicine were of natural origin, e.g. penicillin (produced by fungi) and streptomycin (from bacteria). Currently, antibiotics are obtained by chemical modification of compounds of natural origin (e.g. amoxicillin), or chemical synthesis (e.g. sulfamethoxazole).

Antibiotics are a diverse group of chemicals. Based on their chemical structure and mode of action, they can be subdivided into ß-lactams, sulphonamides, quinolones, tetracylines, macrolides, aminoglycosides and others. An overview of important classes of antibiotics is given in Table 1. Antibiotics are often complex molecules with different functionalities within the same molecule, e.g. ciprofloxacin (Kummerer, 2009). Therefore, they can be neutral, cationic or zwitterionic under different $\mathrm{pH}$ conditions. Because of different functionalities with in a single molecule, their physico-chemical and biological properties such as $\log \mathrm{K}_{\mathrm{ow}}$ (Cunningham, 2008), photo reactivity, sorption behavior, antibiotic activity and toxicity may change with $\mathrm{pH}$. 
Table 1. Target antibiotics and their classification

\begin{tabular}{lcl}
\hline Antibiotic & CAS number & Classification \\
\hline Sulfadiazine & $68-35-9$ & Sulfonamide \\
Sulfathiazole & $72-14-0$ & Sulfonamide \\
Sulfamerazine & $127-79-7$ & Sulfonamide \\
Sulfamethazine & $57-68-1$ & Sulfonamide \\
Sulfamethizole & $144-82-1$ & Sulfonamide \\
Sulfachlorpyridazine & $80-32-0$ & Sulfonamide \\
Sulfamethoxazole & $723-46-6$ & Sulfonamide \\
Sulfadimethoxine & $122-11-2$ & Sulfonamide \\
Enoxacin & $74011-58-8$ & Fluoroquinolone \\
Ofloxacin & $82419-36-1$ & Fluoroquinolone \\
Norfloxacin & $70458-96-7$ & Fluoroquinolone \\
Ciprofloxacin & $85721-33-1$ & Fluoroquinolone \\
Danofloxacin & $112938-08-0$ & Fluoroquinolone \\
Enrofloxacin & $93106-60-6$ & Fluoroquinolone \\
Sarafloxacin & $98105-99-8$ & Fluoroquinolone \\
Oxytetracycline & $79-57-2$ & Tetracylcines \\
Tetracycline & $60-54-8$ & Tetracylcines \\
Chlortetracycline & $57-62-5$ & Tetracylcines \\
Doxycycline & $564-25-0$ & Tetracylcines \\
Meclocycline & $2013-58-3$ & Tetracylcines \\
Spiramycin & $8025-81-8$ & Macrolides \\
Clindamycin & $18323-44-9$ & Macrolides \\
Tylosin & $1401-69-0$ & Macrolides \\
Erythromycin & $114-07-8$ & Macrolides \\
Clarithromycin & $81103-11-9$ & Macrolides \\
Azithromycin & $83905-01-5$ & Macrolides \\
Roxithromycin & $80214-83-1$ & Macrolides \\
Lincomycin & $154-21-2$ & Lincosamide \\
Amoxycillin & $26787-78-0$ & Miscellaneous \\
Trimethoprim & $738-70-5$ & Quinolone \\
Nalidixic acid & $389-08-2$ & Quinolone \\
\hline
\end{tabular}




\subsection{Sources of Antibiotics in the environment}

\subsubsection{Natural sources}

Antibiotics are originally of natural origin. Some species of fungi and bacteria naturally existing in soil produce antibiotics for inhibiting the growth of other microorganisms in their territory. For example, a group of Actinomycetes, such as Streptomycetes, existing in soil, produce streptomycin antibiotic; Fungi in the genus pencillium produce pencillins; other examples include aminoglycosides, tetracyclines, novabiocin, etc. (Fleming, 2001; Kawaguchi et al., 2013). Mankind recognized the ability of microbes to produce antibiotics and started using for his own benefits such as treating infectious diseases.

In general, the antibiotic activity varies with bacterial density; for example, in the free water phase, the bacterial density is much lower compared to sewage sludge or soil (Kummerer, 2009). However, the contamination of free water phase with sewage effluents may influence the bacterial proliferation.

\subsubsection{Antibiotic production}

As the industrial effluents were mostly regulated, the contribution of antibiotic manufacturing plants for the total antibiotic concentrations in sewage influents was assumed to be of minor importance. In contrast, in a recent study by Larsson et al. it was found that, in some developing Asian countries, the antibiotic concentrations in industrial 
effluents were up to several $\mathrm{mg} \mathrm{L}^{-1}$ (Larsson et al., 2007). Considering the fact that trace occurrence of antibiotic residues in pharmaceutical production plants effluents is not uncommon, manufacturing plants in developed countries can also make a significant contribution along with other domestic sources for total antibiotic concentration in sewage treatment plant influents (STPs) (Khetan and Collins, 2007; Lillenberg et al., 2010).

\subsubsection{Usage}

Antibiotics have been widely used in human and veterinary medicine, as well as in farming and aquaculture for the purpose of prevention or treatment of infectious diseases. Out of several thousand tons of antibiotics consumed every year worldwide. The United States is among the most intensive users according to prescription statistics data (expressed as DDD per day and capita) collected by the Center for Disease Dynamics, Economics and Policy (CDDEP, Washington DC). France is the highest user of antibiotics followed by Greece, Italy, Belgium and the United States. For the first time in 2012, the United States Food and Drug Administration (USFDA) agency released the public document on systemic antibacterial drugs sold in the US, showing that about 3.28 million kilograms of antibiotics sold for human medical use in year 2010, and over 13.06 million kilograms for food-animal use in 2009 (CVM, 2010; Pham, 2012). Moreover, 16,465 kilograms antibiotic active ingredients was used in plant agriculture in the US in 2009 (Stockwell and Duffy, 2012). This means that about $80 \%$ of antibiotics sold in the US are for non-human use, and moreover, about $90 \%$ of the animal consumption is for 
non-therapeutic purposes, such as growth promoters (UCS, Union of Concerned Scientists, 2001). Class wise antibiotics sales data, both in human and food-producing animals, is shown in Table 2 (CVM, 2010; Pham, 2012). B-lactams (pencillins, cephalosporins and carbapenems) make up the largest share of human use antibiotics, followed by sulphonamides, quinolones and macrolides, whereas in animal husbandry tetracyclines and ionophores were the mostly used.

Table 2. Nationwide antibacterial drug use in humans and food producing animals in the U.S.

\begin{tabular}{ccc}
\hline & $\begin{array}{c}\text { Annual Totals in } \\
\text { Antibiotic class }\end{array}$ & $\begin{array}{c}\text { Annual Totals in } \\
\text { Kilograms, Year 2010* } \\
\text { Kilograms, Year 2009* }\end{array}$ \\
\hline Penicillins & $1,439,930$ & 610,514 \\
Cephalosporins & 502,561 & 41,328 \\
Sulfa and TMP & 479,484 & 517,873 \\
Quinolones & 281,557 & --- \\
Macrolides & 164,309 & 861,985 \\
Nitroimidazoles & 114,991 & --- \\
Tetracyclines & 129,183 & $4,611,892$ \\
Lincosamides & 69,235 & 115,837 \\
Carbapenems & 13,173 & --- \\
Aminoglycosides & 6,991 & 339,678 \\
Oxazolidinones & 5,144 & --- \\
Monobactams & 3,782 & --- \\
Ionophores & --- & $3,740,627$ \\
Lipopeptides & 1,123 & --- \\
Others & 67,443 & $2,227,366$ \\
Total & $3,278,906$ & $13,067,100$ \\
\hline$*$ in humans & $* *$ in food-producing animals & \\
& &
\end{tabular}




\subsubsection{Occurrence}

In both humans and animals, consumed antibiotic will be assimilated, and subjected to various metabolic reactions and finally excreted in urine and feces. For antibiotics, elimination through the metabolic processes is not complete, resulting in excretion of unchanged active parent compound along with metabolic products (Hirsch et al., 1999). In humans, the percent excretion of antibiotic as the parent drug is molecule specific and may range from 10 to $60 \%$ (Zuccato et al., 2005). On an average, if the volume of all antibiotics used is totaled the metabolic rate is estimated to be $30 \%$, implying that $70 \%$ of the used antibiotic is excreted unchanged (Kummerer and Henninger, 2003).

Along with human and animal excretions, the disposed unused and expired medication will pass through the sewage drains, and reach Waste Water Treatment Plants (WWTPs). Sorption (e.g., tetracyclines), hydrolysis (e.g., penicillins), photo and biodegradation play significant role in attenuating antibiotic persistence. However, several investigations have shown that conventional treatment processes employed in WWTPs are not efficient in degrading or removing antibiotics completely (Heberer et al., 2002; Batt et al., 2006; Deblonde et al., 2011, Anquandah et al., 2011). Eventually, they are released in to local aquatic surroundings via WWTPs effluents (Jorgensen and Halling-Sorensen, 2000). Moreover, by the application of antibiotic residue containing animal manure and sludge to agricultural fields, antibiotics leach into surface waters, and/or infiltrating in to ground water (Hirsch et al., 1999). As ground water and surface water are the main sources of drinking water, antibiotics are often detected in drinking waters (Ye et al., 2007; 
Watkinson et al., 2009). Figure 1 shows the possible sources and pathways of antibiotics in the aquatic environment (Anderson et al., 2011).

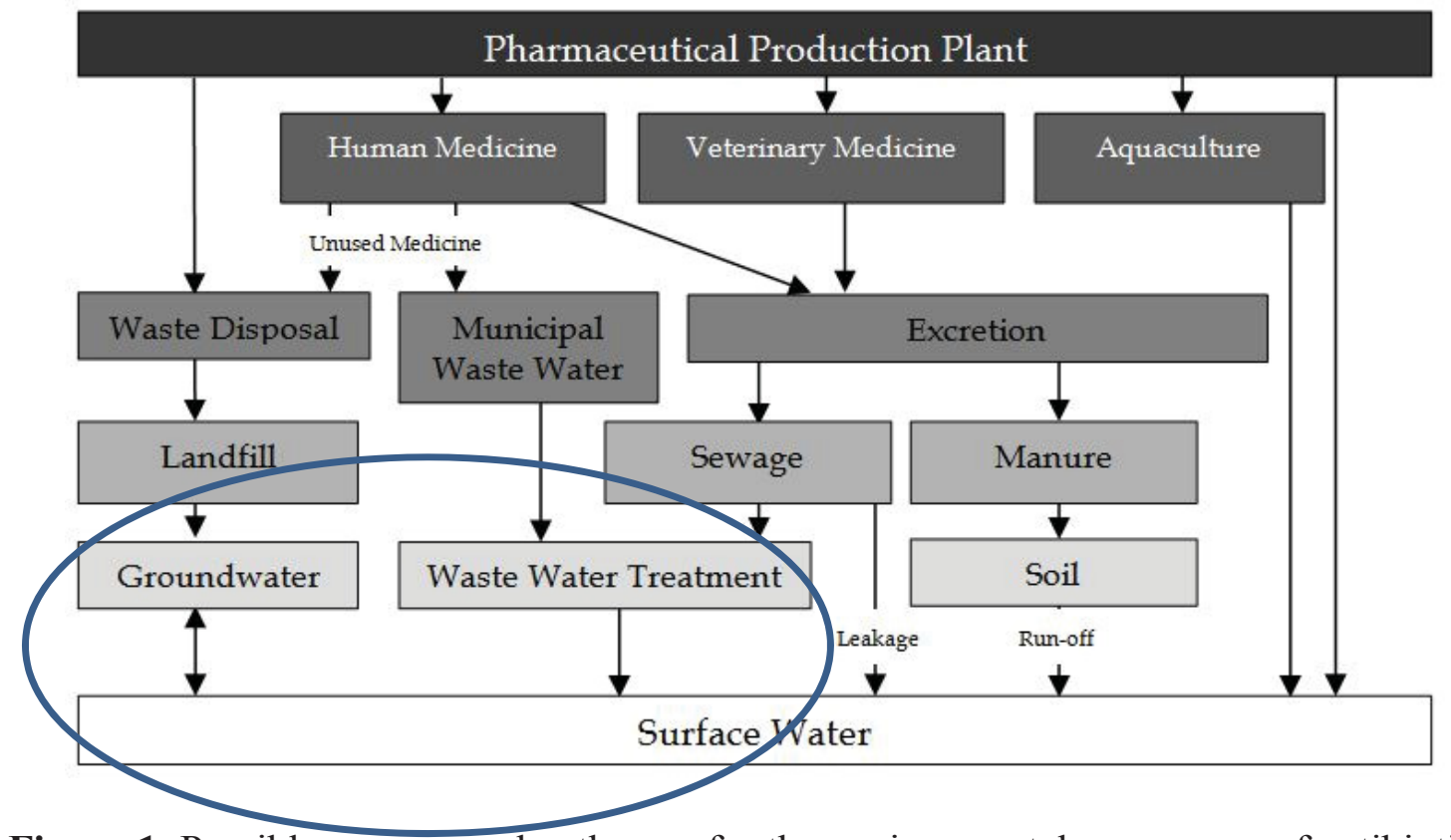

Figure 1. Possible sources and pathways for the environmental occurrence of antibiotics, modified from Anderson et al., 2011.

\subsubsection{Significance}

Antibiotics have revolutionized medicine in many respects, and countless lives have been saved; their discovery was a turning point in human history. Unfortunately, the use of these wonder drugs has been associated with the rapid appearance of resistant strains (Davies and Davies, 2010). Higher antibiotic consumption and inappropriate use could be the main reasons for rapid spread of antibiotic resistance (Barbosa and Levy, 2000). Many publications reported on occurrence of antibiotics and their resistant strains in 
various aquatic environmental compartments (Levy, 1997; Huovinen, 2001; Kummerer and Henninger, 2003; Kummerer, 2004; Martinez, 2008). Chronic exposure to low doses of antibiotics lead to the selective proliferation of resistant bacteria, which could transfer the resistant genes to other unrelated bacteria in a phenomenon called horizontal gene transfer (exchange and fuse of plasmids, chromosome fragments (Bakkali, 2013)). Places where microbial population density is high, such as sewage systems, hospital effluents, and/or animal farms are acting as the reservoirs or sinks for antibiotics and their resistant strains (Holzel et al., 2010). The occurrence of antibiotics in aquatic environments is of ecotoxicological concern too, because of their ability to potentially alter the ecosystem (Kummerer, 2009). Antibiotics can inhibit the growth of microorganisms in sewage treatment systems, and may also have the ability to seriously affect the whole microbial community structure in the local environments, wherever they are present. The effects include but not limited to reduced organic matter degradation (by impacting the biological oxidation processes used in sewage treatment systems), disrupting key bacterial cycles critical to aquatic ecology (nitrification/denitrification), soil fertility (Watkinson et al., 2009).

Antibiotics may adversely affect organisms of different tropic levels such as algae, invertebrates, and to a little extent on fish. Blue-green algae (cyanobacteria) are very sensitive to many antibiotics, such as amoxicillin, spiramycin, sarafloxacin and tetracycline (Boxall et al., 2004). As algae are the basis of the food chain, even slight decreases in the algal population may affect the equilibrium in an aquatic system. In some cases some trophic levels may be completely wiped out, causing the community structure to be remarkably changed (Wollenberger et al., 2000). This effect can make its 
way up the food chain and may be the cause of the trends observed towards lower biodiversity. Other ecotoxicological concerns, such as adverse reproductive effects in the early life stages of Daphnia magnam (clarithromycin, trimethoprim, and neomycin), depressed hatching rate of Artemia sp. cysts, and high mortality rate for nauplii, serve as examples of negative effects of antibiotics on aquatic organisms (Macri et al., 1988; Migliore. L, 1993 ; Wollenberger et al., 2000; Kummerer, 2009).

The effects of antibiotics on human health may include: allergic reactions (e.g. ßlactams), negative interaction of tetracyclines with developing teeth in young children, nephrotoxicity (e.g. gentamicin) and increased sensitivity to light due to quinolones, and because of their antimicrobial activity, a negative interaction within the human gut (Sanchez et al., 2004; Hadjipour, 2011). However, there were no direct evidences to date the effects are caused by the consumption of drinking water containing antibiotic traces. Hence, in addressing the public health concerns over the drinking water quality and identifying the contamination sources, determining their fate in the environment and assessing the potential ecological health risks associated with short and long term exposure to antibiotics in the aquatic environments, efficient analytical methodologies are required for continuous surveillance of antibiotics and their bioactive metabolites at environmentally relevant concentrations.

Consumed antibiotics are converted into metabolites through a biological process called metabolism. Metabolites also reach environment through STPs and other sources along with the parent molecule. Some metabolites can be transformed back to the parent molecule in the WWTPs treatment process E.g., Sulfamethoxazole (Bonvin et al., 2012). Metabolites may have hazardous effects similar to the parent drugs (Bedner and 
Maccrehan, 2006). Therefore it is important to study the metabolites along with their parent forms to assess the occurrence, fate and transport of antibiotics in the environment

To address the ecological health concerns, to identify the contamination sources and also to assess environmental fate of antibiotics robust analytical methods are crucial. The main challenges for the detection of antibiotics in environmental compartments include relatively low analyte concentrations (ng/L), complexity of environmental matrices, and diverse physico-chemical properties of the antibiotics. Hence, determination of antibiotics in the environmental matrices requires highly sensitive and selective methods, especially in multiple residue analysis.

\subsection{Hypothesis}

On the basis of the above mentioned facts, the two main hypotheses for the current study are,

1. It is possible to develop a single, part-per trillion analytical method for the determination of multiple classes of antibiotics.

2. Occurrence of antibiotics or their metabolites in South Florida waters could pose an ecological risk. 


\subsection{Objectives}

1. To develop a robust and high throughput online SPE-LC-MS/MS method that is sensitive enough for the trace level detection of antibiotics in complex environmental water matrices

2. To apply the developed analytical methodology to analyze both treated (drinking waters and reclaimed waters) and untreated environmental water samples (river waters and ground waters)

3. To identify the potential antibiotic metabolites in environmental water samples using a high resolution mass spectrometry

4. To assess the potential ecological risk associated with antibiotic residues in reclaimed and surface waters using available literature on toxicity exposure data 


\section{CHAPTER 2}

Online solid-phase extraction-liquid chromatography-electrospray-tandem mass spectrometry method for determination of multiple classes of antibiotics

(Panditi, V., Batchu, S., Gardinali, P., 2013. Analytical and Bioanalytical Chemistry, 405 (18), 5953-5964) 


\subsection{Introduction}

The environmental concentrations of antibiotics are typically low (sub $\mu \mathrm{g}$-to- ng/L) and generally requires preconcentration for their detection. Though several extraction techniques such as liquid-liquid extraction (LLE) (Koch et al., 2005), solid-phase microextraction (SPME) were previously reported (Balakrishnan et al., 2006; McClure and Wong, 2007), solid phase extraction (SPE) is the most widely used method of choice for the sample preconcentration (Kim and Carlson, 2007).

In the typical SPE preconcentration, sample volumes ranging from $200 \mathrm{~mL}$ to $1000 \mathrm{~mL}$ will be passed on to SPE sorbents that are preconditioned with organic and aqueous solvents to retain all the analytes of interest. The classical stationary phases (sorbent materials) for solid phase extraction of antibiotics include non-polar phase (e.g., chemically bonded silica with $\mathrm{C}_{8}$ or $\mathrm{C}_{18}$ organic group), ion-exchange phase and polymeric phase. Among them, Oasis MCX mixed mode sorbent to extract polar to medium-polar analytes and the Oasis HLB (Hydrophilic Lipophilic Balanced phase, Waters Corp.) sorbent to extract both polar and nonpolar analytes under the same conditions were the mostly used for the simultaneous extraction of multiple residues with markedly different chemical characteristics (Petrovic et al., 2005; Hernandez et al., 2007; Seifrtova et al., 2009). The retained analytes are eluted with organic solvents of varying polarity. Then the eluents are dried and reconstituted for further analysis (chromatographic separation and determination). The major drawback of this procedure compared to new online SPE is that the sample throughput is very low, takes almost one day to prepare a batch of 12 samples on a typical SPE vacuum manifold. 
For the chromatographic separation of antibiotics, in the previous years several methods were reported using gas chromatography (GC) with its high resolving power (Ternes, 2001; Richardson, 2006). However antibiotics are polar, less volatile molecules derivatization is the additional step necessary for GC analysis and thus liquid chromatography is the preferred technique of choice. Reversed-phase liquid chromatography (RPLC) had been commonly used for their separation. Formic acid and ammonium acetate are the widely used additives in mobile phase to enhance the ionization efficiency and to control $\mathrm{pH}$, therefore improved method detection limits in mass spectrometric analysis (Kim and Carlson, 2007).

In both LC-MS and LC-MS/MS analysis of antibiotics, two ionization interfaces, electrospray ionization and atmospheric pressure chemical ionization were commonly used due to their sensitivity and robustness. Between the two ionization methods reported for the analysis of antibiotics, selection of choice is usually based on the polarity of analytes and additives used in mobile phase (Hao et al., 2007). Since antibiotics are polar and moderately non-polar, thermally labile in nature, electrospray ionization (ESI) is the well suited soft ionization technique and by far the most frequently applied ionization technique for the detection of antibiotics, although it is known to be more prone to signal suppression compared to atmospheric pressure chemical ionization (APCI) (Sorensen and Elbaek, 2004; Hernandez et al., 2007). In the literature, use of internal standards, especially isotopic-labeled internal standards, performing matrix-matched calibrations, standard addition methods or simply diluting the samples were described to compensate for matrix effects (Lindsey et al., 2001; Hernandez et al., 2007; Seifrtova et al., 2009). 
Among the mass analyzers, both quadrupole (single and triple) and ion trap (IT) were the widely used for MS and MS/MS detection and quantification of antibiotics. In the context of quadrupole mass analyzers, compared to MS, where need to rely on single ion monitoring; $\mathrm{MS}^{2}$ has the multiple reactions monitoring (MRM) ability, which detects both the precursor ion and fragment ions of analytes. MRM is the sensitive and selective way of measuring analytes (Hao et al., 2007), as it can reduce the matrix interference that leads to false positives especially in environmental matrices where the analyte concentrations are in ng/L levels (Gobel et al., 2004; Vieno et al., 2006; Feitosa-Felizzola et al., 2007). Triple quadrupole (QqQ) is the frequently used $\mathrm{MS}^{2}$ detector in LC-MS/MS analysis (Hernandez et al., 2007; Trenholm et al., 2008) for the quantitation purposes. In traditional offline SPE-LC-MS/MS analysis of antibiotics, sample preconcentration by offline solid-phase extraction (SPE) is the time consuming step and hinders the sample throughput. By hyphenating the SPE step with LC-MS/MS, it is possible to lower the analysis time and to increase the sample throughput without significant losses of sensitivity as reported elsewhere (Pozo et al., 2006; Feitosa-Felizzola et al., 2007; Ding et al., 2009; Garcia-Ac et al., 2009; Garcia-Galan et al., 2010, Ramirez et al., 2013). However, most of these studies were either focused on a particular class of antibiotics (Stoob et al., 2005) or very few target antibiotics were selected from each class (Tang et al., 2006). Dinh et. al. described the most comprehensive analytical method for the determination of 23 antibiotics in river waters. Usual sample preparation steps like filtration, $\mathrm{pH}$ adjustment and use of EDTA (chelating agent) were required and two runs were performed for each sample to achieve optimal recovery for all classes of antibiotics, thus doubling the analysis time. Moreover, the suitability of the method for other 
complex matrices such as reclaimed water and waste waters was not tested (Dinh et al., 2011). Lopez-Serna et al., reported a comprehensive online SPE method for the analysis of antibiotics, the method included 20 antibiotics in different water matrices with a long run time of $37 \mathrm{~min}$ (Lopez-Serna et al., 2010). Thus, there is a need for fast analytical methodology capable of detecting most classes of antibiotics at environmentally relevant concentrations possibly with minimal sample preparation, and suitable for application to different water matrices.

The objective of this study was to develop a comprehensive analytical method for the analysis of multiple classes of antibiotics in various water matrices, aiming to achieve trace levels detection and better recoveries by using an online SPE in combination with LC-MS/MS determination.

\subsection{Experimental}

\subsubsection{Standards, reagents, and solutions}

Lincomycin, trimethoprim, amoxycillin, nalidixic acid, tylosin, sulfadiazine, sulfamethoxazole, sulfathiazole, sulfamethazine, sulfamethizole, sulfamerazine, sulfadimethoxine, sulfachlorpyridazine, enoxacin, ciprofloxacin, danofloxacin, norfloxacin, ofloxacin, sarafloxacin, enrofloxacin, roxithromycin, azithromycin, clarithromycin, clindamycin, spiramycin, erythromycin, meclocycline, doxycycline, tetracycline, oxytetracycline, chlortetracycline were purchased from Sigma-Aldrich 
Canada (Oakville, ON). Isotopically labeled antibiotics (Sulfamethoxazole-d4, spiramycin-d3, sulfadiazine-d4, erythromycin- ${ }^{13} \mathrm{C}-\mathrm{d} 3, \quad$ norfloxacin-d5) and demeclocycline were used as surrogates and/or internal standards. Sulfamethoxazole-d4, spiramycin- $\mathrm{d} 3$, sulfadiazine- $\mathrm{d} 4$, erythromycin- ${ }^{13} \mathrm{C}-\mathrm{d} 3$ were purchased from Toronto Research Chemicals (Toronoto, Canada) and norfloxacin-d5 from CDN Isotope Laboratories (Quebec, Canada). All isotopically labeled standards had purity higher than 95\% (isotopic purity $>99 \%$ ). Optima LC/MS grade formic acid, acetonitrile and water were purchased from Fisher Chemical (Fairlawn, New Jersey, USA). Membrane filters ( $0.45 \mu \mathrm{m}$ and $0.2 \mu \mathrm{m}$ pore size) were purchased from Millipore (Billerica, MA).

Stock solutions of $1 \mathrm{mg} / \mathrm{mL}$ were prepared in methanol for all antibiotics except for the fluoroquinolones which were dissolved in $5 \% \mathrm{NaOH}(0.1 \mathrm{M})-95 \%$ methanol to get uniform solution (Batt and Aga, 2005). Stock solutions of surrogate standards (0.1 $\mathrm{mg} / \mathrm{mL}$ ) were also prepared in methanol. All stock solutions were kept in the dark at -18 ${ }^{\circ} \mathrm{C}$ and used for no more than one year. Working standard solution (WS1) mixture was prepared by spiking stock solutions of antibiotic in methanol and the spike level was selected based on their instrumental detection. This solution was prepared fresh every 3 months. A dilution factor of 1000 was applied to prepare a second working standard solution in LC/MS grade water on the day of analysis, which was used to prepare calibration solutions and quality control samples for the given analysis batch. The three types of water matrices used in the method development were reclaimed, river and deionized water. Structures of the selected antibiotics are shown in Table 3. 
Table 3. Structures of the selected antibiotics

\section{Tetracyclines}

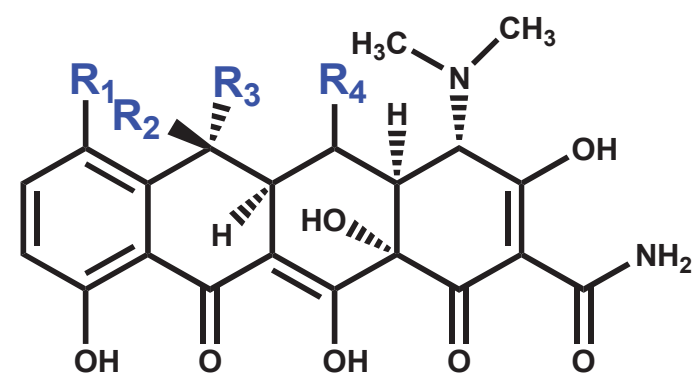

\begin{tabular}{lcccc}
\hline & $\mathrm{R}_{1}$ & $\mathrm{R}_{2}$ & $\mathrm{R}_{3}$ & $\mathrm{R}_{4}$ \\
\hline Oxytetracycline & $\mathrm{H}$ & $\mathrm{OH}$ & $\mathrm{CH}_{3}$ & $\mathrm{OH}$ \\
Tetracycline & $\mathrm{H}$ & $\mathrm{OH}$ & $\mathrm{CH}_{3}$ & $\mathrm{H}$ \\
Chlortetracycline & $\mathrm{Cl}$ & $\mathrm{OH}$ & $\mathrm{CH}_{3}$ & $\mathrm{H}$ \\
Doxycycline & $\mathrm{H}$ & $\mathrm{H}$ & $\mathrm{CH}_{3}$ & $\mathrm{OH}$ \\
Meclocycline & $\mathrm{Cl}$ & $\mathrm{CH}_{2}$ & & $\mathrm{OH}$ \\
\hline
\end{tabular}

Mechanism of action: Protein synthesis inhibitor

\section{Sulfonamides}

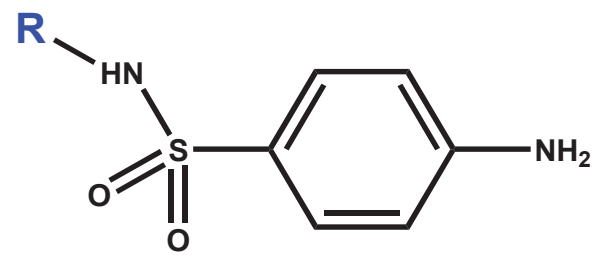




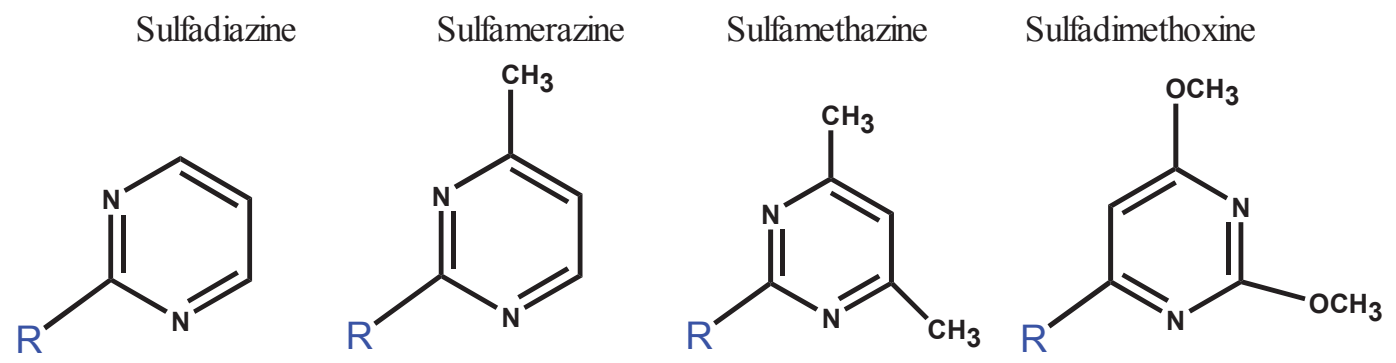

Sulfamethizole Sulfathiazole Sulfamethoxazole Sulfachlorpyridazine

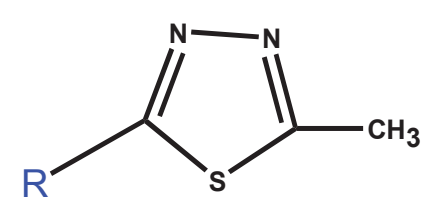<smiles>[R]c1nccs1</smiles><smiles>[R]c1cc(C)on1</smiles><smiles>[R]c1ccc(Cl)nn1</smiles>

Mechanism of action: competitive inhibitors of the enzyme dihydropteroate synthetase (DHPS), an enzyme involved in folate synthesis

\section{Macrolides}

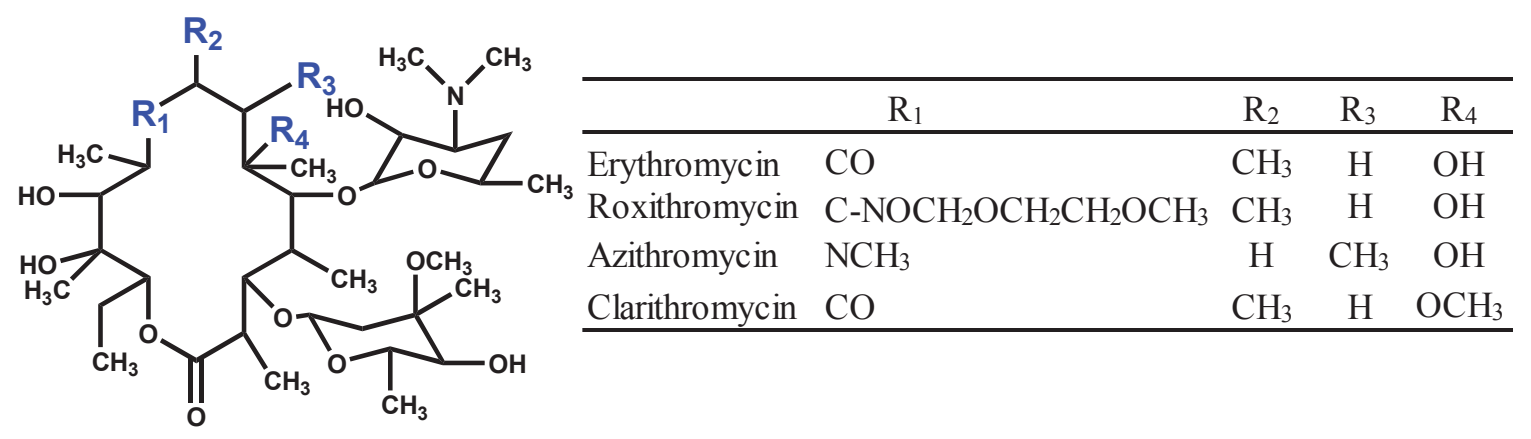




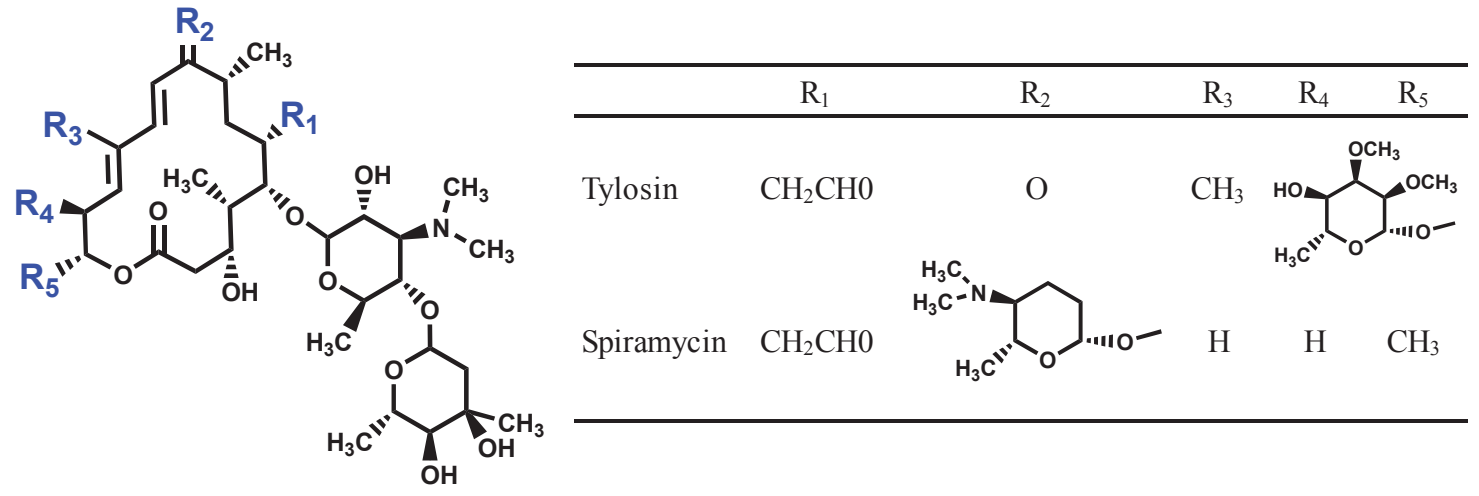

Mechanism of action: protein synthesis inhibitors

\section{Lincosamides}

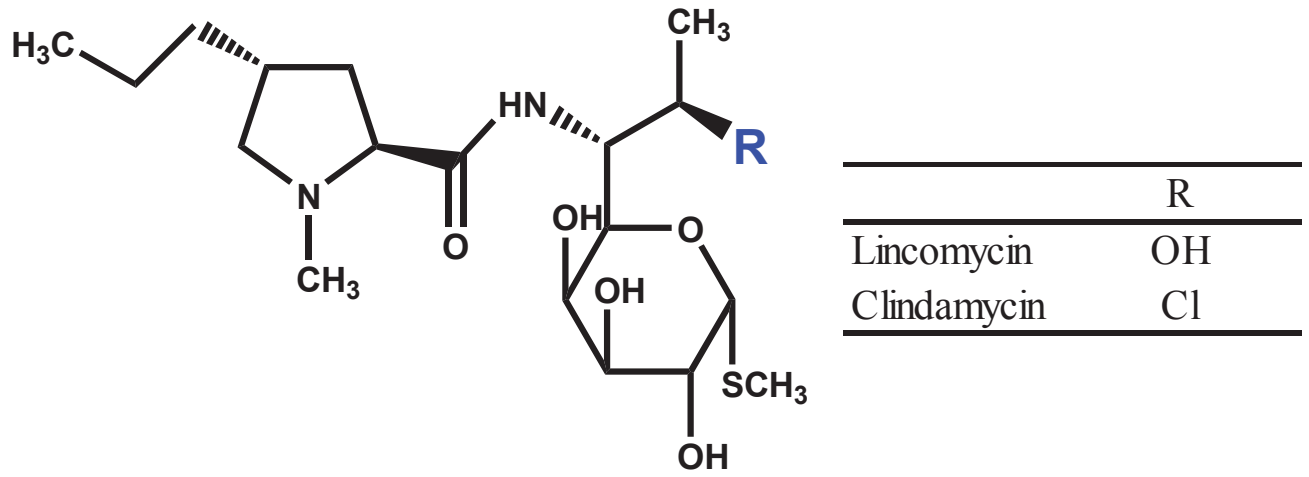

Mechanism of action: protein synthesis inhibitors

\section{Quinolones}




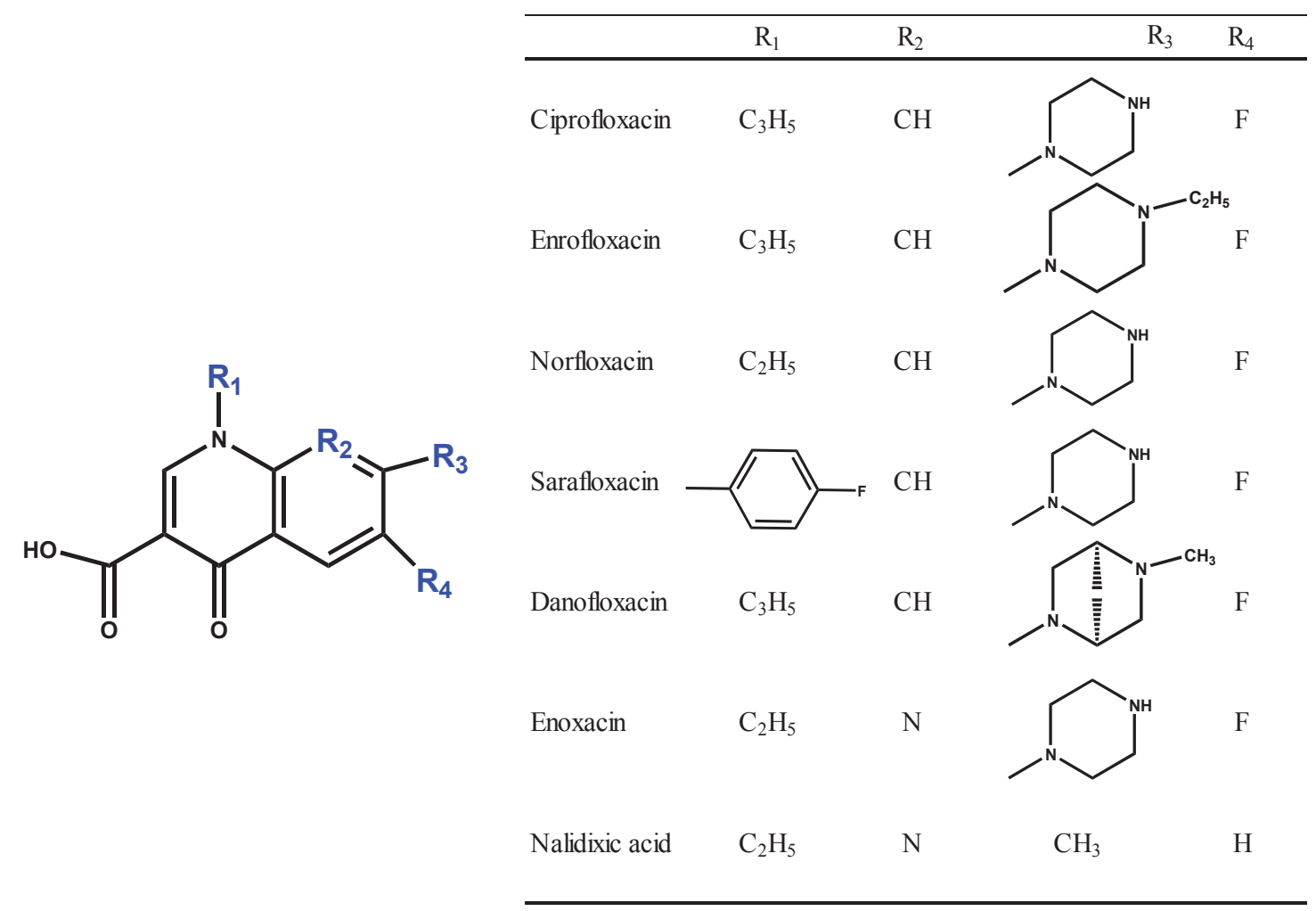

Mechanism of action: inhibit bacterial DNA replication by blocking the enzyme DNA topoisomerase.

\subsubsection{Instrumentation}

Both sample preconcentration and chromatographic separation were performed using an EQuan system developed by Thermo Fisher Scientific, San Jose, CA, USA. The system allows the injection and preconcentration of up to $20 \mathrm{~mL}$ of sample using a high-flow pump (loading pump), and loading column (SPE column); liquid chromatography using a low-flow pump (analytical pump), and analytical column (Figure 2). Sample delivery in the EQuan system was carried out using a HTC-PAL autosampler equipped with a $5 \mathrm{~mL}$ injection syringe and a $10 \mathrm{~mL}$ (PEEK) loop. 
The LC/MS system was equipped with six port dual switching valve that can operate in two different positions. In "load" position, the high-flow pump is connected to sample loop, loading column and to waste in sequential order; and in "inject" position the low flow pump is connected to loading column, analytical column and mass spectrometer in sequential order. At the start up, the divert valve was at the "load" position and the HTCPAL autosampler was programmed to draw the sample from the vial and inject into the injection loop using the full loop mode. The high-flow Accela UPLC pump was used for sample loading and the low-flow Accela MS pump was used for liquid chromatography. The injected sample from the loop was then transferred to the load column with $100 \%$ of solvent A (LC/MS grade water) at a specified flow rate $(\mathrm{mL} / \mathrm{min})$. The loading column with all analytes retained was then washed with about $1.5 \mathrm{~mL}$ of $100 \%$ solvent A (LC/MS grade water) to minimize matrix effects. Then the divert valve was switched to the "inject" position and the column is back flushed into the analytical column using the analytical pump. Column switching between load column and analytical column was performed using a standard 6-port valve. Sample loading and preconcentration was performed on a HyperSep Retain PEP $(20 \mathrm{~mm} \times 3.0 \mathrm{~mm}$ I.D) manufactured by Thermo Fisher Scientific, San Jose, CA, USA. Liquid chromatography was carried out using a Hypersil Gold $\mathrm{C}_{18}$ column $(50 \mathrm{~mm} \times 2.1 \mathrm{~mm}, 1.9 \mu \mathrm{m})$. 


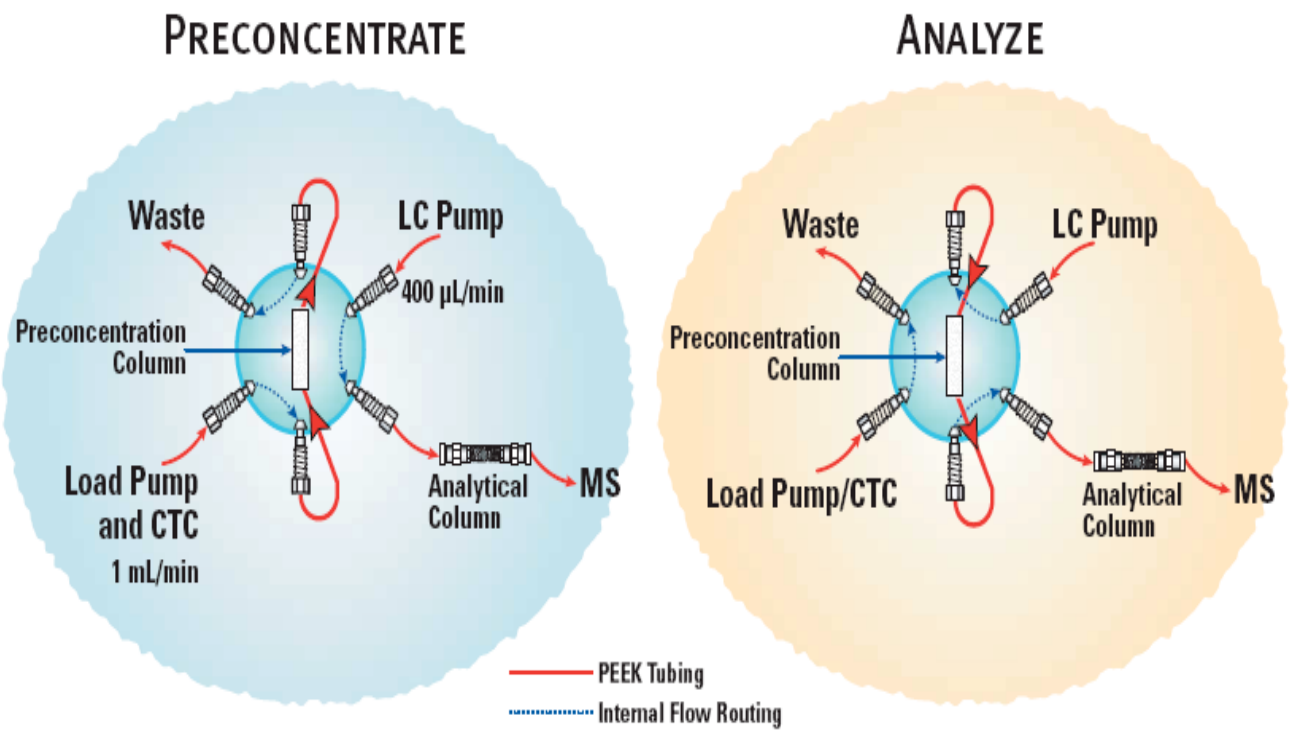

Figure 2. Schematic of online solid phase extraction using Thermo Fisher EQuan system

The LC-MS was equipped with an Ion Max API Heated Electrospray Ionization (H-ESI) Source, operated in positive ionization mode. Where the analytes in solution phase are transformed to gas phase charged droplets with the help of heated auxiliary gas and the ionized. Detection of analytes was performed on a TSQ Quantum Access triple quadrupole Mass Spectrometer (Thermo Scientific, San Jose, CA, USA). For all analytes, optimum ionization conditions and SRM transitions were selected by infusing a $2 \mathrm{mg} / \mathrm{L}$ individual standard solution through a syringe pump at a flow rate of $50 \mu \mathrm{L} / \mathrm{min}$. For all analytes, $[\mathrm{M}+\mathrm{H}]^{+}$was selected as the parent ion except for spiramycin and spiramycin-d3 for which the doubly charged ion $[\mathrm{M}+\mathrm{H}]^{2+}$ was monitored. Subsequent identification of the two most abundant fragment ions and selection of the optimum collision energies (CEs) was carried out in the product ion scan mode. MS/MS optimized parameters for quantitative analysis are shown in Table 4. 
Erythromycin is easily converted to its metabolite, anhydro-erythromycin in acidic $\mathrm{pH}$ (Kim et al., 2004). In order to verify the efficiency of transformation of erythromycin to its anhydrous form, calibration solutions were prepared by spiking varying levels of stock solutions of erythromycin (or erythromycin $-{ }^{13} \mathrm{C}-\mathrm{d} 3$ ) into optima LC/MS water to which $20 \%$ optima LC/MS grade formic acid was added. Data was acquired for two SRM transitions $734.2 \rightarrow 157.9,540.14$ (erythromycin) and $716.2 \rightarrow 157.9,540.1$ (anhydroerythromycin) and the area ratios were compared. Anhyrdo-erythromycin $(\mathrm{m} / \mathrm{z} 716)$ accounted for $93.4 \pm 2.5 \%(\mathrm{n}=9)$ in comparison to erythromycin $(\mathrm{m} / \mathrm{z} 734)$, indicating that more than $90 \%$ of erythromycin is converted to anhydro- erythromycin under the source conditions used in this method. Similarly two SRM transitions $738 \rightarrow 162.0,580.4$ (labeled standard) and $720.2 \rightarrow 161.9,120.0$ (anhydro form of labeled standard) were monitored for erythromycin- ${ }^{13} \mathrm{C}-\mathrm{d} 3$ indicated a $95.3 \pm 0.7 \% \quad(\mathrm{n}=7)$ conversion of erythromycin $-{ }^{13} \mathrm{C}-\mathrm{d} 3$. Based on these results, $\mathrm{m} / \mathrm{z} 716$ and $\mathrm{m} / \mathrm{z} 720$ were used for the quantitation of erythromycin and erythromycin- ${ }^{13} \mathrm{C}-\mathrm{d} 3$ respectively (Table 4). 
Table 4. Optimized parameters for the detection of all analytes and internal standards in MS/MS SRM mode

\begin{tabular}{|c|c|c|c|}
\hline Antibiotic & $\begin{array}{c}\text { Parent } \\
\text { ion } \mathrm{m} / \mathrm{z}\end{array}$ & Product ions $\mathrm{m} / \mathrm{z}$ & $\begin{array}{c}\text { Collision } \\
\text { energy } \\
\text { (CE) }\end{array}$ \\
\hline Sulfadiazine & 250.970 & $92.118,108.143$ & 32 \\
\hline Sulfathiazole & 255.945 & $92.182,108.128$ & 30 \\
\hline Sulfamerazine & 264.994 & $108.094,171.959$ & 30 \\
\hline Sulfamethazine & 279.022 & $124.102,92.158$ & 28 \\
\hline Sulfamethizole & 270.956 & $92.172,108.110$ & 25 \\
\hline Sulfachlorpyridazine & 284.946 & $92.116,108.111$ & 28 \\
\hline Sulfamethoxazole & 253.979 & $92.181,108.128$ & 32 \\
\hline Sulfadimethoxine & 310.986 & $92.173,108.083$ & 32 \\
\hline Enoxacin & 321.033 & $205.921,234.001$ & 35 \\
\hline Ofloxacin & 362.019 & $260.964,343.992$ & 32 \\
\hline Norfloxacin & 361.090 & $233.003,276.013$ & 32 \\
\hline Ciprofloxacin & 332.065 & $202.972,245.002$ & 55 \\
\hline Danofloxacin & 358.059 & $282.993,340.016$ & 32 \\
\hline Enrofloxacin & 360.072 & $202.984 \mathrm{~m} 244.985$ & 40 \\
\hline Sarafloxacin & 386.055 & $298.98,322.000$ & 32 \\
\hline Oxytetracycline & 461.045 & $200.95,426.007$ & 28 \\
\hline Tetracycline & 445.066 & $153.943,410.102$ & 30 \\
\hline Chlortetracycline & 479.048 & $153.949,462.103$ & 25 \\
\hline Doxycycline & 445.060 & $266.895,320.929$ & 25 \\
\hline Meclocycline & 476.989 & $225.998,234.806$ & 30 \\
\hline Spiramycin & 422.241 & $88.130,174.150$ & 21 \\
\hline Clindamycin & 425.073 & $126.095,377.025$ & 30 \\
\hline Tylosin & 916.227 & $155.92,173.870$ & 28 \\
\hline Erythromycin & 716.275 & $157.953,540.143$ & 25 \\
\hline
\end{tabular}




\begin{tabular}{lccl}
\hline Clarithromycin & 748.266 & $157.915,558.123$ & 35 \\
Azithromycin & 749.500 & $157.8,591.3$ & 34 \\
Roxithromycin & 837.358 & $115.992,157.92$ & 34 \\
Lincomycin & 407.127 & $126.114,359.077$ & 30 \\
Amoxycillin & 398.034 & $159.158,348.94$ & 32 \\
Trimethoprim & 291.047 & $260.989,274.99$ & 34 \\
Nalidixic acid & 233.013 & $104.161,186.979$ & 50 \\
Sulfamethoxazole-d4 & 258.004 & $96.19,112.100$ & 32 \\
Norfloxacin-d4 & 325.075 & $238.042,261.046$ & 35 \\
Spiramycin-d3 & 423.661 & $101.097,174.017$ & 21 \\
Sulfadiazine-d4 & 255.008 & $96.163,112.145$ & 32 \\
Erythromycin- ${ }^{13} \mathrm{C}-\mathrm{d} 3$ & 720.227 & $120.016,161.943$ & 28 \\
Demeclocycline & 465.135 & $153.980,288.930$ & 31 \\
\hline
\end{tabular}

The capillary temperature was $375{ }^{\circ} \mathrm{C}$, vaporizer temperature was $350^{\circ} \mathrm{C}$ and the spray voltage was $4.0 \mathrm{kV}$. Nitrogen was used as a sheath gas and as an auxiliary gas at a flow rate of 40 and 20 arbitrary units, respectively. Instrument control and data acquisition was performed using Xcalibur 2.1 software (Thermo Scientific, San Jose, CA, USA). Isotopically labeled tetracyclines are not commercially available. Hence, demeclocycline at high concentration $(2 \mu \mathrm{g} / \mathrm{mL})$ was used as an internal standard for the quantification of tetracyclines. LC-MS/MS chromatograms of all target analytes and internal standards, in a fortified and unfortified reclaimed water sample were shown in Figures 3 and 4, respectively. 

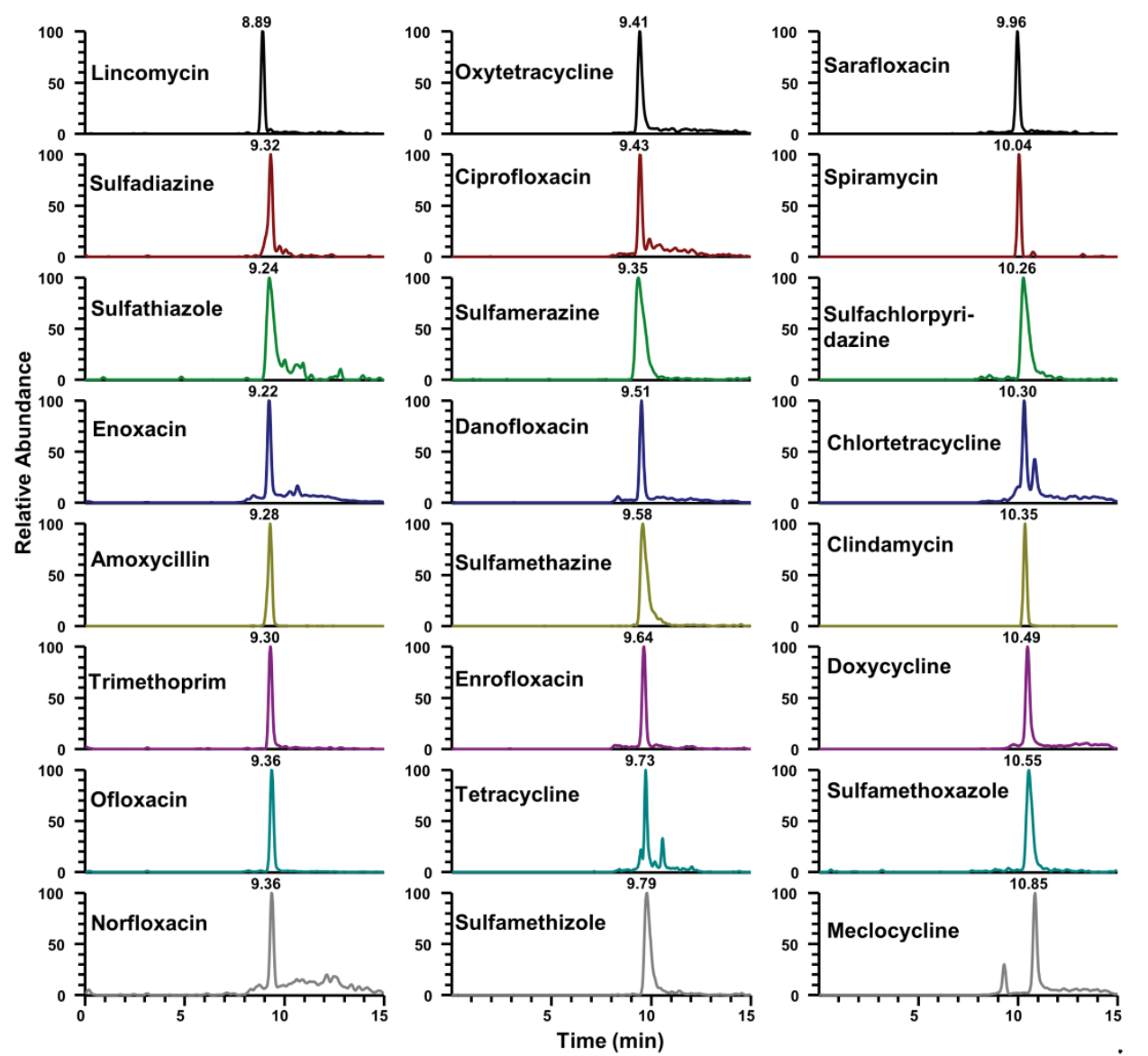


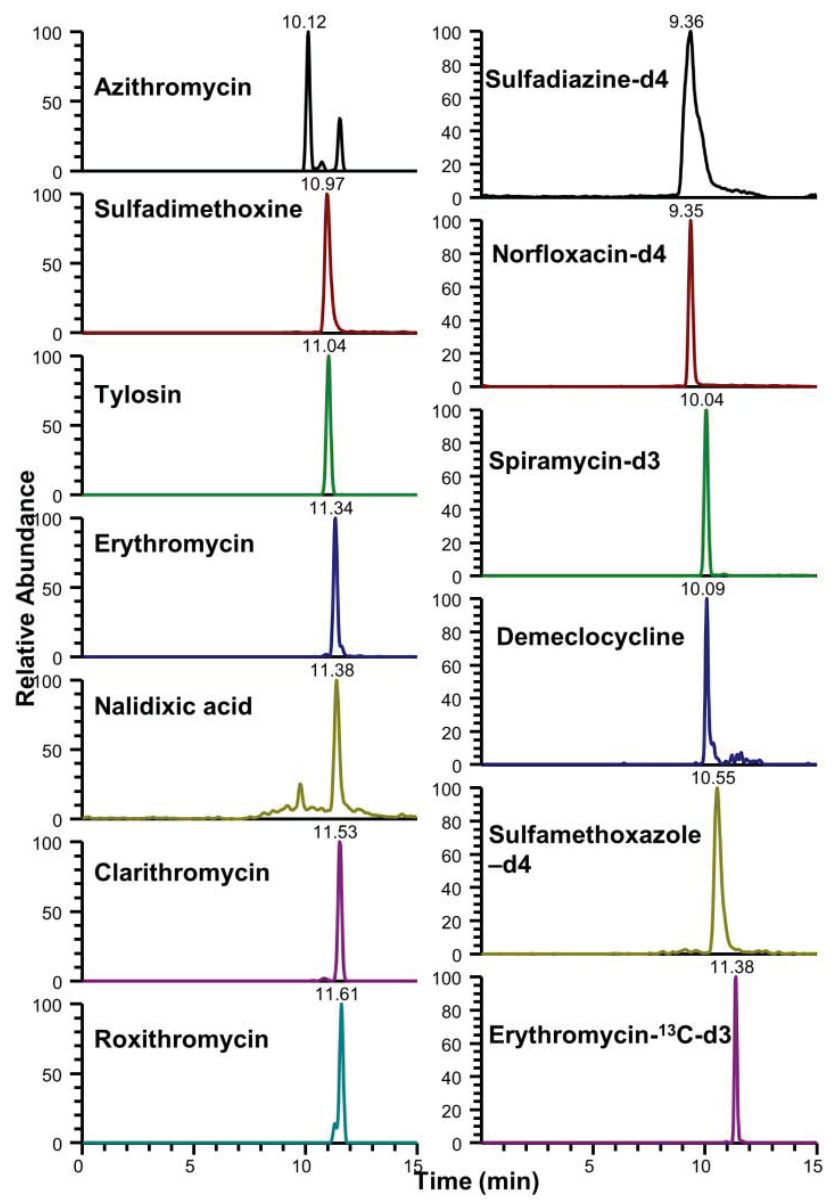

Figure 3. SPE-LC-MS/MS chromatograms of a reclaimed water sample fortified with antibiotics at a concentration equivalent to calibration 5 (CS5), 23-301 ng/L 


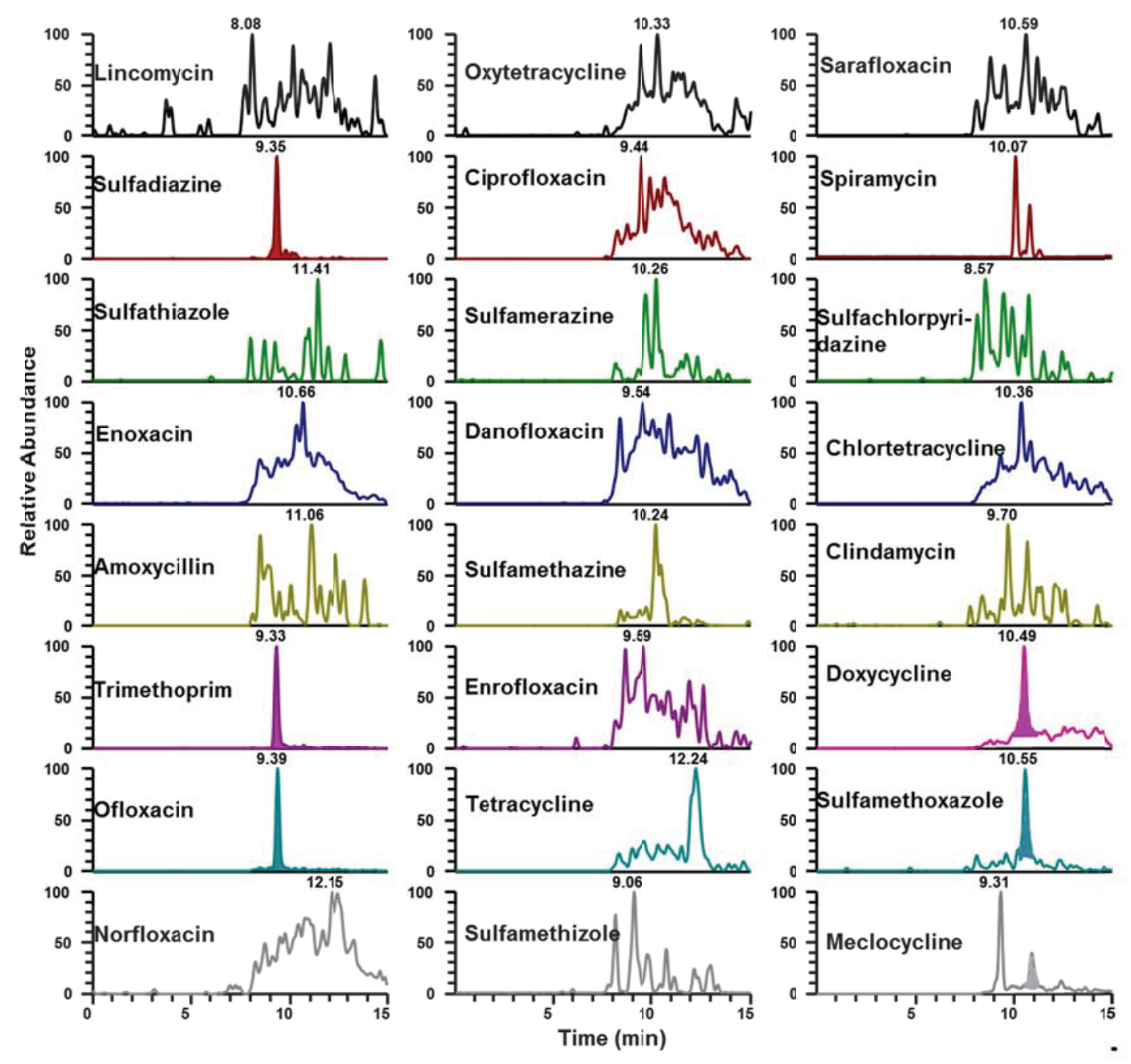




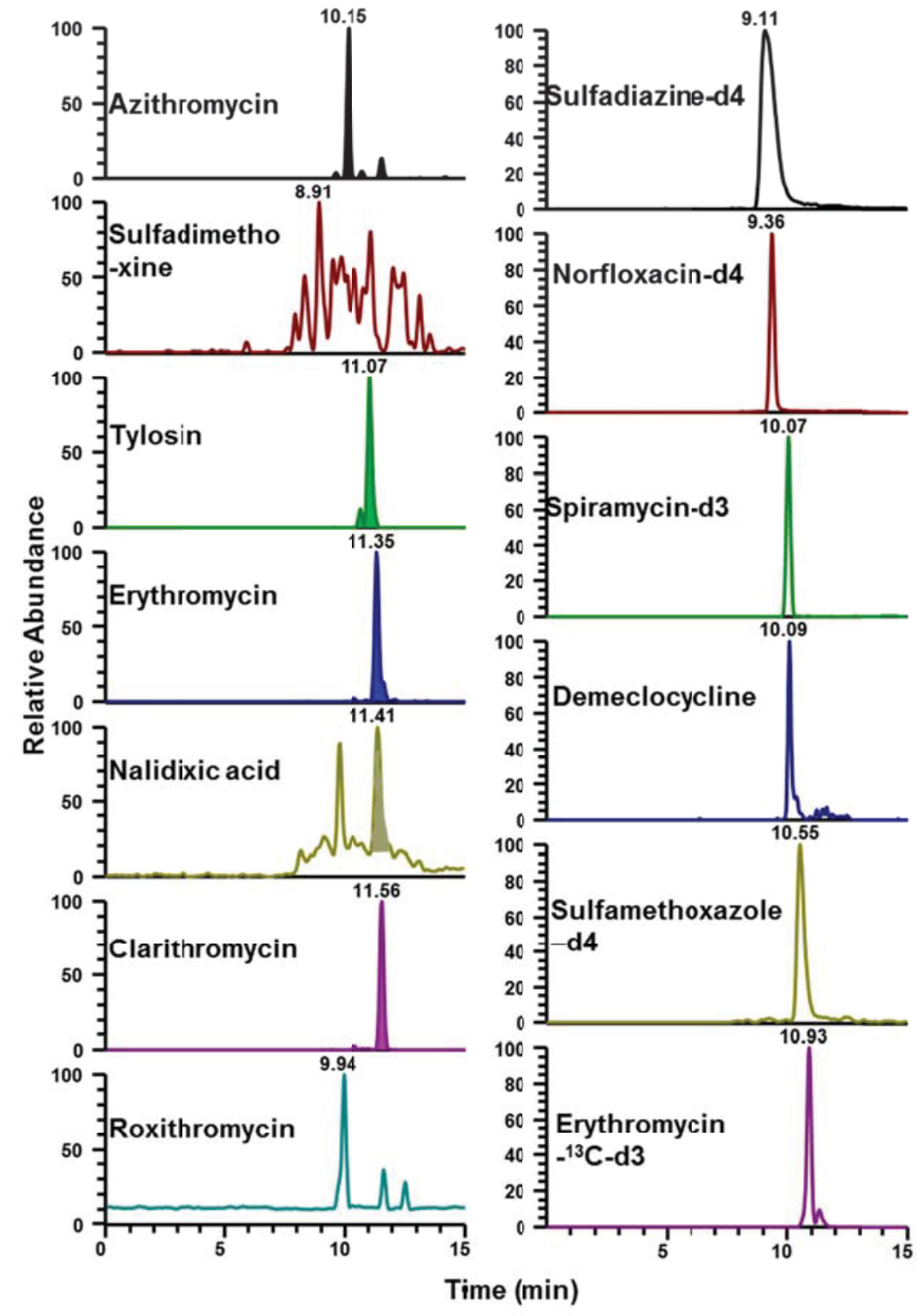

Figure 4. SPE-LC-MS/MS chromatograms of an unfortified reclaimed water sample. Analytes with concentration above MDL include sulfadiazine, trimethoprim, ofloxacin, doxycycline, sulfamethoxazole, meclocycline, azithromycin, tylosin, erythromycin, nalidixic acid and clarithromycin. 


\subsubsection{Online SPE-optimization}

Three types of loading columns, three sample loading rates $(1.0 \mathrm{~mL} / \mathrm{min}, 2.0 \mathrm{~mL} / \mathrm{min}$ and $5.0 \mathrm{~mL} / \mathrm{min})$ and three sample volumes $(1.0 \mathrm{~mL}, 5.0 \mathrm{~mL}$ and $10.0 \mathrm{~mL})$ were tested in order to select the best conditions for SPE recoveries and detection limits for both reclaimed and river water matrices. Loading columns included a HyperSep retain PEP (porous polystyrene divinylbenzene, $20 \mathrm{~mm}$ x $3.0 \mathrm{~mm} \mathrm{I}$. D. x $12 \mu \mathrm{m}$ ), Hypersil gold aQ

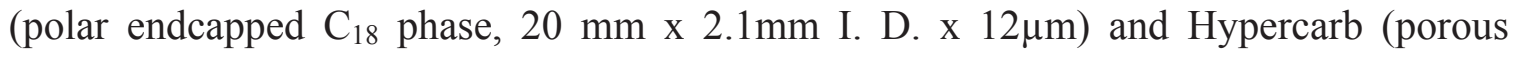
graphitic carbon, $20 \mathrm{~mm} \times 2.1 \mathrm{~mm} \mathrm{I}$. D. x $7 \mu \mathrm{m}$ ) from Thermo Scientific, San Jose, CA, USA. At least two antibiotics were selected from each class (4 sulfonamides, 3 fluoroquinolones, 2 tetracyclines, 4 macrolides, lincomycin and trimethoprim) to study the matrix effect in reclaimed and river water compared to deionized water $(n=3)$. Among them, the selection was random. In this part of the study sulfamethoxazole-d4 was used as internal standard for quantitation of tetracyclines.

\subsubsection{Quantitation of tetrayclines}

For all analytes selected under the present study, quantitation was performed using an internal standard approach. Five isotopically labeled internal standards used in the method were norfloxacin $\mathrm{d} 5$, sulfamethoxazole $\mathrm{d} 5$, sulfadiazine $\mathrm{d} 4$, erythromycin ${ }^{13} \mathrm{C} \mathrm{d} 3$, spiramycin d3 and demeclocycline. Structural similarity between the analyte of interest and internal standard was chosen as a criterion in selecting the internal standard for the given analyte. Since isotopically labeled tetracycline was not commercially available 
during the time of method development, sulfamethoxazole-d5 was chosen as an internal standard based on retention time similarity, for the quantitation of tetracycline compounds.

\subsubsection{Matrix effect}

The ESI source is highly susceptible to components in the matrix, which may result in signal suppression or enhancement (Mallet et al., 2004; Yang et al., 2005; KasprzykHordern et al., 2008). In order to understand the degree of ion suppression or enhancement caused by the reclaimed water matrix, its effects were calculated using the equation given below $(\mathrm{n}=7)$ :

$$
\% \text { Matrixeffect }=\left[\frac{\left(\mathrm{A}_{\mathrm{S}}-\mathrm{A}_{U S}\right)}{\mathrm{A}_{0}}-1\right] * 100 \% \% \text { Matrixeffect }=\left[\frac{\left(\mathrm{A}_{\mathrm{S}}-\mathrm{A}_{U S}\right)}{\mathrm{A}_{0}}-1\right] * 100 \%
$$

(Equation 1)

where $R_{s}$ is the peak area ratio of analyte to internal standard (IS) measured in spiked sample matrix, $\mathrm{R}_{\text {us }}$ is the peak area ratio of analyte to IS measured in unspiked sample matrix and $\mathrm{R}_{0}$ is the peak area ratio of analyte to IS spiked in deionized water.

\subsubsection{Dynamic range and linearity}

A 7-point calibration set was freshly prepared by transferring varying levels of working standard solution into a $11-\mathrm{mL}$ glass vial to which $53 \mu \mathrm{L}$ of $20 \%$ optima LC/MS grade formic acid and $50 \mu \mathrm{L}$ of internal standard mixture in methanol $(1 \mu \mathrm{g} / \mathrm{mL}$ of norfloxacin 
$\mathrm{d} 5,0.2 \mu \mathrm{g} / \mathrm{mL}$ of sulfamethoxazole $\mathrm{d} 5,2 \mu \mathrm{g} / \mathrm{mL}$ of sulfadiazine $\mathrm{d} 4,1 \mu \mathrm{g} / \mathrm{mL}$ of erythromycin ${ }^{13} \mathrm{C} \mathrm{d} 3,1 \mu \mathrm{g} / \mathrm{mL}$ of spiramycin $\mathrm{d} 3$ and $2 \mu \mathrm{g} / \mathrm{mL}$ of demeclocycline) were added and the final volume was made to $10.5 \mathrm{~mL}$ with LC/MS grade water. The concentration of all analytes ranged from $2 \mathrm{ng} / \mathrm{L}$ to $750 \mathrm{ng} / \mathrm{L}$ except for enoxacin, danofloxacin and amoxycillin (20-1500 ng/L). Calibration curves were built with the relative response ratio (area of the analyte standard divided by area of the internal standard) as a function of the analyte concentration. Linear response was observed for all the analytes in the range used $\left(\mathrm{R}^{2}>0.99\right)$.

The method was applied to reclaimed, river water and drinking waters. In case of reclaimed waters, in order to reduce the effect of the matrix interference, samples were diluted with LC/MS grade water (50:50). Thus, reclaimed water samples were prepared by transferring $10.4 \mathrm{~mL}$ of $50: 50$ diluted sample into a $11-\mathrm{mL}$ vial to which $50 \mu \mathrm{L}$ of $20 \%$ optima LC/MS grade formic acid, $50 \mu \mathrm{L}$ of surrogate mixture in methanol $(1 \mu \mathrm{g} / \mathrm{mL}$ of norfloxacin d5, $0.2 \mu \mathrm{g} / \mathrm{mL}$ of sulfamethoxazole $\mathrm{d} 5,2 \mu \mathrm{g} / \mathrm{mL}$ of sulfadiazine $\mathrm{d} 4,1 \mu \mathrm{g} / \mathrm{mL}$ of erythromycin ${ }^{13} \mathrm{C} \mathrm{d} 3,1 \mu \mathrm{g} / \mathrm{mL}$ of spiramycin $\mathrm{d} 3$ and $2 \mu \mathrm{g} / \mathrm{mL}$ of demeclocycline) were added and the final volume was made to $10.5 \mathrm{~mL}$ with LC/MS grade water. Correspondingly, a dilution factor was applied while reporting the results. The river and drinking water samples were injected at their full strength.

The method was further validated in terms of precision which is determined as relative standard deviation (RSD) calculated from repeated injections $(\mathrm{n}=7)$ of a $20-100 \mathrm{ng} / \mathrm{L}$ spiked matrix (reclaimed water, river water) samples during the same day (repeatability) and on different days (reproducibility). 


\subsubsection{Method accuracy and detection limits}

For the determination of method accuracy in real samples, river and reclaimed water matrices were spiked at two concentration levels representative of typical low and high concentrations (57-755 ng/L) found in those types of water matrices (corresponding MDL is chosen as low level spike and calibration middle point as high level spike, $n=7$ ). As real sample matrices may contain target analytes, non-spiked samples were also analyzed and the concentration found was subtracted from the spiked sample concentration. Analyte recovery from different matrices was calculated using the following equation:

$$
\left.\% \text { Method accuracy }=\frac{\left(C_{S}-C_{U S}\right)}{C_{0}} * 100 \ldots \ldots \ldots \ldots \ldots \ldots \ldots \ldots \ldots \ldots \ldots \ldots \text { Equation } 2\right)
$$

Where $C_{s}$ is the concentration of analyte found in spiked sample matrix, $C_{u s}$ is the concentration of analyte measured in unspiked sample matrix and $\mathrm{C}_{0}$ is the concentration spiked in the sample matrix. In order to assure the quality of the analytical data, a method/procedural blank, a spiked blank, samples duplicates, a matrix spike, and a matrix spike duplicate were analyzed with every sample set (20 samples).

To calculate the method detection limits (MDL), seven replicates of river and reclaimed water samples spiked in the concentration range of 5.7-150 ng/L were analyzed. The MDLs were calculated by multiplying the standard deviation from the seven measurements by the Student $t$ value for six degrees of freedom at the $99 \%$ confidence level $\left(\mathrm{t}_{(7-1,99)}=3.143\right)$, according to procedures outlined by the USEPA (USEPA, 2010). 
The matrix was spiked at two concentrations levels $(n=7)$ selected based on the sample source.

\subsection{Results and discussion}

\subsubsection{Online SPE}

Comparison of the three loading columns tested (HyperSep retain PEP, Hypersil gold aQ and Hypercarb) is shown in the Figure 5. HyperSep Retain PEP column showed the best recoveries for most of the target compounds while both the Hypersil GOLD aQ and the Hypercarb phases showed either high (for ofloxacin) or no retention (for enrofloxacin and norfloxacin), which can be attributed to structural differences between the fluoroquinolones. Thus, HyperSep Retain PEP was selected for further study. This result was expected since the PEP has similar packing material to the Oasis HLB (Hydrophilic lipophilic balance, made of N-vinylpyrrolidone and divinylbenzene) -type cartridges used for enhanced retention of polar analytes in usual offline SPE preconcentration methods (Rao et al., 2008).

For most of the analytes increased breakthrough was observed at high sample loading rates $(5.0 \mathrm{~mL} / \mathrm{min})$ so the $2.0 \mathrm{~mL} / \mathrm{min}$ rate was selected to maintain sample throughput. The observed detection limits were lower for both $5.0 \mathrm{~mL}$ and $10.0 \mathrm{~mL}$ injection volumes compared to $1.0 \mathrm{~mL}$ (results were not shown). However, for samples with complex matrix such as reclaimed water, $10 \mathrm{~mL}$ showed better detection limits except for enoxacin, ofloxacin, norfloxacin. Therefore, $10.0 \mathrm{~mL}$ sample was loaded at a flow rate of 
$2.0 \mathrm{~mL} / \mathrm{min}$ and the optimized load pump and analytical pump gradient cycle is shown in Table 5.

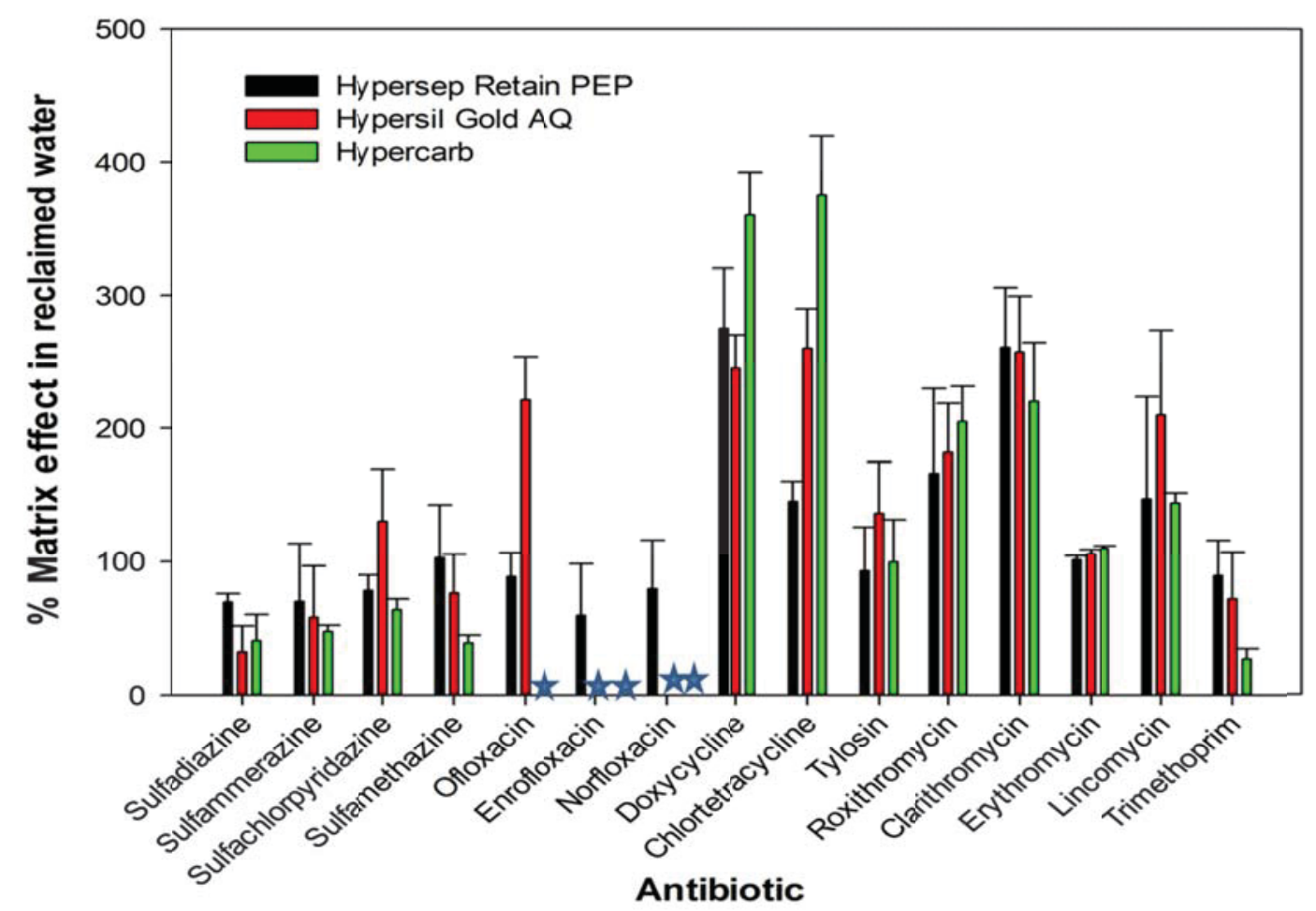

Figure 5. Comparison of loading columns tested for the current study $(n=3)$ Sulfamethoxazole-d4 was used for quantification of tetracyclines instead of demeclocycline ( $t=$ not detected) 
Table 5. Mobile phase program for the load pumps (top) and analytical (bottom)

\begin{tabular}{cccccc}
\hline $\begin{array}{c}\text { Time } \\
(\mathrm{min})\end{array}$ & $\begin{array}{c}\% \mathrm{~A} \\
(\text { Water })\end{array}$ & $\begin{array}{c}\% \mathrm{~B} \\
(\text { Methanol) }\end{array}$ & $\begin{array}{c}\% \mathrm{C} \\
\text { (Acetonitrile) })\end{array}$ & $\begin{array}{c}\% \mathrm{D}(0.1 \% \\
\text { Formic acid } \\
\text { in water })\end{array}$ & $\begin{array}{c}\text { Flow }(\mu \mathrm{L} \\
\text { min- })\end{array}$ \\
\hline 0.0 & 100 & 0 & 0 & 0 & 2000 \\
5.2 & 100 & 0 & 0 & 0 & 2000 \\
6.0 & 0 & 0 & 10 & 90 & 1000 \\
14.0 & 0 & 50 & 50 & 0 & 50 \\
14.2 & 0 & 50 & 50 & 0 & 1000 \\
16.0 & 0 & 50 & 50 & 0 & 1000 \\
16.2 & 100 & 0 & 0 & 0 & 2000 \\
17.0 & 100 & 0 & 0 & 0 & 2000 \\
\hline
\end{tabular}

\begin{tabular}{cccc}
\hline $\begin{array}{c}\text { Time } \\
(\min )\end{array}$ & $\begin{array}{c}\% \mathrm{C} \\
\text { (acetonitrile) }\end{array}$ & $\begin{array}{c}\text { \% D }(0.1 \% \\
\text { formic acid } \\
\text { in water })\end{array}$ & $\begin{array}{c}\text { Flow }(\mu \mathrm{L} \\
\left.\mathrm{min}^{-1}\right)\end{array}$ \\
\hline 0.0 & 10 & 90 & 220 \\
5.5 & 10 & 90 & 220 \\
9.5 & 50 & 50 & 220 \\
10.6 & 95 & 5 & 220 \\
13.8 & 25 & 75 & 220 \\
17.0 & 10 & 90 & 220 \\
\hline
\end{tabular}

\subsubsection{Quantitation of tetrayclines}

As seen in the Figure 5, the percent recovery of tetrayclines in reclaimed waters ranged from $150-375 \%$ and this result was independent of the type of the loading column chosen. As shown in Table 6, among tetracyclines, \% matrix effect (shown as signal suppression or enhancement) varied between -46 to $+170 \%$. Positive value indicates signal enhancement and negative value indicate signal suppression. Although, small deviations in the recovery and/or matrix effect are expected among different tetracyclines 
due to minor differences in the structure (Table 3), the ranges observed couldn't be explained solely based on the structure. The differences in the affinity of tetracycline and sulfamethoxazole-d5 for the stationary phase, which in turn depend on their structure, could possibly explain the observed discrepancy. This led to the selection of an alternative internal standard, demeclocycline from the same family of antibiotics. To overcome any errors introduced by demeclocycline present in environmental water samples, samples were spiked with demeclocycline at much higher concentration. The updated matrix effects results shown in Table 6 support the use of demeclocycline instead of sulfamethoxazole-d5. Therefore, demeclocycline was used as an internal standard for the quantitation of tetracycline in the later parts of the study.

Table 6. Signal suppression/enhancement values of tetrayclines in reclaimed waters using sulfamethoxazole-d5 as internal standard

\begin{tabular}{lcc}
\hline & \% Signal & \% Signal \\
Antibiotic & suppression/enhancement & suppression/enhancement \\
& in reclaimed water using & in reclaimed water using \\
& $\begin{array}{c}\text { Sulfamethoxazole-d5 as } \\
\text { internal standard }\end{array}$ & demeclocycline as \\
& -46.1 & internal standard \\
\hline Oxytetracycline & -23.6 & 0.5 \\
Tetracycline & 3.20 & 1.5 \\
Chlortetracycline & -10.6 & -12 \\
Doxycycline & 170 & 7.8 \\
Meclocycline & & -12 \\
\hline
\end{tabular}




\subsubsection{Matrix effect}

Matrix effects were calculated using equation 1. Positive values indicate signal enhancement and negative values indicate signal suppression (Table 7). The results indicated that the effect of matrix was not the same for all classes of antibiotics and it ranged from \pm 10 (tetracyclines) to \pm 50 (fluoroquinolones), similar to those observed by Lopez-Serna et al. 2010 (Lopez-Serna et al., 2010), i.e., showing higher variation for fluoroquinolones in comparison to other antibiotics. For most of the classes, the signal enhancement or suppression is within $\pm 30 \%$, suggesting that the use of one internal standard per class is sufficient to provide accurate measurements. The selection of the individual internal standard was based on the similarity of structure and/or the similarities of elution times with the target analytes. 
Table 7. Signal suppression/enhancement values in reclaimed water sample matrix

\begin{tabular}{lc}
\hline \multicolumn{1}{c}{ Antibiotic } & $\begin{array}{c}\text { \% Signal suppression/enhancement in } \\
\text { reclaimed water }\end{array}$ \\
\hline Sulfadiazine & 1.2 \\
Sulfathiazole & 21 \\
Sulfamerazine & 3.7 \\
Sulfamethazine & 0.8 \\
Sulfamethizole & -14 \\
Sulfachlorpyridazine & 24 \\
Sulfamethoxazole & 23 \\
Sulfadimethoxine & 0.5 \\
Enoxacin & 59 \\
Ofloxacin & -21 \\
Norfloxacin & -17 \\
Ciprofloxacin & 14 \\
Danofloxacin & -53 \\
Enrofloxacin & -23 \\
Sarafloxacin & 8.0 \\
Oxytetracycline & 0.5 \\
Tetracycline & 1.5 \\
Chlortetracycline & 4.8 \\
Doxycycline & 7.8 \\
Meclocycline & -12 \\
Spiramycin & 7.5 \\
Clindamycin & 15 \\
Tylosin & -13 \\
Anhydroerythromycin & 27 \\
Clarithromycin & -31 \\
Azithromycin & 25 \\
Roxithromycin & 5.6 \\
Lincomycin & 11 \\
Amoxycillin & 11 \\
Trimethoprim & \\
Nalidixic acid & - \\
\hline
\end{tabular}

The developed method was validated in terms of precision and accuracy. The intra-and inter-day precision of the method was good indicated by relative standard deviations between 4.3-16.4 and 6.8-21.6, respectively (Table 8). 
Table 8. Intra- and inter- day precision for all analytes expressed as \% RSD

\begin{tabular}{|c|c|c|}
\hline Antibiotic & $\begin{array}{l}\text { Intra-day precision } \\
\text { \%RSD }(n=5)\end{array}$ & $\begin{array}{l}\text { Inter-day precision } \\
\% \mathrm{RSD}(\mathrm{n}=3)\end{array}$ \\
\hline Sulfadiazine & 8.2 & 10.2 \\
\hline Sulfathiazole & 6.5 & 6.8 \\
\hline Sulfamerazine & 4.3 & 9.5 \\
\hline Sulfamethazine & 9.1 & 8.6 \\
\hline Sulfamethizole & 5.4 & 10.6 \\
\hline Sulfachlorpyridazine & 11.1 & 10.8 \\
\hline Sulfamethoxazole & 7.4 & 10.6 \\
\hline Sulfadimethoxine & 12.4 & 15.8 \\
\hline Enoxacin & 15.4 & 20.4 \\
\hline Ofloxacin & 4.8 & 10.4 \\
\hline Norfloxacin & 11.2 & 16.6 \\
\hline Ciprofloxacin & 4.6 & 7.8 \\
\hline Danofloxacin & 14.8 & 21.4 \\
\hline Enrofloxacin & 7.5 & 8.4 \\
\hline Sarafloxacin & 12.9 & 10.7 \\
\hline Oxytetracycline & 7.2 & 11.5 \\
\hline Tetracycline & 5.8 & 10.1 \\
\hline Chlortetracycline & 10.4 & 9.8 \\
\hline Doxycycline & 8.4 & 14.9 \\
\hline Meclocycline & 12.4 & 9.7 \\
\hline Spiramycin & 15.8 & 21.2 \\
\hline Clindamycin & 10.8 & 13.3 \\
\hline Tylosin & 7.2 & 9.5 \\
\hline Anhydroerythromycin & 4.5 & 7.1 \\
\hline Clarithromycin & 8.5 & 10.2 \\
\hline Azithromycin & 12.5 & 12.8 \\
\hline Roxithromycin & 5.6 & 7.4 \\
\hline Lincomycin & 11.1 & 15.8 \\
\hline Amoxycillin & 16.4 & 21.6 \\
\hline Trimethoprim & 5.8 & 9.9 \\
\hline Nalidixic acid & 10.4 & 11.2 \\
\hline
\end{tabular}




\subsubsection{Method accuracy and detection limits}

Both reclaimed water and river water matrices $(n=7$, except for tetracyclines $n=4)$ were tested to calculate method accuracy using equation 2. Results were compared in Figure 6. In both matrices, the method accuracy ranged from $50-150 \%$ for most of the analytes.

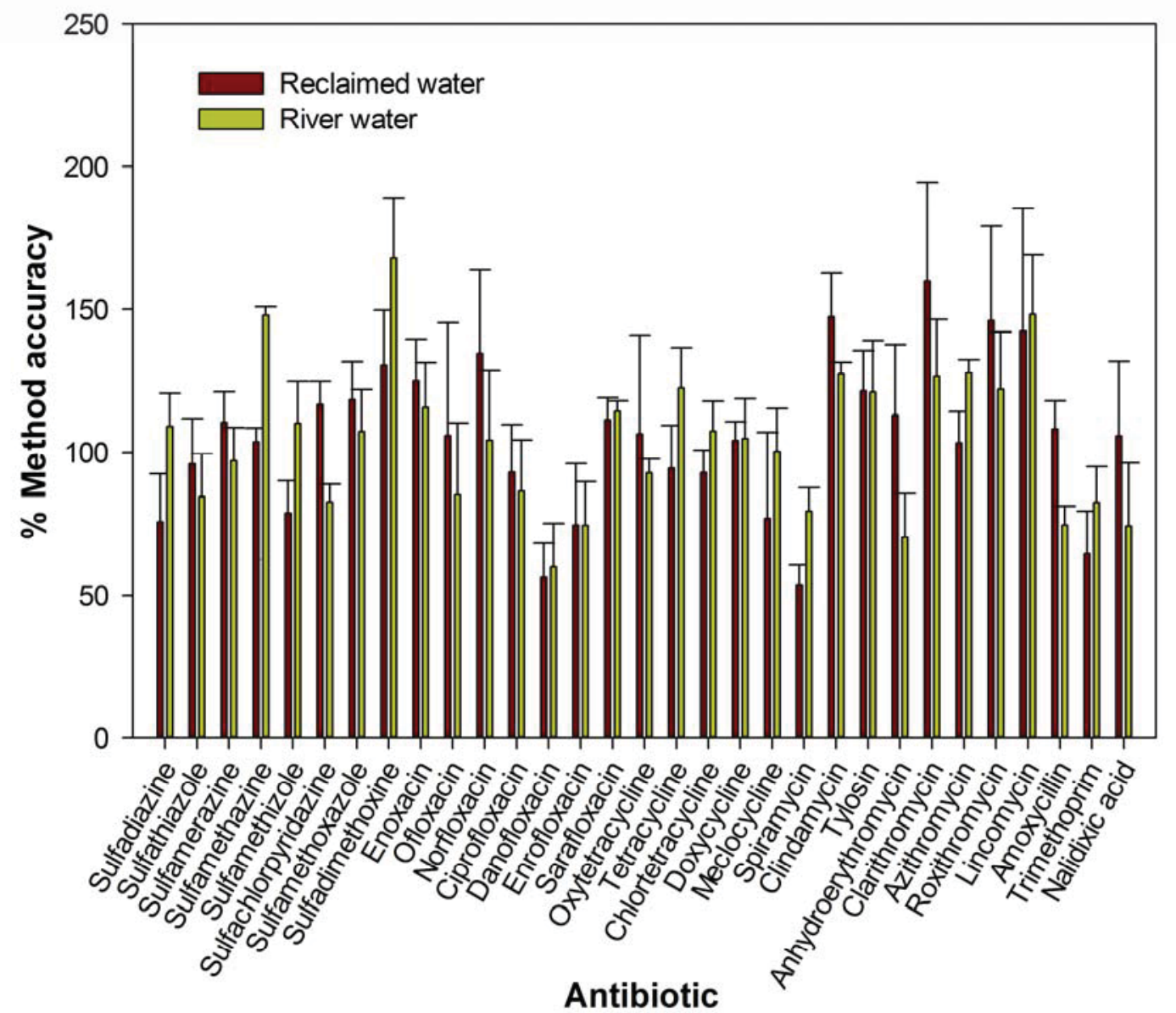

Figure 6. Recovery studies for 31 antibiotics in river and reclaimed water matrices $(n=7$ for all classes of antibiotics except tetracyclines $(n=4)$ 
The statistically calculated MDLs are compared in Figure 7 and tabulated in Table 9, implying that matrix components were influencing the method sensitivity and antibiotic detection.

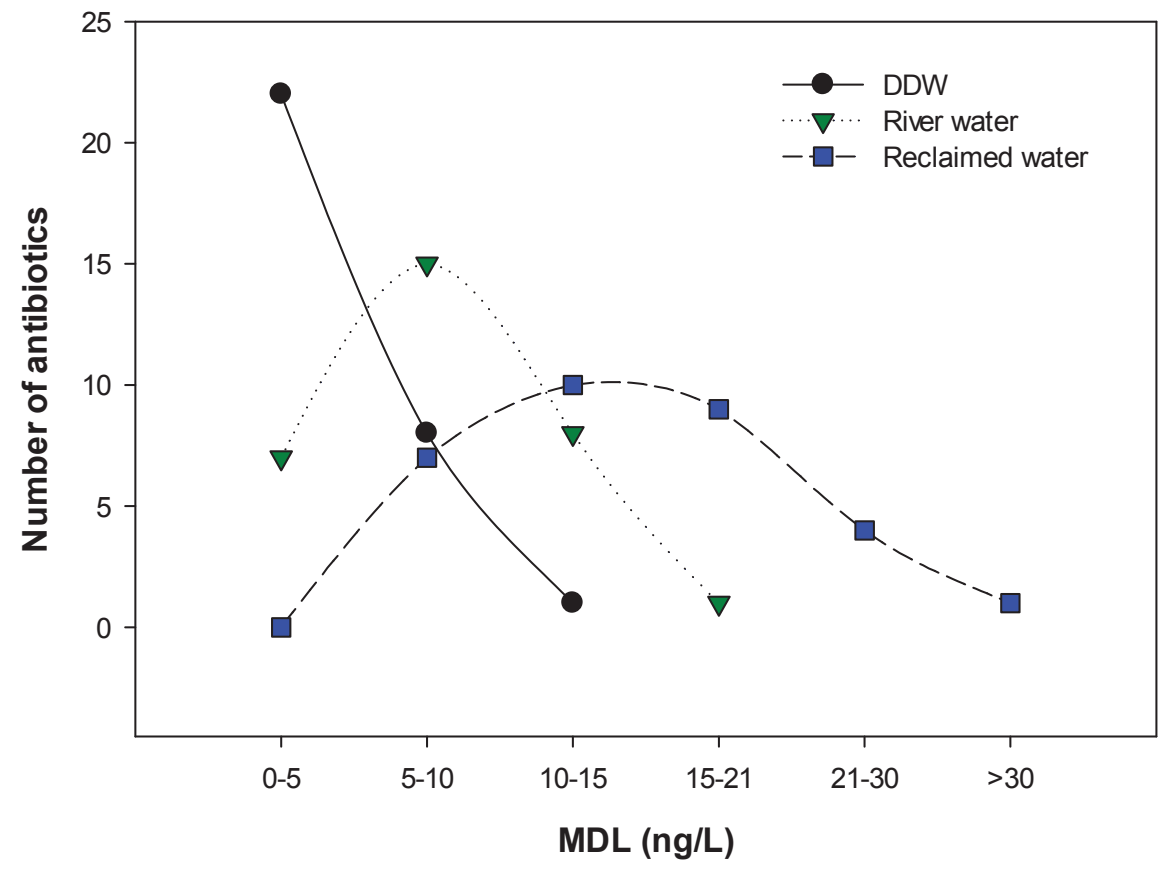

Figure 7. Comparison of MDLs in deionized water, river water and reclaimed water $(n=7)$

Table 9. Method detection limits of target analytes in deionized, river and reclaimed water matrices

\begin{tabular}{llll}
\hline Antibiotic & $\begin{array}{l}\text { MDL in Deionized } \\
\text { water }(\mathrm{ng} / \mathrm{L})\end{array}$ & $\begin{array}{l}\text { MDL in river } \\
\text { water }(\mathrm{ng} / \mathrm{L})\end{array}$ & $\begin{array}{l}\text { MDL in reclaimed } \\
\text { water }(\mathrm{ng} / \mathrm{L})\end{array}$ \\
\hline Sulfadiazine & 7.91 & 8.52 & 20.2 \\
Sulfathiazole & 6.06 & 7.18 & 20.5 \\
Sulfamerazine & 1.69 & 7.23 & 15.2 \\
\hline
\end{tabular}




\begin{tabular}{llll}
\hline Sulfamethazine & 1.32 & 5.81 & 9.75 \\
Sulfamethizole & 3.15 & 10.2 & 16.3 \\
Sulfachlorpyridazine & 5.40 & 9.70 & 10.1 \\
Sulfamethoxazole & 4.60 & 6.40 & 16.6 \\
Sulfadimethoxine & 3.01 & 10.4 & 13.6 \\
Enoxacin & 6.73 & 14.5 & 63.1 \\
Ofloxacin & 1.77 & 9.24 & 28.4 \\
Norfloxacin & 2.35 & 6.82 & 21.1 \\
Ciprofloxacin & 4.44 & 5.91 & 11.9 \\
Danofloxacin & 14.4 & 20.5 & 28.0 \\
Enrofloxacin & 2.02 & 3.54 & 7.66 \\
Sarafloxacin & 3.96 & 4.12 & 5.50 \\
Oxytetracycline & 2.86 & 3.56 & 7.83 \\
Tetracycline & 3.69 & 5.96 & 14.1 \\
Chlortetracycline & 9.74 & 11.4 & 14.2 \\
Doxycycline & 1.28 & 7.86 & 15.6 \\
Meclocycline & 2.08 & 12.1 & 25.0 \\
Spiramycin & 6.58 & 11.5 & 18.5 \\
Clindamycin & 4.51 & 4.61 & 5.58 \\
Tylosin & 4.81 & 8.40 & 10.2 \\
Erythromycin & 6.50 & 7.82 & 8.85 \\
Clarithromycin & 1.85 & 5.47 & 10.7 \\
Azithromycin & 3.81 & 6.15 & 10.8 \\
Roxithromycin & 1.21 & 4.53 & 11.8 \\
Lincomycin & 1.81 & 2.24 & 7.70 \\
Amoxycillin & 3.10 & 14.9 & 23.1 \\
Trimethoprim & 1.58 & 3.19 & 12.0 \\
Nalidixic acid & 5.22 & 11.2 & 15.2 \\
Average & 4.18 & 8.10 & 16.1 \\
\hline
\end{tabular}




\subsection{Conclusions}

An Online Solid phase extraction (SPE) and liquid chromatography in combination with tandem mass spectrometry (LC-MS/MS) method was developed for the simultaneous determination of 31 antibiotics in various water matrices. An Ion Max API Heated Electrospray Ionization (HESI) source operated in the positive ionization mode with two selected reaction monitoring (SRM) transitions was used per antibiotic for positive identity and quantification performed by the internal standard approach, to correct for matrix effects and any losses in the online extraction step. The advantages of developed analytical methodology were, required small sample volume $(10 \mathrm{~mL})$, very little sample preparation and high throughput, the total sample run time was 20 minutes. The method had MDLs in the range of 1.2-9.7 (except danofloxacin), 2.2-15, 5.5-63 ng/L in deionized water, surface water and reclaimed waters, respectively and hence has the potential to measure analytes at their environmental concentrations. The method accuracy in matrix spiked samples ranged from $50-150 \%$ for the studied antibiotics. Furthermore, the method was validated in terms of precision, accuracy and linearity. And the present method is easy to adopt by analytical labs for regular day to day antibiotic analysis. 


\section{CHAPTER 3}

\section{Reclaimed water analysis}

(Panditi, V., Batchu, S., Gardinali, P., 2013. Analytical and Bioanalytical Chemistry, 405 (18), 5953-5964) 


\subsection{Introduction}

Water is an integral part of life. The amount of water used by human society for different activities on a global scale is shown in Figure 8 (Levine and Asano, 2004). The world population is estimated to be increasing at a rate of about $1.2 \%$ per year (UN, 2003) and this steady growth in population demands more water supplies. Earth's limited natural water resources have made humans to think of reuse/reclamation of water to supplement the increasing demand for fresh water. More importantly the sewage effluents containing hazardous chemicals and pathogenic microorganisms that released in to natural aquatic environments were negatively affecting the healthy ecosystems (Boxall, 2004; Kummerer, 2009; Ding and He, 2010; Wang and Gardinali, 2012). Hence, many countries in the world realized the potential effects in both public and environmental health point and taking necessary steps to restrict the contamination of natural water bodies. Reclamation of wastewater is one of the methods of choice widely practiced. Reclaimed water can be defined as the end product of wastewater reclamation that meets water quality requirements for biodegradable materials, suspended matter and pathogens. Different applications of reclaimed water include landscape irrigation, agricultural irrigation in both food and non-food crops, ground water recharge and recreational purposes (Levine and Asano, 2004). 


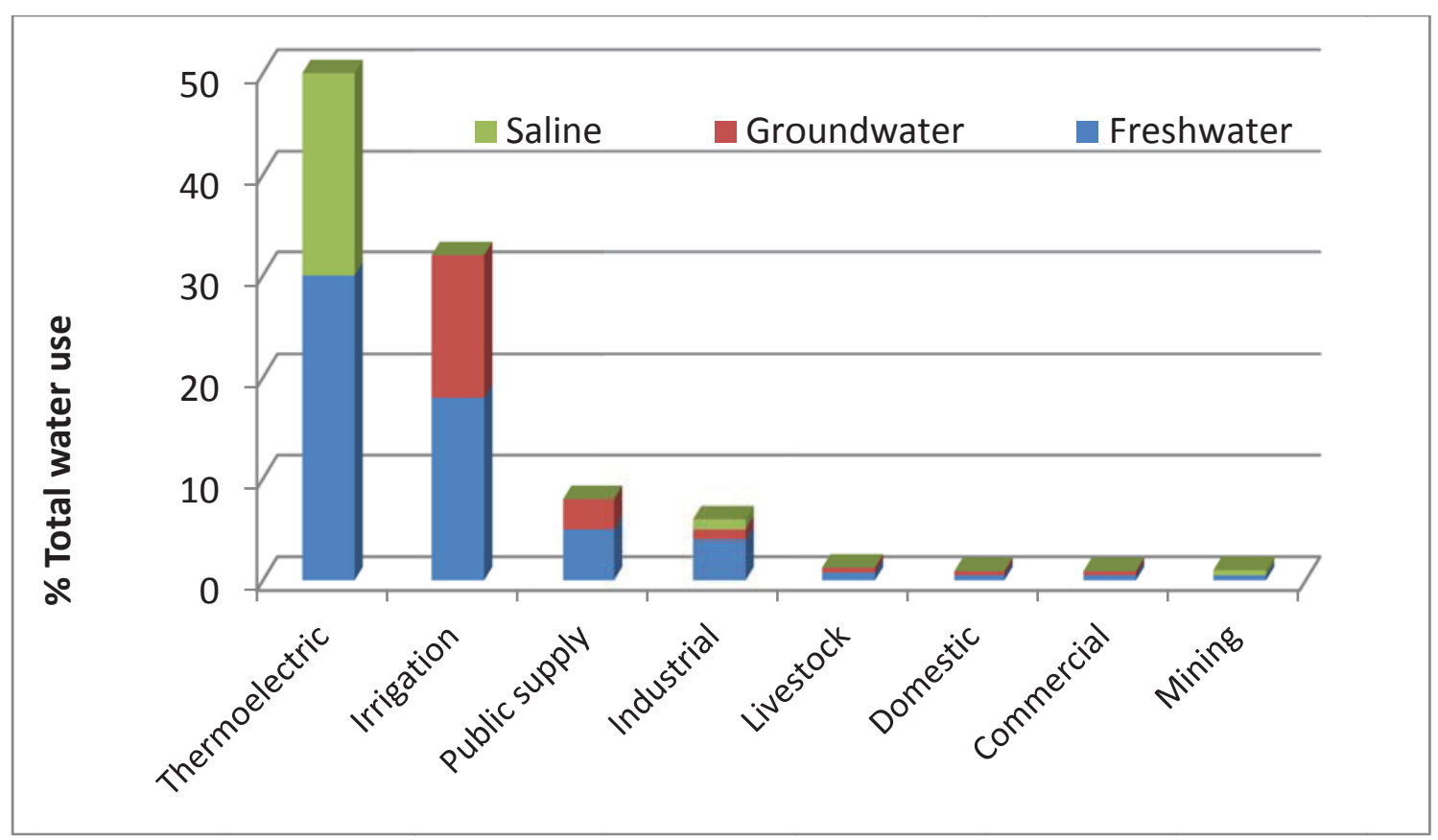

Figure 8. The amount of water used for potable and nonpotable applications on a global scale

In Florida, state law supports water reuse efforts. According to Section 403.064(1), F. S., reuse is a critical component of meeting the state's existing and future water supply needs while sustaining natural systems (CMPD, 2010). In Miami Dade County, the city of Miami supports 20-year irrigation projects to recharge the Biscayne aquifer with highly treated reclaimed water. These projects will be implemented by North and Central District Wastewater Treatment plants (CMPD, 2010). According to Miami Dade Water and Sewer Department's reuse feasibility update report in $2006,7.9 \%$ of wastewater produced (16.2 MGD) is reused. In addition to the existing capacity, the department is planning to produce an additional 18.75 MGD of reclaimed water by the end of 2013 (MDWASD, 2007b). Various steps involved in producing reclaimed water from the wastewater include microfiltration through a series of membranes ( 0.1 to $10 \mu \mathrm{m})$, reverse 
osmosis, treatment with hydrogen peroxide followed by photolysis with UV light (MiamiDade, 2013). To date, FIU Biscayne Bay Campus receives reclaimed water from Miami-Dade North District Waste Water Treatment Facility, which has a capacity to treat $380,000 \mathrm{~m}^{3} /$ day of water (Figure 9). The capacity of the existing reuse system for FIU irrigation is 1.5 million gallons per day (MGD) for irrigating 40 acres of landscape (MDWASD, 2007a). Although reclaimed water is a processed wastewater it may contain residual amounts of biologically active antibiotics which can show adverse effects on sensitive ecosystems. Moreover, as the reclaimed water is used for many different purposes to supplement the fresh water needs, it is necessary to ensure that the reclaimed water is safe for reuse. Hence the quality of reclaimed waters must be monitored.

The main aim of this study is to analyze reclaimed waters for residual antibiotics to determine their concentration profiles, detection frequency and total mass loads estimation using online SPE-LC/MS/MS. To understand significant variation if any, among the different chemical classes the mass loads results were compared with annual antibiotic sales data. 


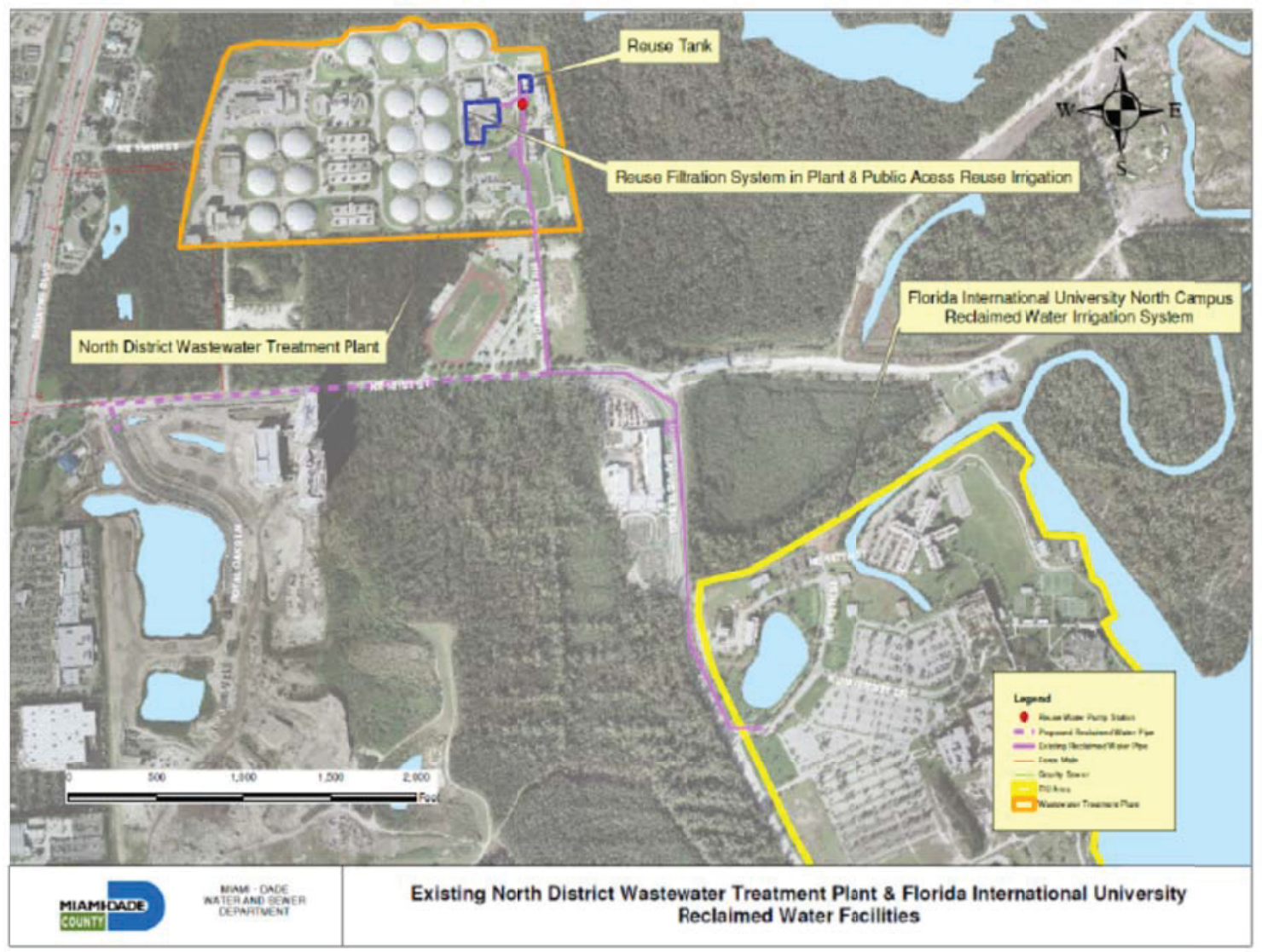

Figure 9. Existing North District Wastewater Treatment plant (circled in orange) and Florida International University reclaimed water facilities (circled in yellow)

\subsection{Sample collection and preparation}

All reclaimed water samples were collected directly from the sprinkler systems after they were flushed for at least 5 minutes once a week from November 2010 until October 2011 (56 samples). After collection, all samples were immediately transported to the laboratory and sequentially filtered through the $0.45 \mu \mathrm{m}$ glass fiber filter and finally through $0.2 \mu \mathrm{m}$ membrane filter to minimize any potential for biodegradation. Filtered samples were stored in the dark at $-18^{\circ} \mathrm{C}$ until the time of analysis. 


\subsection{Applicability of the method to reclaimed water samples}

The method developed was applied to assess the levels of the target compounds in reclaimed waters and the concentrations below the MDL are considered as not detected for the calculation of mean and frequency of detection.

The results for reclaimed waters were plotted as box plots from the highest to the lowest concentration and frequency of detection is shown in parenthesis (Figure 10). The blue line in each box plot indicates mean annual concentration while top and bottom limits represent the $25^{\text {th }}$ and $75^{\text {th }}$ percentile of the distribution respectively. 


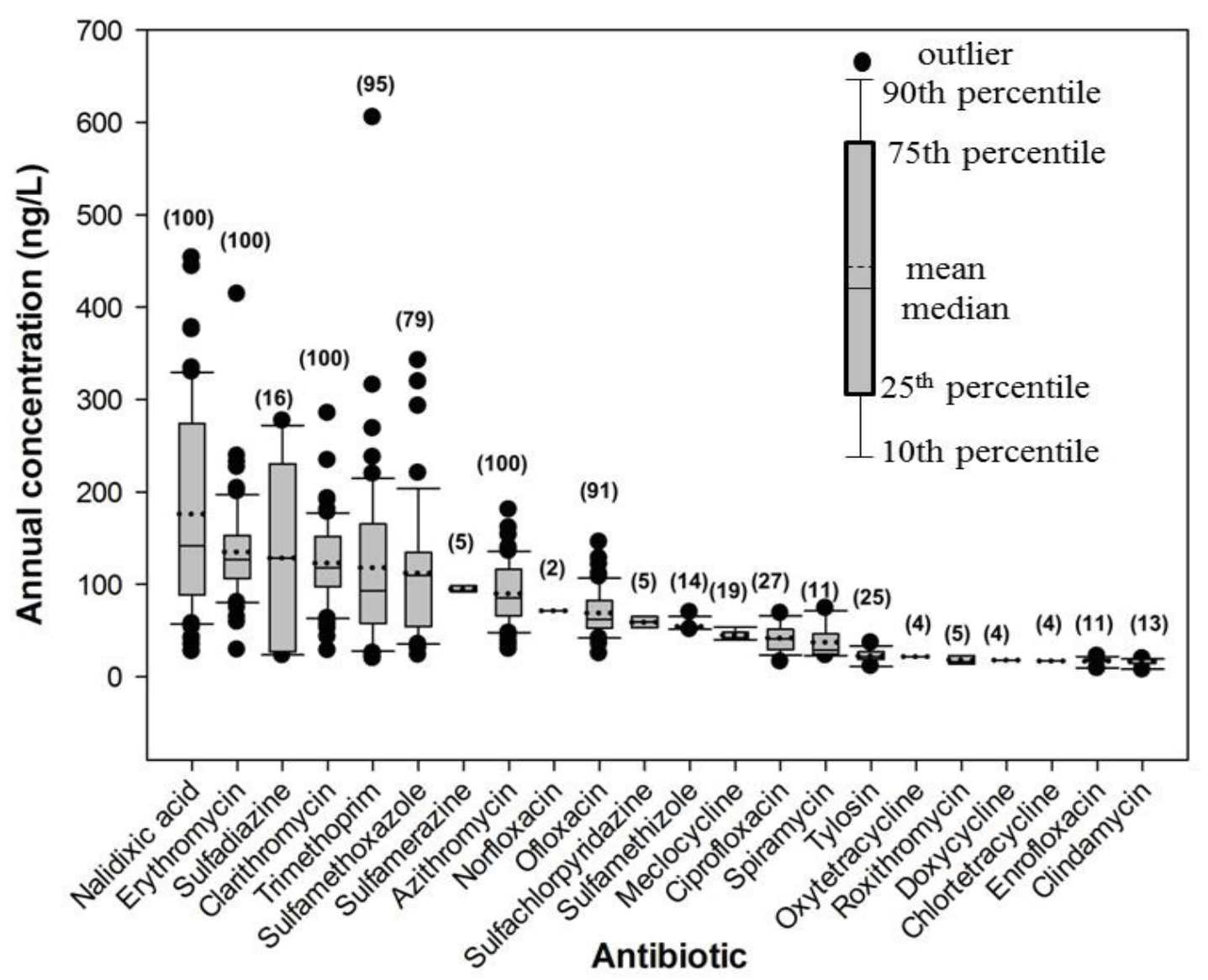

Figure 10. Distribution of antibiotics in reclaimed waters (frequency of detection shown in parenthesis). The boundaries of box plot cover $25^{\text {th }}-75^{\text {th }}$ percentile, the center line indicates median of the sample population, error bars (whiskers) above and below the box refer to $90^{\text {th }}$ and $10^{\text {th }}$ percentiles. The dotted line in each box plot indicates mean annual concentration $(\mathrm{n}=56)$.

Detailed values of mean, median and the concentration range are shown in (Table 10). For nalidixic acid, trimethoprim and clarithromycin, the mean concentration was moderately higher than the median concentration indicating that majority of the samples 
have rather high concentrations. The most frequently detected antibiotics were nalidixic acid, erythromycin (monitored as anhydroerythromycin), clarithromycin, azithromycin, trimethoprim, ofloxacin, and sulfamethoxazole. The same antibiotics have been frequently reported in wastewater effluents in many other studies (Nakata et al., 2005; Feitosa-Felizzola et al., 2007; Segura et al., 2007a; Segura et al., 2007b; Gulkowska et al., 2008; Watkinson et al., 2009; Gao et al., 2012).

Table 10. Reclaimed water statistics for the target analytes $(\mathrm{n}=56)$.

\begin{tabular}{|c|c|c|c|c|}
\hline Antibiotic & $\begin{array}{c}\text { Annual mean } \\
\text { concentration } \\
(\mathrm{ng} / \mathrm{L})\end{array}$ & $\begin{array}{c}\% \% \\
\text { Frequency } \\
\text { of } \\
\text { detection }\end{array}$ & $\begin{array}{l}\text { Concentration } \\
\text { range }(\mathrm{ng} / \mathrm{L})\end{array}$ & $\begin{array}{c}\text { Median } \\
(\mathrm{ng} / \mathrm{L})\end{array}$ \\
\hline Nalidixic acid & 176 & 100 & $27.1-453$ & 142 \\
\hline Erythromycin & 135 & 100 & $28.5-414$ & 127 \\
\hline Sulfadiazine & 128 & 16 & $<$ mdl - 276 & 128 \\
\hline Clarithromycin & 123 & 100 & $27.9-284$ & 118 \\
\hline Trimethoprim & 118 & 95 & $<\operatorname{mdl}-605$ & 92.9 \\
\hline Sulfamethoxazole & 112 & 79 & $<\operatorname{mdl}-341$ & 110 \\
\hline Sulfamerazine & 94.8 & 5 & $<\mathrm{mdl}-100$ & 93.0 \\
\hline Azithromycin & 89.7 & 100 & $29.3-180$ & 85.0 \\
\hline Norfloxacin & 71.3 & 2 & 71.3 & 71.3 \\
\hline Ofloxacin & 68.8 & 91 & $<\mathrm{mdl}-127$ & 61.8 \\
\hline Sulfachlorpyridazine & 58.9 & 5 & $<$ mdl - 66.9 & 58.8 \\
\hline Sulfamethizole & 54.4 & 14 & $<\operatorname{mdl}-69.2$ & 51.7 \\
\hline Meclocycline & 44.5 & 19 & $<$ mdl -53.8 & 41.8 \\
\hline Ciprofloxacin & 41.6 & 27 & $<\mathrm{mdl}-68.0$ & 40.8 \\
\hline Spiramycin & 37.3 & 11 & $<\operatorname{mdl}-73.7$ & 28.4 \\
\hline Tylosin & 22.3 & 25 & $<\mathrm{mdl}-36.3$ & 21.7 \\
\hline Oxytetracycline & 21.1 & 4 & $<\operatorname{mdl}-21.1$ & 21.7 \\
\hline Roxithromycin & 17.9 & 5 & $<$ mdl -25.1 & 15.8 \\
\hline Doxycycline & 17.7 & 4 & $<\operatorname{mdl}-17.7$ & 17.7 \\
\hline Chlortetracycline & 16.9 & 4 & $<\operatorname{mdl}-16.9$ & 16.9 \\
\hline Enrofloxacin & 16.7 & 11 & $<\operatorname{mdl}-21.9$ & 17.2 \\
\hline Clindamycin & 16.3 & 13 & $<\operatorname{mdl}-19.1$ & 18.6 \\
\hline
\end{tabular}


Meclocycline, ciprofloxacin, tylosin were moderately detected, with frequency of detection $19-27 \%$. Tylosin was detected less frequently compared to other macrolides, although its usage has been increasing in the last decade (MAF, 2010). This might reflect its higher removal efficiency in sewage treatment plant (Chang et al., 2010) rather than patterns in consumption. Sulfonamides are most commonly used both in humans and veterinary medicine to treat a variety of infections. The sulfonamides more frequently used for this purpose are sulfamethoxazole, sulfadiazine, sulfamerazine and sulfathiazole (Lopes et al., 2011). Trimethoprim is another antibiotic agent often co-administered with sulfamethoxazole to enhance treatment against a variety of bacterial infections (Masters et al., 2003). In the present study, sulfamethoxazole and sulfadiazine were detected frequently and at rather higher concentration. Trimethoprim was also detected in all reclaimed water samples analyzed due to its heavy consumption and/or incomplete removal in the WWTPs. Similar results were also observed by Chang et al in sewage treatment effluents (Chang et al., 2010).

Seasonal variation is observed in Florida with wet season ranging from May to October and dry season from November to April. Daily effluent flow rate (MGD) data was obtained from the Miami-Dade North District Waste Water Treatment Facility and was multiplied by the individual concentration of all antibiotics (ng/L) to obtain the mass load of antibiotics entering the receiving waters using the equation 3 . The same was plotted against each month starting from November 2010 to October 2011 in Figure 11. In month of February 2011, sprinklers were not turned on for more than a week due to maintenance and only one reclaimed water sample was collected in the entire month. As seen in the Figure 11, the total antibiotic mass loads released in the reclaimed water were high from 
the month of November to March except February and then gradually decreased until September. It seems like daily mass loads were lower in wet season compared to dry season indicating that dilution effects could have played a role in the occurrence of targeted analytes in the reclaimed water. Lei Jiang et al. (Jiang et al., 2011) also observed a similar trend in seasonal variations in overall antibiotic concentrations, i.e., higher concentrations in December (the low water season) and lower concentrations in June (the high water season) for river water samples. However, as the measured concentrations were normalized with daily flow rates the daily mass loads should be nearly constant if there is no significant variation in antibiotic consumption pattern or no changes in reclamation process during the study period. In a recent study by Zhang et al. reported that there is a seasonal variation in antibiotic prescriptions in the United States. According to their study highest prescription rates were from January through March and lowest from July through September (Zhang et al., 2012). It is likely that the data represented here may have been influenced by seasonal variations in antibiotic consumption and possibly contributes to the observed differences in mass loads of antibiotics. The total mass load of antibiotics in reclaimed waters was 472 and $614 \mathrm{~g} / \mathrm{day}$ in wet and dry seasons respectively.

$$
\text { mass load }\left(\frac{g}{\text { day }}\right)=\text { concen. }\left(\frac{n g}{L}\right) \times \text { flow rate }\left(\frac{L}{\text { day }}\right) \times\left(\frac{1}{10^{9}} \times \frac{g}{n g}\right)
$$




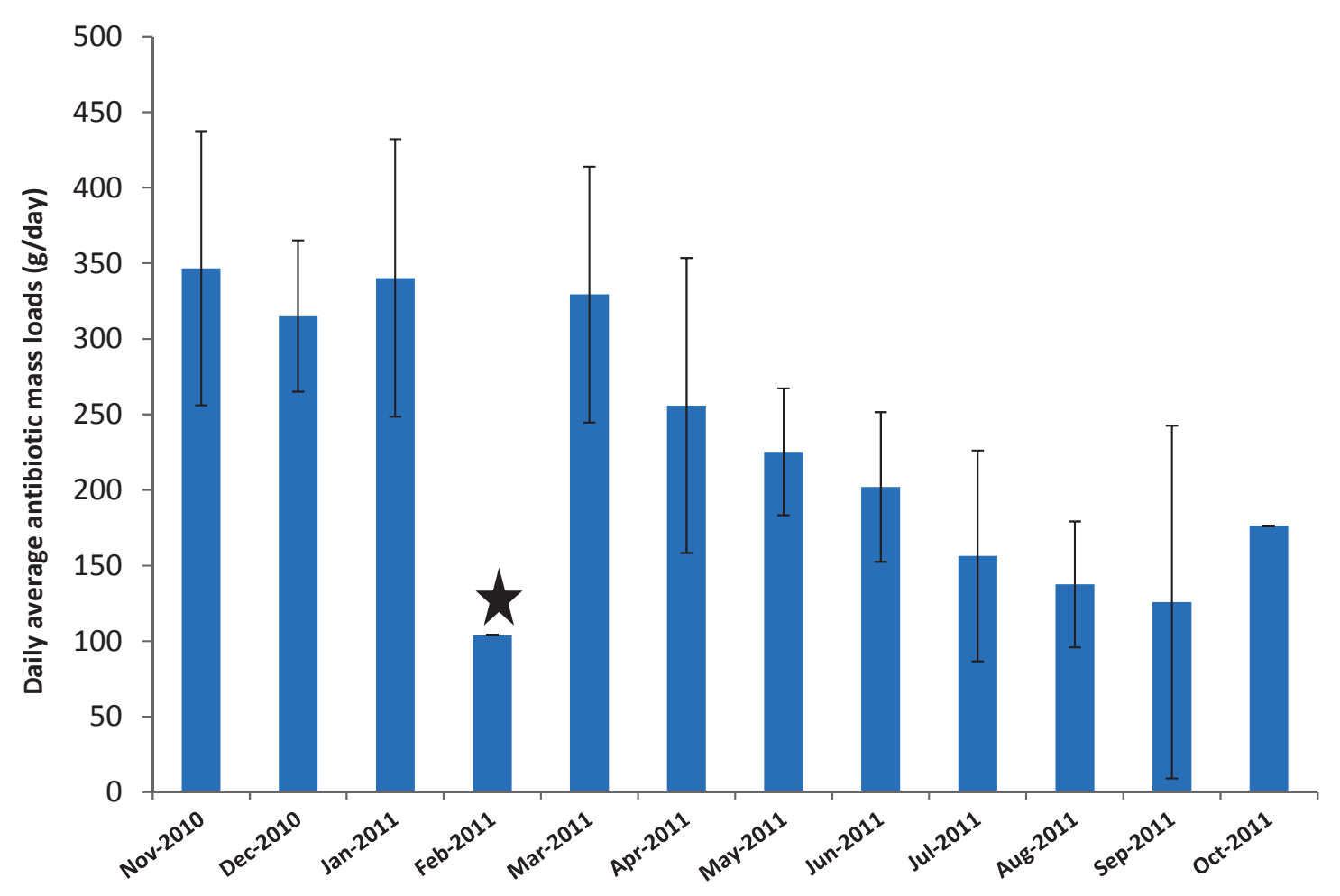

Figure 11. Month wise mass loads (mg/day) distribution of antibiotics in reclaimed waters

$\star$ For February 2011, only one reclaimed water sample was collected due to sprinklers maintenance

Daily Mass load per capita, in $\mu \mathrm{g} /$ day/person of antibiotics was calculated based on the size of the served population Miami Dade North district according to United States Census 2011 (USCB, 2012) (Table 11). These results are comparable to levels of antibiotics found in effluent waters from other studies in North America and Europe (Karthikeyan and Meyer, 2006; Lindberg et al., 2006). The presence of antibiotics in reclaimed waters suggests insufficient removal by waste water treatment process 
resulting in the potential chronic discharge of antibiotics into the environment. This also shows a clear need for developing new water treatment technologies.

Table 11. Estimated mass loads ( $\mu \mathrm{g} /$ day/person) of targeted analytes in reclaimed waters

\begin{tabular}{lcc}
\hline \multicolumn{1}{c}{ Antibiotic } & $\begin{array}{c}\text { Mass loading in } \\
\text { wet season } \\
(\mu \mathrm{g} / \text { day/peson })\end{array}$ & $\begin{array}{c}\text { Mass loading in } \\
\text { dry season } \\
(\mu \mathrm{g} / \text { day/person })\end{array}$ \\
\hline Sulfadiazine & 35 & 127 \\
Nalidixic acid & 77 & 86 \\
Trimethoprim & 37 & 74 \\
Clarithromycin & 47 & 70 \\
Erythromycin & 55 & 70 \\
Sulfamethoxazole & 49 & 57 \\
Sulfamerazine & 45 & 46 \\
Azithromycin & 43 & 44 \\
Ofloxacin & 27 & 38 \\
Sulfachlorpyridazine & 24 & 30 \\
Sulfamethizole & 26 & 26 \\
Spiramycin & 17 & 22 \\
Ciprofloxacin & 19 & 21 \\
Meclocycline & 21 & 14 \\
Roxithromycin & 8 & 9 \\
Clindamycin & 5 & 9 \\
Doxycycline & -- & 8 \\
Chlortetracycline & -- & 8 \\
Tylosin & 11 & 7 \\
Enrofloxacin & 8 & 7 \\
Oxytetracycline & 10 & -- \\
Norfloxacin & 34 & -- \\
\hline & &
\end{tabular}




\subsubsection{Mass loads of antibioites versus consumption data}

According to a recent report by USFDA 3.28 million kilograms of antibiotics were sold for human medical use in 2010 (Pham, 2012). The estimated mass loads of different classes of antibiotics in reclaimed waters was plotted as a function of their sales in 2010 and shown in Figure $12(n=56)$. The high correlation coefficient $\left(R^{2}=0.73\right)$ indicates a positive correlation between sales and mass loads detected. The graph shows that inspite of low consumption, macrolide antibiotics were detected at rather high concentration which could be explained based on their high photostability compared to other classes of antibiotics (Vione et al., 2009; Batchu, 2013).

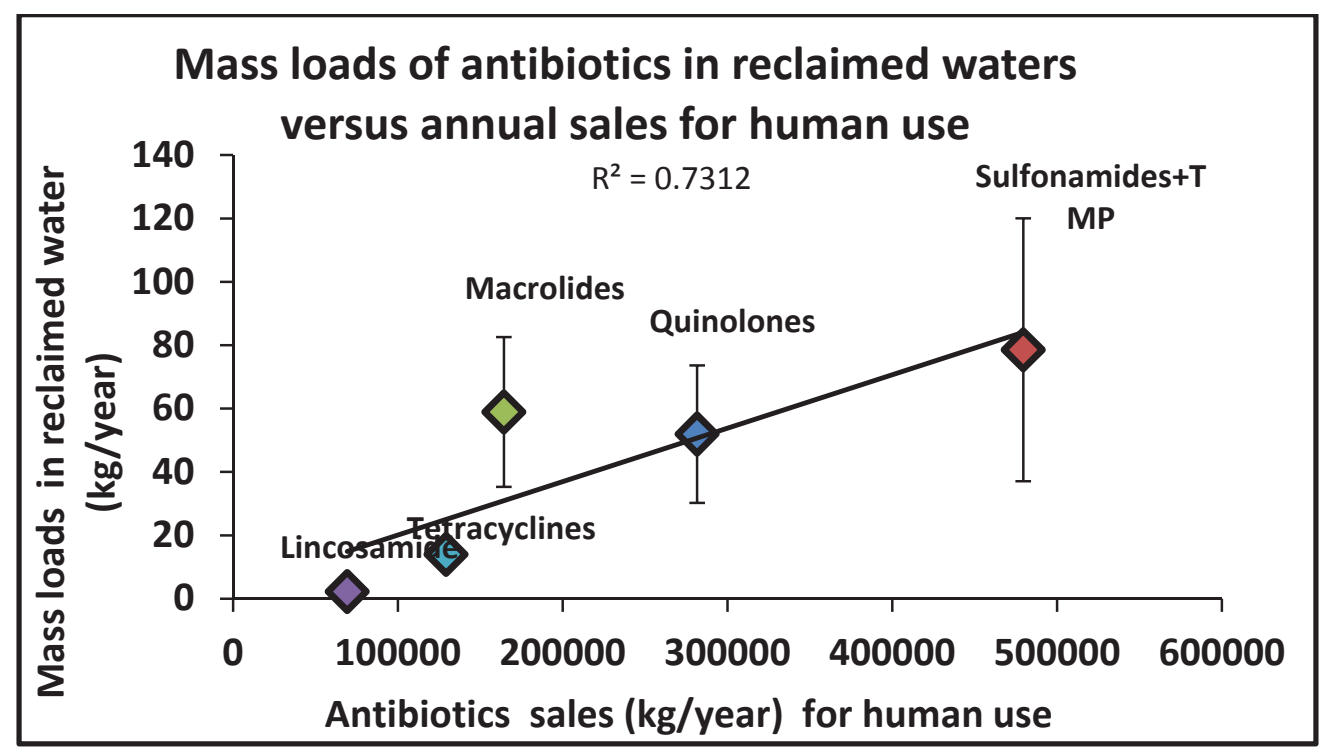

Figure 12. A plot of antibiotics sales in 2010 and their estimated mass loads from the present study 


\subsection{Conclusions}

Detection of antibiotics in reclaimed water indicates that conventional wastewater process used were not sufficient in the complete removal of antibiotics. The developed online SPE-LC-MS/MS method was successfully applied for the quantitation of antibiotics in reclaimed waters collected over a period of one year $(n=56) .22$ out of 31 selected antibiotics were detected in reclaimed waters reaching up to a maximum concentration of $604 \mathrm{ng} / \mathrm{L}$. Nalidixic acid, erythromycin, clarithromycin and azithromycin were detected in all samples analyzed and at higher concentrations (average concentration: 90-176 ng/L). Other most frequently detected antibiotics were trimethoprim, sulfamethoxazole and ofloxacin. Mass loads of antibiotics released in reclaimed waters plotted against sampling month showed seasonal variation i.e., highest from the month of November through March (except February) and then gradually decreased until September, following general antibiotic prescription statistics. Based on the results, Positive correlation was observed between the mass loads of antibiotics released in reclaimed waters and their annual consumption except for macrolides. The possible reason could be the recalcitrant nature of macrolides such as high photostability unlike other antibiotics. Finally, mass load per capita of each antibiotic in reclaimed water was reported. Detection of antibiotics in reclaimed water indicates that conventional wastewater management practices are not effective in the complete removal of antibiotics. 


\section{CHAPTER 4}

\section{Surface water analysis}

Data from Miami Dade water samples (Panditi, V., Batchu, S., Gardinali, P., 2013. Analytical and Bioanalytical Chemistry, 405 (18), 5953-5964). 


\subsection{Introduction}

Antibiotics are considered as emerging contaminants of concern due to their potential adverse effects on ecosystem and human health (Wollenberger et al., 2000; Kummerer, 2009; Ding and He, 2010). Antibiotics reach sewage treatment plant from various sources such as domestic, industrial wastes and agricultural run offs. Both present and previous studies have showed that the current treatment employed in the sewage treatment plants does not lead to the complete removal of antibiotics; as a result residual antibiotics are continuously released into water ways via wastewater effluents (Feitosa-Felizzola et al., 2007; Gartiser et al., 2007; Panditi et al., 2013) and thus have a large potential to effect the aquatic environment. Various waste disposal options followed by sewage treatment plants include ocean outfalls, deep well injection, soakage pits, drain fields and canals.

In South Florida, waste disposal alternatives are deep well injection and ocean outfalls and surface water (canal) discharges following secondary wastewater treatment, filtration and nutrient removal (Bloetscher et al., 2005). Broward and Miami-Dade counties dispose approximately 510 MGD of the treated effluents collectively into ocean outfalls and deep well injections (Struhs, 2003).

Previous studies have shown that antibiotics from wastewater discharges were relatively persistent and make their way into the surrounding surface waters as far as 100 meters (Batt et al., 2006). Not only that antibiotics reach surface waters through traditional waste disposal pathway but also through agricultural runoffs (Davis et al., 2006), if the sludge form the sewage treatment plant used for landfill or as fertilizer in agriculture (Holzel et al., 2010), to a little extent poorly maintained leaky sewage pipelines and septic systems 
close to surface waters. So far there were no studies reported on antibiotic concentrations in South Florida surface waters. Therefore, it is essential to determine the frequently detected antibiotics and their environmental concentration in South Florida surface waters to understand the potential ecological risk.

In the present study, surface water samples were collected from the major canals in South Florida, under Miami Dade and Broward Counties. Miami River passes through downtown Miami and reaches Biscayne Bay. It has a long history of water quality problems from wastewater intrusions from aging leaky sewage collection and pumping systems and receives large amounts of domestic effluents (Gardinali, 2002; MRC, 2002) and hence included in the present study.

\subsection{Sample collection and preparation}

$500-\mathrm{mL}$ of the surface waters were collected from Miami River and major canals passing through Miami-Dade $(\mathrm{n}=35)$ and Broward counties $(\mathrm{n}=18)$ in a Polyethylene terephthalate (PETE) bottle. The samples from Broward County were provided by a Broward County Environmental Monitoring lab. The details of the sampling locations are shown in Table 12 and Figure 13. Samples HWO1 and HWO2 were collected from Hollywood waste water treatment plant ocean outfalls.

Table 12. Surface waters sampling site, latitude and longitude details

\begin{tabular}{ccc}
\hline Sample name & Latitude & Longitude \\
\hline Florida City canal (1) & $25^{\circ} 26^{\prime} 53.85^{\prime \prime} \mathrm{N}$ & $80^{\circ} 27^{\prime} 30.12^{\prime \prime} \mathrm{W}$ \\
Florida City canal (2) & $25^{\circ} 26^{\prime} 53.94^{\prime \prime N}$ & $80^{\circ} 24^{\prime} 47.75^{\prime \prime} \mathrm{W}$
\end{tabular}




\begin{tabular}{|c|c|c|}
\hline North Canal drive (1) & $25^{\circ} 27^{\prime} 46.37^{\prime \prime} \mathrm{N}$ & $80^{\circ} 24^{\prime} 38.06^{\prime \prime} \mathrm{W}$ \\
\hline North Canal drive (2) & $25^{\circ} 27^{\prime} 46.18^{\prime \prime} \mathrm{N}$ & $80^{\circ} 22^{\prime} 16.36^{\prime \prime} \mathrm{W}$ \\
\hline Mowry Canal (1) & $25^{\circ} 28^{\prime} 25.23^{\prime \prime} \mathrm{N}$ & $80^{\circ} 24^{\prime} 38.25^{\prime \prime} \mathrm{W}$ \\
\hline Mowry Canal (2) & $25^{\circ} 28^{\prime} 16.21^{\prime \prime} \mathrm{N}$ & $80^{\circ} 23^{\prime} 1.74^{\prime \prime W}$ \\
\hline Military Canal & $25^{\circ} 29^{\prime} 21.52^{\prime \prime} \mathrm{N}$ & $80^{\circ} 21^{\prime} 44.03^{\prime \prime} \mathrm{W}$ \\
\hline Princeton Canal & $25^{\circ} 31^{\prime} 10.41^{\prime \prime} \mathrm{N}$ & $80^{\circ} 21^{\prime} 48.12^{\prime \prime} \mathrm{W}$ \\
\hline Black Creek Canal (1) & $25^{\circ} 32^{\prime} 56.45^{\prime \prime} \mathrm{N}$ & $80^{\circ} 20^{\prime} 50.97 " \mathrm{~W}$ \\
\hline Black Creek Canal (2) & $25^{\circ} 32^{\prime} 39.54^{\prime \prime} \mathrm{N}$ & $80^{\circ} 19^{\prime} 56.39^{\prime \prime} \mathrm{W}$ \\
\hline Cutler Canal & $25^{\circ} 36^{\prime} 34.96^{\prime \prime} \mathrm{N}$ & $80^{\circ} 19^{\prime} 2.05^{\prime \prime W}$ \\
\hline C113 Canal & $25^{\circ} 30^{\prime} 25.21^{\prime \prime} \mathrm{N}$ & $80^{\circ} 28^{\prime} 44.82^{\prime \prime} \mathrm{W}$ \\
\hline Snapper Creek Canal (1) & $25^{\circ} 40^{\prime} 4.19^{\prime \prime} \mathrm{N}$ & $80^{\circ} 16^{\prime} 55.14^{\prime \prime} \mathrm{W}$ \\
\hline Snapper Creek Canal (2) & $25^{\circ} 41^{\prime} 29.85^{\prime \prime} \mathrm{N}$ & $80^{\circ} 18^{\prime} 11.41^{\prime \prime W}$ \\
\hline Coral Gables Canal & $25^{\circ} 42^{\prime} 19.09^{\prime \prime} \mathrm{N}$ & $80^{\circ} 15^{\prime} 34.96^{\prime \prime} \mathrm{W}$ \\
\hline Miami River (1) & $25^{\circ} 46^{\prime} 51.56^{\prime \prime} \mathrm{N}$ & $80^{\circ} 12^{\prime} 38.49^{\prime \prime} \mathrm{W}$ \\
\hline Miami River (2) & $25^{\circ} 46^{\prime} 11.01^{\prime \prime N}$ & $80^{\circ} 11^{\prime} 29.40^{\prime \prime} \mathrm{W}$ \\
\hline Canal 11 (1) & $25^{\circ} 51^{\prime} 11.72^{\prime \prime N}$ & $80^{\circ} 11^{\prime} 47.23^{\prime \prime W}$ \\
\hline Canal 11 (2) & $25^{\circ} 52^{\prime} 16.70^{\prime \prime} \mathrm{N}$ & $80^{\circ} 14^{\prime} 33.28^{\prime \prime} \mathrm{W}$ \\
\hline Canal 12 & $25^{\circ} 52^{\prime} 30.68^{\prime \prime} \mathrm{N}$ & $80^{\circ} 10^{\prime} 59.29^{\prime \prime} \mathrm{W}$ \\
\hline Canal 13 (1) & $25^{\circ} 55^{\prime} 42.53^{\prime \prime N}$ & $80^{\circ} 9^{\prime} 30.50^{\prime \prime} \mathrm{W}$ \\
\hline Canal 13 (2) & $25^{\circ} 55^{\prime} 46.86^{\prime \prime} \mathrm{N}$ & $80^{\circ} 10^{\prime} 3.80^{\prime \prime} \mathrm{W}$ \\
\hline OS1 & $26^{\circ} 4^{\prime} 96.36^{\prime \prime} \mathrm{N}$ & $80^{\circ} 6573.21^{\prime \prime} \mathrm{W}$ \\
\hline OS2 & $26^{\circ} 6^{\prime} 13.41 " \mathrm{~N}$ & $80^{\circ} 5^{\prime} 61.59^{\prime \prime} \mathrm{W}$ \\
\hline OS3 & $26^{\circ} 9^{\prime} 59.68^{\prime \prime} \mathrm{N}$ & $80^{\circ} 5^{\prime} 28.02^{\prime \prime} \mathrm{W}$ \\
\hline Port Everglades PE1 & $26^{\circ} 5^{\prime} 61.68^{\prime \prime} \mathrm{N}$ & $80^{\circ} 6^{\prime} 30.36^{\prime \prime} \mathrm{W}$ \\
\hline Pharm 1 & $26^{\circ} 5^{\prime} 12.76^{\prime \prime} \mathrm{N}$ & $80^{\circ} 5^{\prime} 54.73^{\prime \prime} \mathrm{W}$ \\
\hline Pharm 2 & $26^{\circ} 1 ' 20.83^{\prime \prime} \mathrm{N}$ & $80^{\circ} 6^{\prime} 12.85^{\prime \prime} \mathrm{W}$ \\
\hline Pharm 3 & $26^{\circ} 0^{\prime} 21.57^{\prime \prime} \mathrm{N}$ & $80^{\circ} 6^{\prime} 10.98^{\prime \prime} \mathrm{W}$ \\
\hline Pharm 4 & $25^{\circ} 59^{\prime} 24.15^{\prime \prime} \mathrm{N}$ & $80^{\circ} 6^{\prime} 8.12^{\prime \prime} \mathrm{W}$ \\
\hline HWO1 & $26^{\circ} 0^{\prime} 35.79^{\prime \prime} \mathrm{N}$ & $80^{\circ} 5^{\prime} 4.17^{\prime \prime} \mathrm{W}$ \\
\hline HWO2 & $26^{\circ} 1^{\prime} 0.56^{\prime \prime} \mathrm{N}$ & $80^{\circ} 5^{\prime} 5.51^{\prime \prime} \mathrm{W}$ \\
\hline QC-37 & $26^{\circ} 8^{\prime} 27.30^{\prime \prime} \mathrm{N}$ & $80^{\circ} 6^{\prime} 24.96^{\prime \prime} \mathrm{W}$ \\
\hline QC-10 & $26^{\circ} 8 ' 35.55^{\prime \prime} \mathrm{N}$ & $80^{\circ} 7{ }^{\prime} 3.83^{\prime \prime} \mathrm{W}$ \\
\hline QC-15 & $26^{\circ} 6^{\prime} 59.81^{\prime \prime N}$ & $80^{\circ} 8^{\prime} 10.61^{\prime \prime W}$ \\
\hline QC-38 & $26^{\circ} 5 ' 32.55^{\prime \prime} \mathrm{N}$ & $80^{\circ} 6^{\prime} 46.58^{\prime \prime} \mathrm{W}$ \\
\hline QC-39 & $26^{\circ} 4^{\prime} 9.97 " \mathrm{~N}$ & $80^{\circ} 7^{\prime} 0.16^{\prime \prime} \mathrm{W}$ \\
\hline QC-24 & $26^{\circ} 3 ' 27.43^{\prime \prime} \mathrm{N}$ & $80^{\circ} 8^{\prime} 55.55^{\prime \prime} \mathrm{W}$ \\
\hline QC40 & $26^{\circ} 2^{\prime} 9.90^{\prime \prime} \mathrm{N}$ & $80^{\circ} 7^{\prime} 1.75^{\prime \prime} \mathrm{W}$ \\
\hline
\end{tabular}




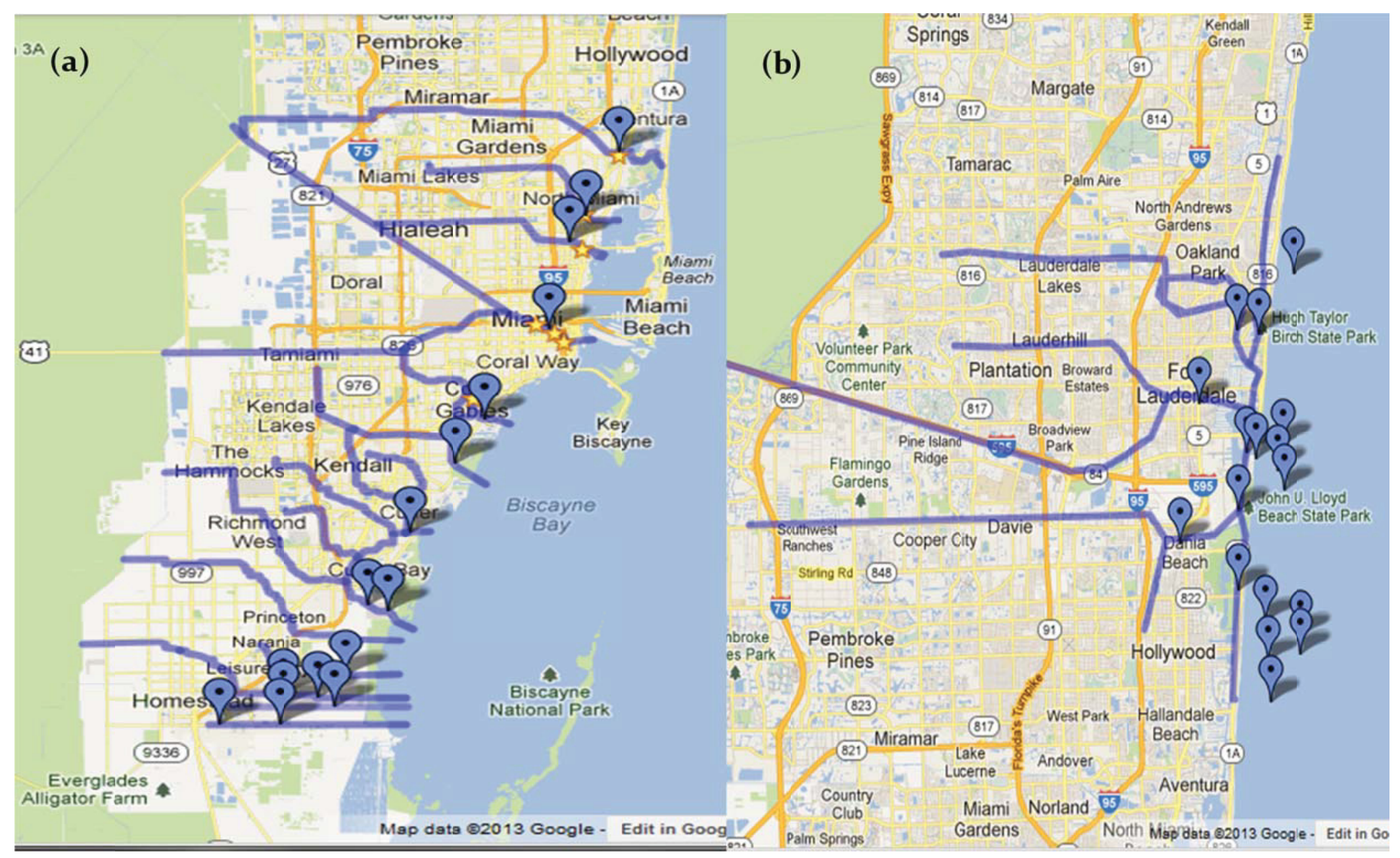

Figure 13. Canals sampled during the study a) from Miami-Dade County b) from Broward County 


\subsection{Analysis of surface waters}

The method described in chapter 2 was applied for the analysis of antibiotics in surface waters. Samples were injected full strength for the determination of antibiotics. As some of the samples were salt waters, the method detection limits were statistically calculated using 7 replicates of salt waters spiked with target analytes in the concentration range of $5.7-150 \mathrm{ng} / \mathrm{L}$.

\subsection{Results and Discussion}

The MDLs obtained shown in Table 13, were higher compared to the ones in river and reclaimed water and which was expected as the method was not optimized for the salt waters. However, the detection limits obtained were still low enough to measure analytes in environmental waters.

Table 13. Method detection limits of target analytes in salt waters

\begin{tabular}{lc}
\hline Antibiotic & $\begin{array}{r}\text { MDL in salt water } \\
(\mathrm{ng} / \mathrm{L})\end{array}$ \\
\hline Sulfadiazine & 36.0 \\
Sulfathiazole & 56.3 \\
Sulfamerazine & 24.4 \\
Sulfamethazine & 11.3 \\
Sulfamethizole & 33.3 \\
Sulfachlorpyridazine & 5.58 \\
Sulfamethoxazole & 10.2 \\
Sulfadimethoxine & 23.1 \\
Enoxacin & 88.1 \\
Ofloxacin & 10.6 \\
\hline
\end{tabular}




\begin{tabular}{ll}
\hline Norfloxacin & 18.8 \\
Ciprofloxacin & 7.20 \\
Danofloxacin & 26.3 \\
Enrofloxacin & 13.8 \\
Sarafloxacin & 9.16 \\
Oxytetracycline & 40.6 \\
Tetracycline & 20.6 \\
Chlortetracycline & 13.9 \\
Doxycycline & 15.6 \\
Meclocycline & 12.4 \\
Spiramycin & 65.2 \\
Clindamycin & 29.4 \\
Tylosin & 36.1 \\
Erythromycin & 32.0 \\
Clarithromycin & 14.6 \\
Azithromycin & 19.4 \\
Roxithromycin & 43.7 \\
Lincomycin & 7.88 \\
Amoxycillin & 56.3 \\
Trimethoprim & 13.0 \\
Nalidixic acid & 16.5 \\
Average & 26.2 \\
\hline
\end{tabular}

A plot of total antibiotic concentrations measured versus sampling locations is shown in Figure 14. Error bars are shown for the sampling locations with multiple samples from the same location. Number of antibiotics detected in each sampling location is shown in parenthesis above the bar. The highest antibiotic concentrations were found in the sample 
collected at the Hollywood ocean outfall (HWO1). The other sampling station with high antibiotic concentrations is Miami River and this result shows that the Miami River is clearly under the influence of anthropogenic discharges.
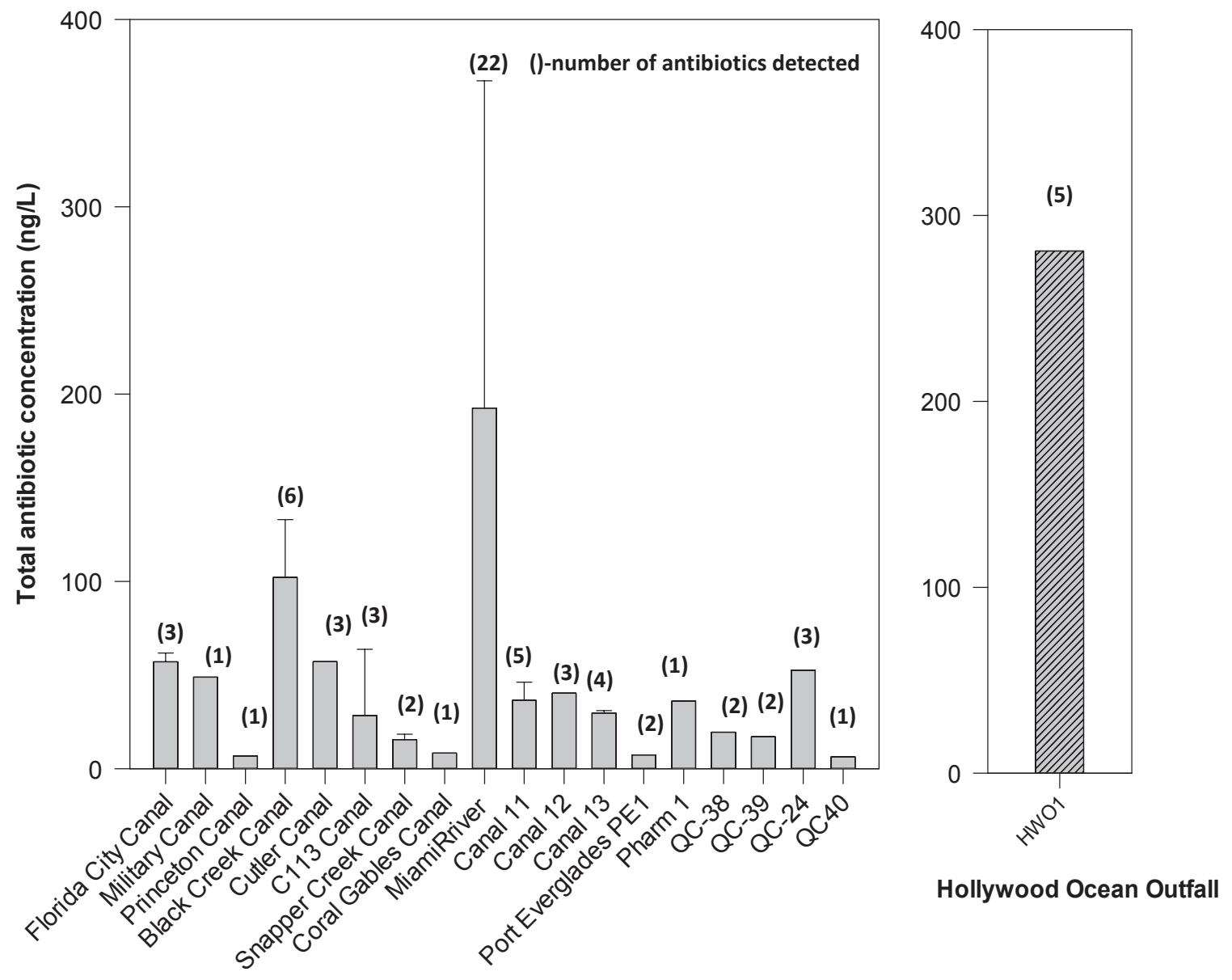

Surface water sampling locations

Figure 14. Distribution of antibiotics in major canals from Miami-Dade and Broward counties presented as the total concentration detected. ()- indicate the number of antibiotics detected in the selected sampling location 
To our knowledge this is the first report on the study of antibiotics in an open water body in South Florida. Though there is no direct evident release of wastewater effluents in the area, along with high human activity, the existence of drainage overflows or leaching from landfills during storm events could be a potential source for these observations (Gardinali and Zhao, 2002). The Miami River drains in to Biscayne Bay, which is not only a natural habitat for many estuarine organisms and algal communities but also an important recreational area for the city of Miami. Presence of residual antibiotics in these water bodies is a concern due to the potential risk for proliferation of antibiotic resistant organisms (Daughton and Ternes, 1999). Moderately high antibiotic concentrations found in Black Creek Canal could be due to its close proximity to both landfill and a sewage treatment plant. Canals with no traces of antibiotics include North Canal drive, Mowry Canal, QC-37, QC-10, QC-15, OS1, OS2, OS3, Pharm 2, Pharm 3, Pharm 4, HWO1 and HWO2.

The distribution of antibiotics in the sampled canals is shown as box plots in Figure 15. The blue and black lines in the box plot indicate mean and median of the sample population, respectively. Antibiotics detected at relatively higher concentrations (based on average) include tylosin, sulfadiazine, erythromycin and meclocycline and the antibiotics detected most frequently (19-25\%) are erythromycin, sulfadiazine, trimethoprim and sulfamethoxazole. Erythromycin, trimethoprim and sulfamethoxazole were among those detected in all reclaimed waters analyzed Detailed information on the type and concentration of antibiotic detected in each sampling location are shown in Table 14. 


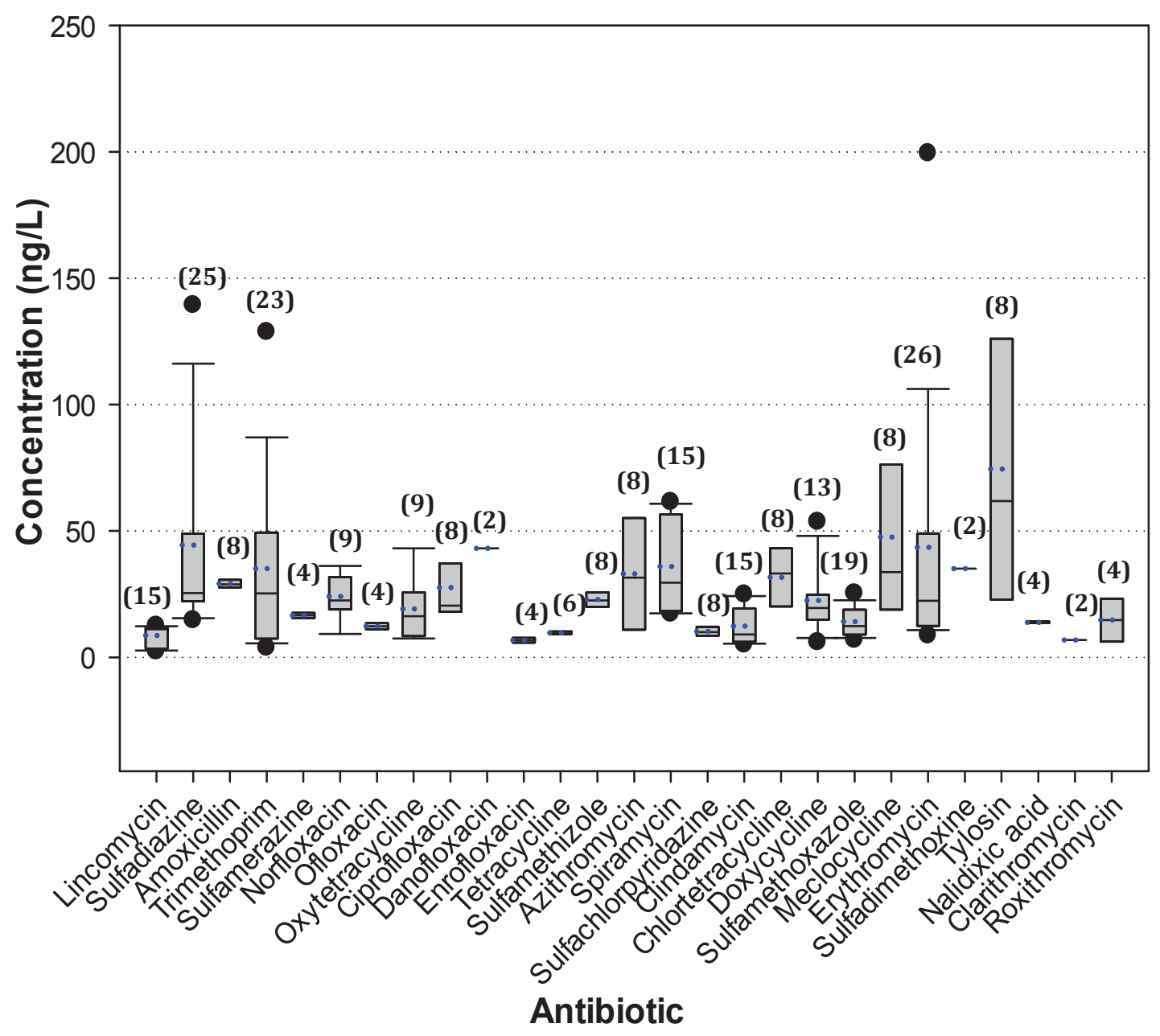

Figure 15. Distribution of antibiotics in surface waters; values in parenthesis indicate percent frequency of detection 
Table 14. Distribution of antibiotics in the selected sample locations in ng/L

\begin{tabular}{|c|c|c|c|c|c|c|c|c|c|c|c|c|c|c|c|c|c|c|c|}
\hline Antibiotic & $\begin{array}{c}\text { Florida } \\
\text { City } \\
\text { Canal }\end{array}$ & $\begin{array}{l}\text { Military } \\
\text { Canal }\end{array}$ & $\begin{array}{c}\text { Princeton } \\
\text { Canal }\end{array}$ & $\begin{array}{l}\text { Black } \\
\text { Creek } \\
\text { Canal }\end{array}$ & $\begin{array}{l}\text { Cutler } \\
\text { Canal }\end{array}$ & $\begin{array}{l}\text { C113 } \\
\text { Canal }\end{array}$ & $\begin{array}{c}\text { Snapper } \\
\text { Creek } \\
\text { Canal }\end{array}$ & $\begin{array}{l}\text { Coral } \\
\text { Gables } \\
\text { Canal }\end{array}$ & $\begin{array}{l}\text { Miami } \\
\text { River } \\
\text { Canal }\end{array}$ & $\begin{array}{c}\text { Canal } \\
11\end{array}$ & $\begin{array}{c}\text { Canal } \\
12\end{array}$ & $\begin{array}{c}\text { Canal } \\
13\end{array}$ & QC-38 & QC-39 & $\begin{array}{c}\text { QC- } \\
24\end{array}$ & $\begin{array}{c}\text { QC- } \\
40\end{array}$ & $\begin{array}{c}\text { Port } \\
\text { Evergl } \\
\text { ades } \\
\text { PE1 } \\
\end{array}$ & $\begin{array}{l}\text { Phar } \\
\text { m } 1\end{array}$ & HW01 \\
\hline Lincomycin & --- & --- & --- & --- & --- & 3.30 & --- & --- & 10.0 & --- & --- & --- & 11.1 & --- & --- & --- & 3.50 & --- & --- \\
\hline Sulfadiazine & --- & --- & --- & 24.2 & 14.6 & 42.3 & --- & --- & 56.0 & --- & 24.0 & --- & --- & --- & --- & --- & --- & --- & --- \\
\hline Amoxicillin & --- & --- & --- & --- & --- & --- & --- & --- & 29.2 & --- & --- & --- & --- & --- & --- & --- & --- & --- & --- \\
\hline Trimethoprim & --- & --- & --- & --- & --- & --- & --- & --- & 49.6 & --- & --- & --- & 8.41 & 8.39 & 11.3 & 6.34 & 3.79 & --- & 129 \\
\hline Sulfamerazine & --- & --- & --- & --- & --- & --- & 17.6 & --- & --- & 15.4 & --- & --- & --- & --- & --- & --- & --- & --- & --- \\
\hline Norfloxacin & 26.4 & --- & --- & 22.2 & --- & --- & --- & --- & --- & 9.22 & --- & --- & --- & --- & --- & --- & --- & 36.1 & --- \\
\hline Ofloxacin & --- & --- & --- & --- & --- & --- & --- & --- & --- & 11.0 & --- & --- & --- & --- & --- & --- & --- & --- & 13.5 \\
\hline Oxytetracycline & --- & --- & --- & --- & --- & --- & --- & --- & 26.4 & --- & --- & --- & --- & 8.72 & --- & --- & --- & --- & --- \\
\hline Ciprofloxacin & --- & --- & --- & 34.9 & 22.7 & --- & --- & --- & 17.8 & --- & --- & --- & --- & --- & --- & --- & --- & --- & 66.9 \\
\hline Danofloxacin & --- & --- & --- & --- & --- & --- & --- & --- & 43.1 & --- & --- & --- & --- & --- & --- & --- & --- & --- & --- \\
\hline Enrofloxacin & --- & --- & --- & --- & --- & --- & --- & --- & 7.7 & --- & --- & --- & --- & --- & --- & --- & --- & --- & --- \\
\hline Tetracycline & --- & --- & --- & --- & --- & --- & --- & --- & 43.1 & 9.43 & --- & 9.76 & --- & --- & --- & --- & --- & --- & --- \\
\hline Sulfamethizole & --- & --- & --- & --- & --- & --- & --- & --- & 17.8 & --- & --- & 18.4 & --- & --- & -- & --- & -- & --- & --- \\
\hline Azithromycin & --- & 48.9 & --- & --- & --- & --- & --- & --- & 43.1 & --- & 7.69 & --- & --- & --- & --- & --- & --- & --- & 61.2 \\
\hline Spiramycin & --- & --- & --- & --- & --- & --- & --- & --- & 35.9 & --- & & --- & --- & --- & --- & --- & --- & --- & --- \\
\hline Sulfachlorpyridazine & --- & --- & --- & 11.3 & --- & --- & --- & --- & 10.6 & --- & 8.65 & --- & --- & --- & --- & --- & --- & --- & --- \\
\hline Clindamycin & --- & --- & --- & --- & --- & --- & --- & --- & 12.4 & --- & --- & --- & --- & --- & --- & --- & --- & --- & --- \\
\hline Chlortetracycline & --- & --- & --- & --- & --- & --- & --- & --- & 32.9 & 27.9 & --- & --- & --- & --- & --- & --- & --- & --- & --- \\
\hline Doxycycline & --- & --- & --- & --- & --- & --- & --- & --- & 23.7 & --- & --- & 14.7 & --- & --- & --- & --- & --- & --- & --- \\
\hline Sulfamethoxazole & 18.5 & --- & --- & 19.7 & 19.8 & --- & --- & 8.35 & 9.81 & --- & --- & 6.89 & --- & --- & --- & --- & --- & --- & 10.4 \\
\hline Meclocycline & --- & --- & --- & --- & --- & --- & --- & --- & 47.6 & --- & --- & --- & --- & --- & --- & --- & --- & --- & --- \\
\hline Erythromycin & 12.2 & --- & --- & 8.67 & --- & 11.0 & --- & --- & 56.5 & --- & --- & --- & --- & --- & --- & --- & --- & --- & --- \\
\hline Sulfadimethoxine & --- & --- & --- & --- & --- & --- & --- & --- & --- & --- & --- & --- & --- & --- & 35.2 & --- & --- & --- & -- \\
\hline Tylosin & --- & --- & --- & --- & --- & --- & --- & --- & 74.4 & --- & --- & --- & --- & --- & --- & --- & --- & --- & 141 \\
\hline Nalidixic acid & --- & --- & --- & --- & --- & --- & 13.5 & --- & 14.1 & --- & --- & --- & --- & --- & --- & --- & --- & --- & --- \\
\hline Clarithromycin & --- & --- & 6.86 & --- & --- & --- & --- & --- & --- & --- & --- & --- & --- & --- & --- & --- & -- & --- & --- \\
\hline Roxithromycin & --- & --- & -- & --- & --- & --- & --- & --- & 23.2 & --- & --- & --- & --- & --- & 6.21 & --- & -- & -- & --- \\
\hline
\end{tabular}




\subsection{Conclusions}

Major canals from Miami-Dade \& Broward counties and ocean outfall were analyzed for the presence of antibiotics. Results showed that highest concentrations of antibiotics were detected in ocean outfall followed by Miami River canal and Black Creek canal. High concentrations in Miami River canal might be due to drainage overflows or leaching from landfills whereas detections in Black Creek canal may be due to the influence of a nearby sewage treatment plant and a landfill. The highest frequency of detection for any antibiotic detected in surface waters is $33 \%$ (for erythromycin) and the average concentration of antibiotics detected was lower compared to the same in reclaimed waters. Detection of 22 antibiotics (out of 31) in Miami River waters showing that it could be more contaminated in comparison to other canals tested in this study. Detection of antibiotics in surface water indicates the possible contamination of some of the South Florida surface waters with wastewater intrusion. 


\section{CHAPTER 5}

\section{Drinking water and Ground water analysis}

Results from drinking waters (Panditi, V., Batchu, S., Gardinali, P., 2013. Analytical and Bioanalytical Chemistry, 405 (18), 5953-5964). 


\subsection{Introduction}

Antibiotics have been detected in waste waters and surface waters worldwide at concentrations reaching up to few $\mu \mathrm{g} / \mathrm{L}$ (Nakata et al., 2005; Yang et al., 2005; Karthikeyan and Meyer, 2006; Segura et al., 2007b; Gulkowska et al., 2008). Previous studies have shown that antibiotics may possibly migrate into ground waters from the contaminated surface waters (Meyer et al., 1999; Heberer et al., 2002). Usage of the contaminated ground waters as sources of drinking water rises concern over the potential for these antibiotics to occur in finished drinking waters and thus, to affect human health through chronic exposure at low levels. In a drinking water treatment plant, ground water will be subjected to coagulation, sedimentation, filtration and chlorination to make it potable. The removal efficiency of antibiotics in the drinking water treatment plant varies both among chemicals and between different processes employed in the treatment plants (EPA, 2013).

To date, limited research had been published on the existence of antibiotics in drinking waters in different countries. In a study conducted by USGS and Centers for Disease Control and Prevention, Stackelberg et al., analyzed raw, settled, filtered and finished drinking water samples from a drinking water treatment plant (DWTP), which is located in a heavily populated and highly urbanized drainage basin for the presence of 106 organic waste-water related contaminants, including 25 antibiotics. Although no traces of antibiotics were found in the finished drinking waters, erythromycin (measured as anhydroerythromycin) and sulfamethoxazole were detected in more than $10 \%$ of stream and raw water supplies of the drinking water treatment plant at concentrations reaching as 
high as $1 \mu \mathrm{g} / \mathrm{L}$ (Stackelberg et al., 2004) Only erythromycin was detected (1-2 ng/L) in treated drinking waters from a DWTP located in the Llobregat River (NE Spain) while other antibiotics showed removal rates greater than $99 \%$ and thus were not detected (Boleda et al., 2013). In a more recent survey conducted by the Ontario Ministry of the Environment (MOE) in 2011, Kleywegt et al., found tylosin (max: $31 \mathrm{ng} / \mathrm{L}$ ), tetracycline (max: $15 \mathrm{ng} / \mathrm{L}$ ), erythromycin (max: $155 \mathrm{ng} / \mathrm{L}$ ), enrofloxacin (max: $13 \mathrm{ng} / \mathrm{L}$ ), lincomycin (max: $1413 \mathrm{ng} / \mathrm{L}$ ), roxithromycin (max: $41 \mathrm{ng} / \mathrm{L}$ ), sulfamethoxazole (max: $2 \mathrm{ng} / \mathrm{L}$ ) and trimethoprim (max: $15 \mathrm{ng} / \mathrm{L}$ ) in majority of drinking water systems collected over a 16 month period, indicating that they survive the conventional water treatment processes and persist in potable-water supplies. Until now, this is the first study reporting the occurrence of antibiotics at such high concentrations in finished drinking waters (Kleywegt et al., 2011).

All these studies highlight the importance of monitoring source waters that could be prone to contamination such as in South Florida. The Biscayne Aquifer often referred to as groundwater or the water table is located just below the surface of the land in South Florida and provides virtually all of the water that is used by South Florida residents, visitors and businesses. Because this drinking water supply is so close to the surface (barely a few feet down in most places), it is especially prone to contamination (MiamiDade) and hence the quality of ground water is of foremost concern in Florida (Barlett, 2012). There is no research on the occurrence of antibiotics in South Florida drinking waters, which is crucial for public health and safety and thus is the objective of this part of the study. 


\subsection{Experimental}

\subsubsection{Sample collection and preparation}

Drinking water samples $(n=54)$ were collected from homes located in the Miami-Dade County area. Drinking water protocols were standardized asking the sampler to run the water for at least 5 minutes and rinse the container at least three times with the tap water. After collection, all samples were immediately transported to the laboratory and sequentially filtered through the $0.45 \mu \mathrm{m}$ glass fiber filter and finally through $0.2 \mu \mathrm{m}$ membrane filter to minimize any potential for biodegradation. Filtered samples were stored in the dark at $-18^{\circ} \mathrm{C}$ until time of analysis.

Drinking water samples were prepared by transferring $10.5 \mathrm{~mL}$ of the sample to a $11-\mathrm{mL}$ vial containing $50 \mu \mathrm{L}$ of $20 \%$ optima $\mathrm{LC} / \mathrm{MS}$ grade formic acid and $50 \mu \mathrm{L}$ of surrogate mixture in methanol $(1 \mu \mathrm{g} / \mathrm{mL}$ of norfloxacin $\mathrm{d} 5,0.2 \mu \mathrm{g} / \mathrm{mL}$ of sulfamethoxazole $\mathrm{d} 5,2$ $\mu \mathrm{g} / \mathrm{mL}$ of sulfadiazine $\mathrm{d} 4,1 \mu \mathrm{g} / \mathrm{mL}$ of erythromycin ${ }^{13} \mathrm{C} \mathrm{d} 3,1 \mu \mathrm{g} / \mathrm{mL}$ of spiramycin $\mathrm{d} 3$ and $2 \mu \mathrm{g} / \mathrm{mL}$ of demeclocycline), the final solution was shaken on a vertex and subsequently analyzed by LC-MS/MS.

Ground water samples $(n=8)$ were collected from Miami-Dade and Broward County areas using peristaltic pump. The tubing was rinsed twice before each sample collection. Field blank samples were also collected in the same sampling locations for each sample. All samples were processed similar to the drinking waters. Second set of drinking waters $(n=5)$ were collected along with ground water samples. During collection, both sampling 
container and filed blank container were opened at the same time and filled with sample and deionized water, respectively. The headspace was kept minimal in all bottles.

\subsubsection{Optimization of analytical methodology}

Previously, antibiotic residues in drinking waters had been extracted using offline SPE (Watkinson et al., 2009) or online SPE (Garcia-Galan et al., 2011) and detected based on single quadrupole (Kolpin et al., 2002) or ion trap or triple quadrupole (Ye et al., 2007; Watkinson et al., 2009; Boleda et al., 2013) or time of flight mass spectrometry (GarciaGalan et al., 2011). Most of these published methods focus on the detection of pharmaceuticals including antibiotics, whereas the present method was optimized for the detection of antibiotics only in various environmental matrices, including drinking waters. In the major Miami-Dade DWTPs, the conventional treatment process consists of screening, grit removal, primary sedimentation, activated sludge treatment by oxygenation and chlorination (Wang, 2012). Thus, finished drinking water samples contain residual amounts of chlorine from disinfection, which might either alter the stability of antibiotics or interfere with the analysis. Ascorbic acid was efficiently used to remove traces of free chlorine and chloramine from drinking water samples in an offline

preconcentration step (Ye et al., 2007). However, the effect of ascorbic acid under the present experimental settings (samples acidified with $20 \%$ formic acid and online preconcentration) could be significantly different and hence was examined in the present study. 
To check the effect of ascorbic acid on the recovery of selected analytes, the samples were filtered through $0.45 \mu \mathrm{m}$ glass fiber filter, spiked with $30 \mu \mathrm{L}$ of ascorbic acid (2 $\mathrm{g} / \mathrm{L}$ ), followed by the addition of formic acid and internal standard solution. Compared to the samples with no ascorbic acid, the spiked samples showed less mean recoveries for all antibiotics except lincomycin, clindamycin and amoxicillin (results were not shown). Hence, the drinking water samples were analyzed within seven days of collection without the addition of ascorbic acid.

\subsection{Results and Discussion}

\subsubsection{Occurrence of antibiotics in drinking waters}

Erythromycin was detected in $82 \%$ of drinking water samples suggesting the ubiquitous nature of this compound in the environment, and therefore the need of continuous monitoring and stringent guidelines for surface/drinking water. No antibiotics were detected in ground waters. Even though drinking water standards and health advisories were not established for antibiotics (Stackelberg et al., 2004), erythromycin was recently added to USEPA contaminant candidate list 3 for drinking waters (EPA, 2009). Its concentration ranged from not detected (n.d.) to $66 \mathrm{ng} / \mathrm{L}$ in the samples measured during the present study. Both norfloxacin and ofloxacin were detected only once at 17 and 37 $\mathrm{ng} / \mathrm{L}$. These results indicate that ground water in South Florida could be under the influence of anthropogenic waste water. Spatial distribution of total concentrations (erythromycin, norfloxacin, ofloxacin) in various sampling locations were shown in 
Figure 16 with the quantitative variation in total concentrations shown with dots of different colors starting from white $(<\mathrm{MDL})$, green (MDL-10 ng/L), blue (10-20 ng/L), yellow (20-30 ng/L), organe (30-40 ng/L) and red (60-80 ng/L). The figure also shows the locations of two major drinking water treatment plants, Hialeah and John E. Preston plant and The Alexander Orr, Jr. plant. The Hialeah and John E. Preston plant serves most Miami-Dade residents living between the Miami-Dade-Broward County line and SW 8th Street. The Alexander Orr, Jr. water treatment plant, serves most County residents living between SW 8th Street and SW 264th Street. The other drinking water treatment plant not shown in the graph is South Dade Water Supply System, which is comprised of five smaller water treatment plants that serve residents south of SW $264^{\text {th }}$ Street in the unincorporated areas of the County (MiamiDade). The pink lines in the figure define the limits for the areas served by these three drinking water treatment plants.

\subsubsection{Statistical analysis}

The total antibiotic concentration (for samples with total concentrations greater than MDL only) versus different drinking water treatment plants under study were compared in Figure 17 and the sample size in each plant was shown in paranthesis above the error bar. Note that only three samples were collected from South Dade water supply system. The figure shows that the average concentration of samples from Hialeah and John E.Preston plant and The Alexander Orr, Jr. plant were similar and was lower than the average of South Dade Water Supply System's samples. 


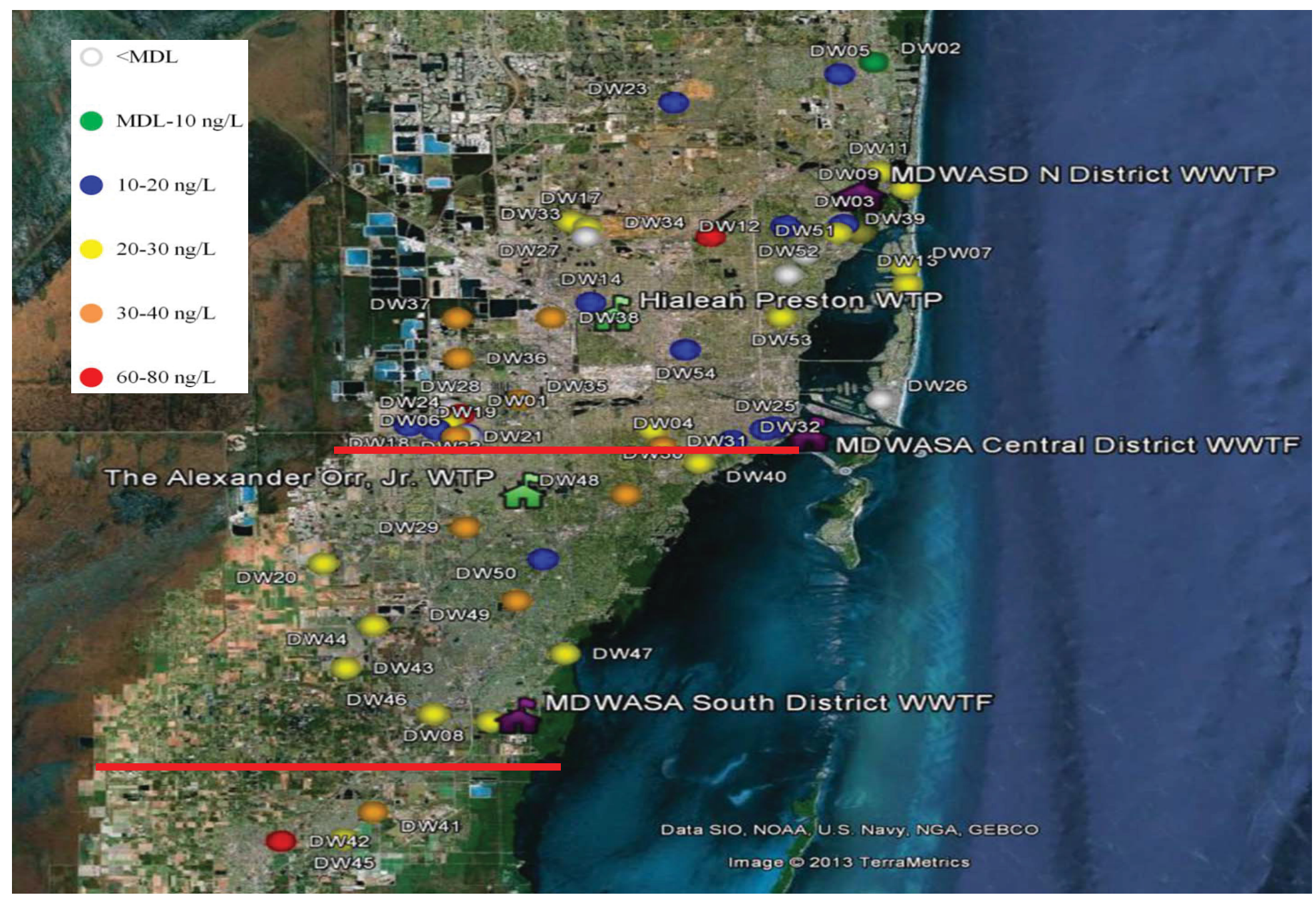

Figure 16. Distribution of total concentration of antibiotics in Miami-Dade County drinking waters 
In order to verify if the difference observed in the means among the treatment plants is significantly different, ANOVA (analysis of variance) was performed using Sigmaplot v12 and results showed that the difference in the mean values among the treatment groups is not statistically significant $(\mathrm{P}=0.118$, Table 15$)$.

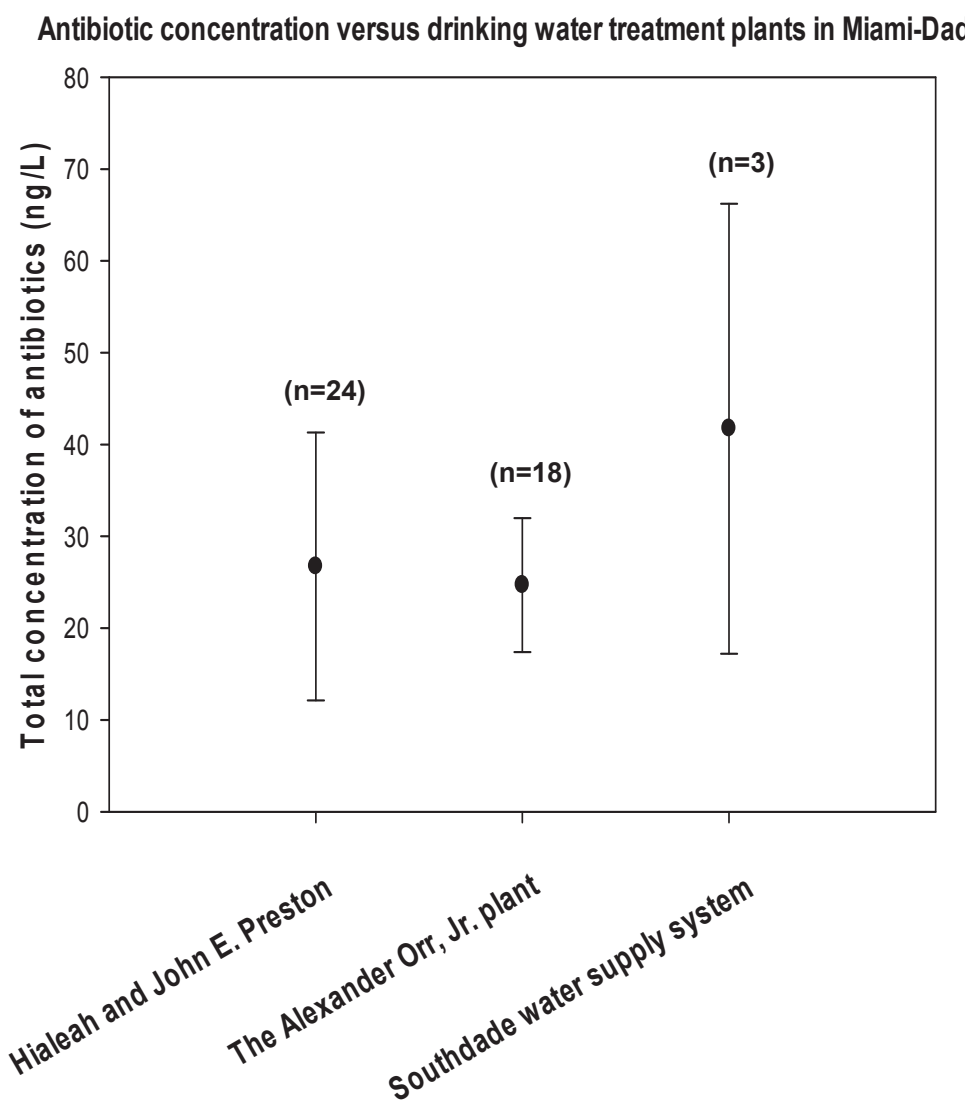

Figure 17. Comparison of samples from the three drinking water treatment plants 
Table 15. Results of an ANOVA test using the samples from three major drinking water treatment plants

\begin{tabular}{lccccc}
\hline \multicolumn{1}{c}{ Group Name } & N & Missing & Mean & $\begin{array}{c}\text { Std } \\
\text { Dev }\end{array}$ & $\begin{array}{c}\text { Standard } \\
\text { Error }\end{array}$ \\
\hline $\begin{array}{l}\text { Hialeah and John E. Preston } \\
\text { Plant }\end{array}$ & 24 & 0 & 26.727 & 14.591 & 2.978 \\
$\begin{array}{l}\text { The Alexander Orr, Jr. Plant } \\
\text { South Dade water supply }\end{array}$ & 18 & 0 & 24.684 & 7.296 & 1.72 \\
system & 3 & 0 & 41.731 & 24.503 & 14.147 \\
Source of Variation & & & & & \\
$\begin{array}{l}\text { Between Groups } \\
\text { Residual }\end{array}$ & DF & SS & MS & F & P \\
Total & 2 & 748.981 & 374.491 & 2.246 & $\mathbf{0 . 1 1 8}$ \\
\hline
\end{tabular}

A plot of the total antibiotic concentration measured at a given sampling site and the location's distance from the drinking water treatment plant for both Hialeah and John E.Preston plant and The Alexander Orr, Jr. plant were shown in Figures 18-19. The plots indicate that there is no correlation between the two factors considered for plot. Assuming that all the three treatment plants were equally efficient in removing the antibiotics from source waters, random distribution of concentrations among the samples may be explained based on the variation in the source water composition on the day of collection as well as the residence time of the finished drinking water in the treatment plant before its distribution (not monitored in the present study). The major source of water for the all treatment plants is Biscayne Aquifer which lies very close to the surface and therefore it is easily prone to contamination by anthropogenic intrusions (MiamiDade). If a treatment plant withdraws water from a well that is under the influence of contamination sources such as waste water treatment plant or agricultural fields, the 
finished drinking water from the drinking water treatment plant might show higher concentration compared to the finished waters of other drinking water treatment plants. Absence of significant difference between the concentrations measured among the samples representing different plants might indicate that the source of contamination is random rather than be specific.

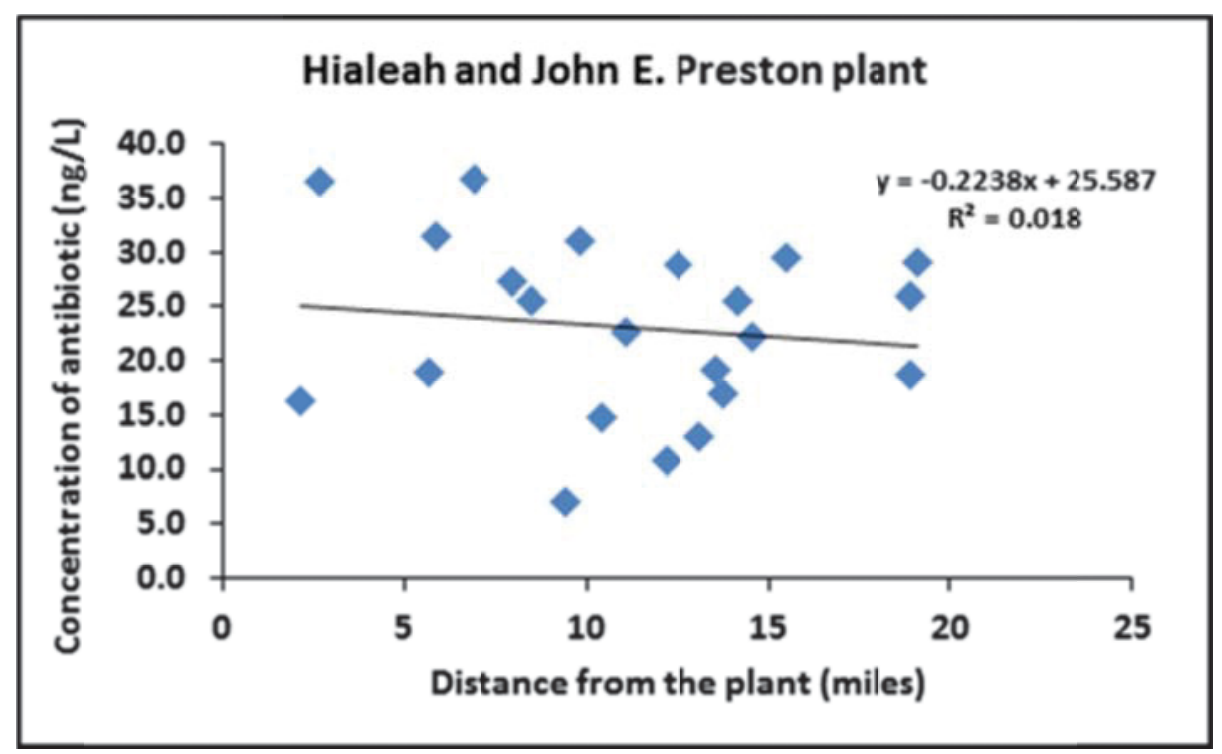

Figure 18. Distribution of samples collected from Hialeah and John E. Preston drinking water treatment plant as a function of sampling location distance from treatment plant 


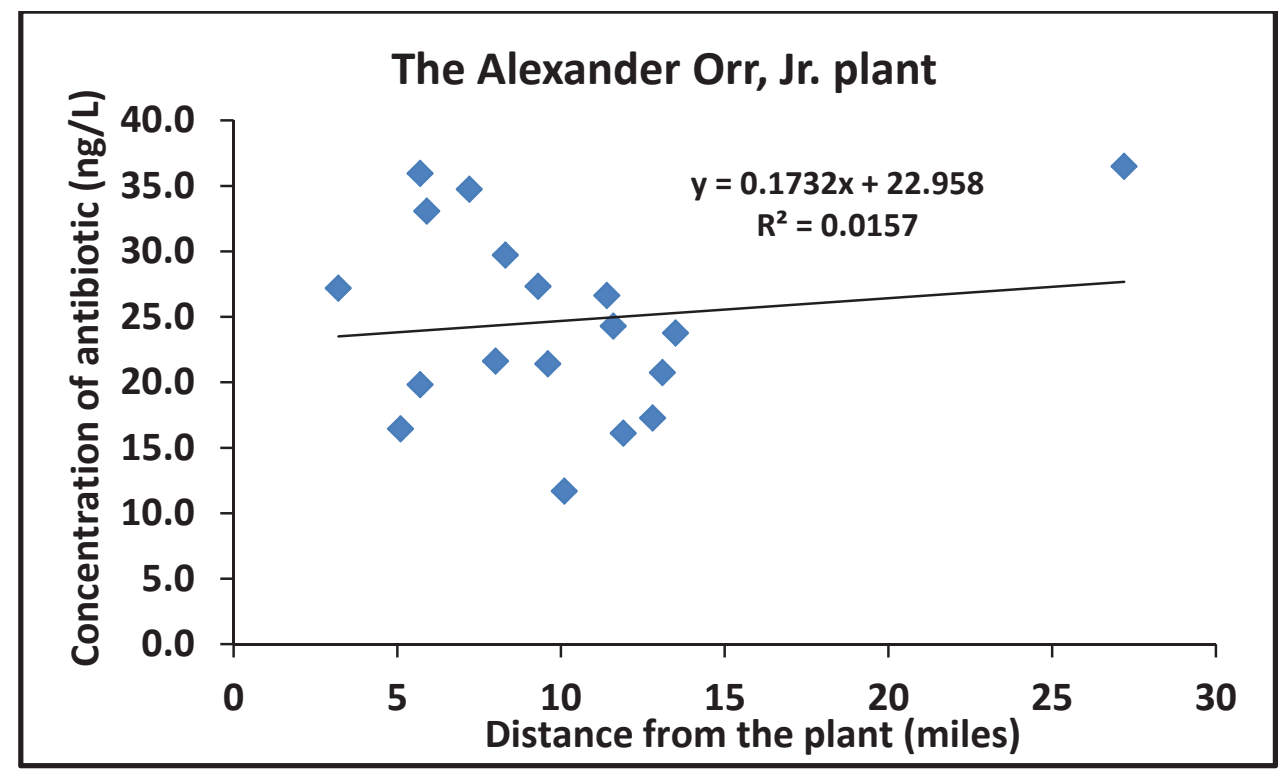

Figure 19. Distribution of samples collected from The Alexander Orr, Jr. drinking water treatment plant as a function of sampling location distance from treatment plant

Ye et al. (Ye et al., 2007) detected erythromycin, roxithromycin, tylosin and sulfamethoxazole in drinking water samples in the concentration range of $1.4-4.9 \mathrm{ng} / \mathrm{L}$. Lopez-Serna et al. (Lopez-Serna et al., 2010) also detected macrolides azithromycin, clarithromycin, spiramycin $(3.6$ - $21 \mathrm{ng} / \mathrm{L})$, sulfonamide sulfamethazine $(4.1 \mathrm{ng} / \mathrm{L})$ and fluoroquinolones enoxacin, ofloxacin, ciprofloxacin, enrofloxacin, norfloxacin (13 - 33 $\mathrm{ng} / \mathrm{L}$ ) in the effluents of a drinking water treatment plant. It must be noted that the type of antibiotics detected in drinking waters vary greatly from one study to another and this may be due to the fact that both sources and treatment technologies will greatly differ from one country to another. 
There were no antibiotics detected in the second set of drinking water $(\mathrm{n}=5)$ and ground water $(n=8)$ samples collected from Miami Dade county and Broward county, the sampling locations were shown in Figure 20.

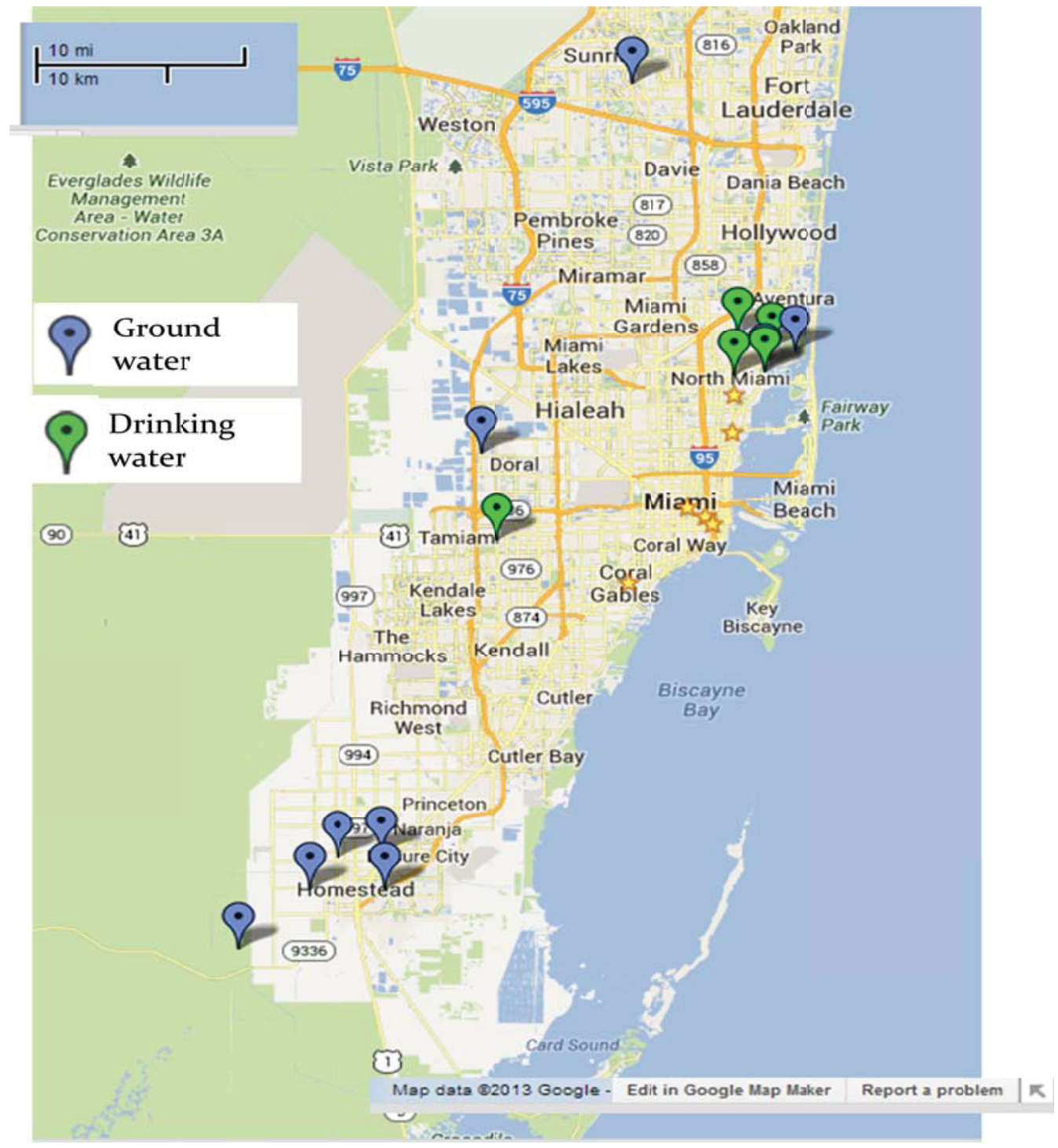

Figure 20. Drinking water and Ground water sampling locations 


\subsection{Conclusions}

The Biscayne Aquifer is the primary source of drinking water for Miami-Dade, Broward and southeastern Palm Beach County. It is an unconfined aquifer and lies very close to the surface. Therefore, it interacts directly with natural and man-made bodies of surface water such as streams, canals and reservoirs and thus susceptible to anthropogenic discharges. Initial results from this study shows that both drinking and surface waters are influenced by anthropogenic antibiotic inputs. However no traces of antibiotics were detected when samples $(n=5)$ were collected. Results from this set of samples were not conclusive enough due to limited number of samples compared to first set of samples $(n=56)$. Since detection of antibiotic residues in drinking water raises the public concern over drinking water quality, it is recommended to include multiple sampling locations to continuously monitor the quality of both ground and drinking waters. 


\section{CHAPTER 6}

Identification of antibiotic metabolites and their transformation products in reclaimed water using high resolution benchtop Orbitrap mass spectrometry 


\subsection{Introduction}

Occurrence and widespread distribution of antibiotic residues in the aquatic environment, has drawn much attention worldwide both in research and public community. Their environmental occurrence is of particular concern due to the potential spread and induction of bacterial resistance (Diaz-Cruz and Barcelo, 2006) and their ability to potentially alter ecosystem functioning (Kummerer, 2009). Hence antibiotics have been included among the group of emerging environmental contaminants of increasing concern (Kolpin et al., 2002). Antibiotics are released into aquatic environment largely through discharge of wastewater treatment plant effluents (WWTPs). After consumption by humans and animals, antibiotics will go through series of metabolic processes and which are often incomplete, so as a result bio-active unchanged antibiotics and their metabolites are excreted and eventually reach WWTPs (McArdell et al., 2003).

Much attention has been paid to unchanged antibiotics compounds while assessing their environmental occurrence and lesser importance to transformation products (Celiz et al., 2009). Here the term transformation product is used in broader sense to include, metabolites formed by biochemical transformation of parent drug in organisms (Gobel et al., 2004) and sewage treatment processes such as chemical, photo and microbial biological oxidation (Homem and Santos, 2011; Bonvin et al., 2012). Drugs or chemicals that enter the human body are cleared mainly by the solo or combination of three mechanisms: metabolism, renal and bile excretion. Metabolism, a primary route of detoxification for most of the drugs, involves series of enzymatic biotransformation reactions to cause chemical alteration or degradation (Liska, 1998). In general the 
metabolic reactions can be classified into two phases, phase I and phase II (Murphy, 2001). Phase I metabolic reactions include, oxidation, reduction and hydrolysis, where the parent drug will be transformed into a more polar metabolite by adding or revealing functions groups such as $-\mathrm{OH},-\mathrm{NH}_{2},-\mathrm{SH}$ and $-\mathrm{COOH}$, etc. The liver is the major metabolic site and first intestinal organ that a drug molecule passes through after absorption from the gut (Liska, 1998). The mechanism involves a variety of enzymes such as cytochrome P450 (CYP1, CYP2 and CYP3), that catalyze the oxidation and hydroxylation and NADPH-CYP reductase introducing reactive and polar groups into their substrates (williams, 1947; Liska, 1998; Danielson, 2002; Gu et al., 2003). Phase II metabolism is a conjugative reaction, where the molecule is conjugated with polar groups such as glucuronic acid, glutathione (GSH), sulfate, or glycine catalyzed by group of enzymes called transferases (williams, 1947; Liska, 1998; Holcapek et al., 2008), hence finally converted to more water soluble, hydrophilic species thereby being easily excreted. The metabolite can also be active with the desired therapeutic effect instead of the parent drug when is administered as pro-drug (Guengerich, 2001) one such example is enrofloxacin, which metabolizes to the bioactive ciprofloxacin. The activation of a drug by metabolism can also result in a toxic product (Guengerich, 2011). Hence, it is important to assess the risk of metabolites as well.

Although different analytical instrumentation have been employed in the determination of antibiotics in environmental matrices (Ternes, 2001; Petrovic et al., 2005; Richardson, 2006; Hernandez et al., 2007), liquid chromatography coupled to mass spectrometry, especially tandem mass spectrometry has made impressive progress and is by far the most widely used within this field. With improved selectivity and high sensitivity offered 
by tandem mass spectrometry, the unequivocal detection of antibiotics in complex environmental matrices even at parts-per-trillion level made practically possible.

However many studies considered the detection and quantification of parent drugs, with very little attention given to the potential contributions that metabolites may have. Scarcity of available environmental data on the metabolites excreted into the natural ecosystem is may mainly be attributed to their relatively high polarity and the lack of reference substances, which resulting in difficulty to analyze them (Diaz-Cruz and Barcelo, 2006). Hence, current analysis of targeted metabolites in environmental matrices using tandem mass spectrometry is limited to compounds whose metabolites are well known and the standards are available to confirm their identity (Gobel et al., 2004; Celiz et al., 2009), for example anhydroerythromycin, which is routinely detected in environmental analysis studies (Wang and Gardinali, 2012; Panditi et al., 2013). However, the advent of highly sensitive and powerful analytical instrumentation and increasing number of studies reporting the environmental presence of metabolites is indicating the urge to include the bio-active metabolites as well in routine antibiotic analysis. In wastewater treatment process through physical, chemical, biological means or under certain environmental conditions, excreted metabolites can also be transformed back to the parent compound (Bonvin et al., 2012) and potentially more dangerous than the parent compound (Dantas et al., 2008; Homem and Santos, 2011), one such example is back transformation of acetylsulfamethazine to the active parent compound during the storage of manure (Berger et al., 1986). Erythromycin, the most commonly detected antibiotic in environmental waters is always detected as anhydroerythromycin, a degradation product formed with the loss of one water molecule (Hirsch et al., 1999). 
Very little is known about degradation products and epimers of tetracyclines in the aquatic environment. These products are mainly formed through hydrolysis and photolysis reactions yielding relatively more water soluble anhydro-, epi-, and iso- forms of tetracycline (Halling-Sorensen et al., 2002; Diaz-Cruz and Barcelo, 2006). Therefore it is important to include bio-active metabolites as well as transformation products in routine antibiotic analysis to get an overall idea on occurrence, fate and distribution of antibiotics in the environment.

In recent years, the advent of hybrid high resolution mass spectrometers, such as quadrupole time of flight (QTOF), triple quadrupole time of flight (QqTOF), Fourier transform ion cyclotron resonance (FTICR), Orbitrap, and linear ion trap-Orbitrap (LTQOrbitrap), with elevated resolution $(>40,000)$ and high mass accuracy $(<5 \mathrm{ppm})$ capabilities, has made the conditions ideal for screening and positive confirmation of unknown metabolites and transformation products both in metabolic profiling and environmental studies (Stolker et al., 2004; Gros et al., 2009; Ferrer and Thurman, 2012; Hernandez et al., 2012; Meyer and Maurer, 2012; Qian et al., 2012). Limitations for the use of TOF instruments are less linear dynamic range $\left(<10^{3}\right)$ and the need for internal calibration (for each pre and post sample injection) to maintain high mass accuracy (Hernandez et al., 2012). In contrast Orbitrap instruments offer relatively higher sensitivity, and better linear dynamic range. Moreover, external calibration is used to obtain high mass accuracy resulting in simplified operational protocol (Lim et al., 2007).

The main objective of this study is to identify the antibiotic metabolites and transformation products in reclaimed water using a Q Exactive Orbitrap mass spectrometer based on accurate mass measurements in combination with characteristic 
MS/MS fragmentation ions in data dependent scan mode and to quantify their relative abundance with respect to the parent antibiotics.

\subsection{Experimental}

\subsubsection{Chemicals and Standards}

All the reference standards for parent drug molecules were purchased from SigmaAldrich (Oakville, ON and Milwaukee, WI) and isotopically labeled antibiotics (Sulfamethoxazole-d4, spiramycin-d3, sulfadiazine-d4, erythromycin- ${ }^{13} \mathrm{C}-\mathrm{d} 3$ ) and demeclocycline were purchased from Toronto Research Chemicals (Toronoto, Canada) CDN Isotope Laboratories (Quebec, Canada) and norfloxacin-d5 from CDN Isotope Laboratories (Quebec, Canada). All isotopically labeled standards presented purity higher than $95 \%$ (isotopic purity $>99 \%$ ). Pierce LTQ Velos ESI positive ion and negative ion calibration solutions for Q Exactive Orbitrap mass spectrometer calibration were procured from Thermo Scientific (Rockford, IL). Optima LC/MS grade formic acid, methanol, acetonitrile and water were purchased from Fisher Chemical (Fairlawn, New Jersey, USA). The $0.1 \%$ formic acid solution in water was prepared daily before the analysis. 


\subsubsection{Sample collection, extraction and preparation}

Reclaimed water $(500 \mathrm{~mL}$ ) was collected in clear PET plastic bottles (polyethylene terephthalate) directly from reclaimed water sprinklers at Florida International University Biscayne Bay Campus (North Miami, FL). Bottles were rinsed twice with sampling water before collection. Water samples were filtered and stored in dark at below $-18^{\circ} \mathrm{C}$ until the extraction. Sample collection, filtration and storage details were described in detail in Chapter 3.

Samples were extracted using offline solid phase extraction (SPE) procedures for multi residue antibiotic analysis. Two different SPE cartridges with distinct sorbent properties were coupled in tandem to ensure retention of all unknown compounds (Diaz-Cruz and Barcelo, 2006; Seifrtova et al., 2009). In this study an Oasis HLB (3 cc/60 mg, Waters Corp., Milford, MA), was placed on top of a Sep-Pak C18 Plus cartridge (900 mg, Waters Corp., Milford, MA) and conditioned with $6 \mathrm{~mL}$ of methanol followed by $6 \mathrm{~mL}$ of deionized water. SPE was performed on 12-port vacuum maniforld. Each reclaimed water sample $(350 \mathrm{~mL})$ was passed through the cartridges, dried and finally eluted with 4 $\mathrm{mL}$ of methanol. The eluents were dried under gentle stream of nitrogen, spiked with the appropriate surrogates and reconstituted to $250 \mathrm{uL}$ with $\mathrm{LC}-\mathrm{MS}$ grade water.

\subsubsection{Liquid Chromatography and High Resolution Mass Spectrometry}

Liquid chromatography was performed using a quaternary Accela pump equipped with a Thermo PAL CTC autosampler. Chromatographic separation of analytes was carried out 
using a Hypersil Gold $\mathrm{C}_{18}$ column $(50 \mathrm{~mm} \times 2.1 \mathrm{~mm}, 1.9 \mu \mathrm{m})$ from Thermo Scientific (Bellefonte, PA). Analytes were separated through the column using a mobile phase consisting of $0.1 \%$ formic acid in water $(\mathrm{v} / \mathrm{v})$ and pure acetonitle programmed in gradiant cycle (acetonitrile \%: $0 \min 10 \%, 2.5 \min 10 \%, 8 \min 50 \%, 11 \min 95 \%, 14$ $\min 95 \% 15 \min 10 \%, 17 \min 10 \%)$. The injection volume and mobile phase flow rate were $10 \mu \mathrm{L}$ and $220 \mu \mathrm{L}$ respectively.

High resolution mass spectrometric analysis (HRMS) was performed on a Q Exactive Orbitrap mass spectrometer (Thermo Scientific, San Jose, CA, USA) equipped Ion Max API heated electrospray ionization source (HESI-II) operated in positive ionization mode. Ionization source parameters were set as follows: Sheath gas 35, Auxiliary gas 35, and sweep gas 5 arbitrary units, similarly spray voltage $4 \mathrm{kV}$, both capillary temperature and vaporization temperature at $300{ }^{\circ} \mathrm{C}$. The HRMS data was acquired in data-dependent cycle, first in full scan mode, scan range from m/z $75-\mathrm{m} / \mathrm{z} 1000$ at a resolving power of 70,000 and then three corresponding data-dependent MS/MS scans at resolving power of 35,000 . The most abundant precursor ions that surpass the preset threshold of $1 * \mathrm{e}^{\wedge} 6$, triggered data-dependent scanning and were subsequently injected to the C-trap for fragmentation.

The isolation window for MS/MS data-dependent scanning was set at $1 \mathrm{~m} / \mathrm{z}$. Normalized collision energy was set to 35 with stepped increment of $25 \%$. High purity nitrogen was used as source gas and argon as collision gas for high pressure induced collision dissociation. Data acquisition and instrumental control was performed using Thermo Scientific Xcalibur software. 


\subsubsection{Data processing and Interpretation}

MetWorks 1.3 (Thermo Scientific, San Jose, CA) software was used for the calculation of exact masses from elemental composition and for tentative identification of potential phase I and phase II metabolites from extracted ion chromatograms (XIC) of the full scan data at high mass accuracy (mass tolerance, $5 \mathrm{ppm}$ ). Acquired HRMS data-dependent spectra of the positively identified targeted and unknown compounds were further investigated using Mass Frontier 7.0 software (MF) (Thermo Scientific). The theoretical spectra generated from the assigned chemical structure by the fragment ion search (FISh) feature in MF were compared with those of observed experimental spectra for spectral matching. The similarities between observed and theoretical spectra were considered in assigning molecular structures for the fragments and for positive assessment of metabolite identity.

The instrumental detection of accurate masses was studied by injecting $10 \mu \mathrm{L}$ of an antibiotic standards mixture at the beginning of analysis and the data is shown in Table 16. The mass accuracy of observed accurate masses was below $1.5 \mathrm{ppm}$ for all antibiotics, excluding spiramycin, shows that the instrument is in excellent condition and ready for analysis. 
Table 16. Mass accuracy of selected antibiotics based on exact mass and observed mass measurements

\begin{tabular}{|c|c|c|c|c|}
\hline Name & $\begin{array}{l}\text { Elemental } \\
\text { Composition }\end{array}$ & $\begin{array}{l}\text { Exact Mass } \\
(\mathrm{m} / \mathrm{z})\end{array}$ & $\begin{array}{c}\text { Observed } \\
\text { accurate } \\
\text { Mass }(\mathrm{m} / \mathrm{z})\end{array}$ & $\begin{array}{c}\text { Mass } \\
\text { Accuracy } \\
\text { (ppm) }\end{array}$ \\
\hline Erythromycin & $\mathrm{C}_{37} \mathrm{H}_{67} \mathrm{NO}_{13}$ & 734.4685 & 734.4692 & 0.9 \\
\hline Spiramycin & $\mathrm{C}_{43} \mathrm{H}_{74} \mathrm{~N}_{2} \mathrm{O}_{14}$ & 843.5243 & 843.5217 & -3.1 \\
\hline Azithromycin & $\mathrm{C}_{38} \mathrm{H}_{72} \mathrm{~N}_{2} \mathrm{O}_{12}$ & 749.5158 & 749.5159 & 0.1 \\
\hline Clarithromycin & $\mathrm{C}_{38} \mathrm{H}_{69} \mathrm{NO}_{13}$ & 748.4842 & 748.4846 & 0.6 \\
\hline Roxithromycin & $\mathrm{C}_{41} \mathrm{H}_{76} \mathrm{~N}_{2} \mathrm{O}_{15}$ & 837.5319 & 837.5319 & 0.0 \\
\hline Tylosin & $\mathrm{C}_{46} \mathrm{H}_{77} \mathrm{NO}_{17}$ & 916.5264 & 916.5274 & 1.1 \\
\hline Lincomycin & $\mathrm{C}_{18} \mathrm{H}_{34} \mathrm{~N}_{2} \mathrm{O}_{6} \mathrm{~S}$ & 407.2210 & 407.2214 & 0.9 \\
\hline Clindamycin & $\mathrm{C}_{18} \mathrm{H}_{33} \mathrm{ClN}_{2} \mathrm{O}_{5} \mathrm{~S}$ & 425.1871 & 425.1874 & 0.6 \\
\hline Enoxacin & $\mathrm{C}_{15} \mathrm{H}_{17} \mathrm{FN}_{4} \mathrm{O}_{3}$ & 321.1357 & 321.1359 & 0.5 \\
\hline Ofloxacin & $\mathrm{C}_{18} \mathrm{H}_{20} \mathrm{FN}_{3} \mathrm{O}_{4}$ & 362.1511 & 362.1511 & 0.0 \\
\hline Norfloxacin & $\mathrm{C}_{16} \mathrm{H}_{18} \mathrm{FnN}_{3} \mathrm{O}_{3}$ & 320.1405 & 320.1406 & 0.3 \\
\hline Ciprofloxacin & $\mathrm{C}_{17} \mathrm{H}_{18} \mathrm{FN}_{3} \mathrm{O}_{3}$ & 332.1405 & 332.1405 & 0.0 \\
\hline Danofloxacin & $\mathrm{C}_{19} \mathrm{H}_{20} \mathrm{FN}_{3} \mathrm{O}_{3}$ & 358.1561 & 358.1563 & 0.4 \\
\hline Enrofloxacin & $\mathrm{C}_{19} \mathrm{H}_{22} \mathrm{FN}_{3} \mathrm{O}_{3}$ & 360.1718 & 360.1720 & 0.6 \\
\hline Sarafloxacin & $\mathrm{C}_{20} \mathrm{H}_{17} \mathrm{~F}_{2} \mathrm{~N}_{3} \mathrm{O}_{3}$ & 386.1311 & 386.1314 & 0.8 \\
\hline Nalidixic acid & $\mathrm{C}_{12} \mathrm{H}_{12} \mathrm{~N}_{2} \mathrm{O}_{3}$ & 233.0921 & 233.0924 & 1.4 \\
\hline Amoxycillin & $\mathrm{C}_{16} \mathrm{H}_{19} \mathrm{~N}_{3} \mathrm{O}_{5} \mathrm{~S}+\mathrm{CH}_{3} \mathrm{OH}$ & 398.1380 & 398.1384 & 0.9 \\
\hline Tetracycline & $\mathrm{C}_{22} \mathrm{H}_{24} \mathrm{~N}_{2} \mathrm{O}_{8} \mathrm{Na}$ & 445.1605 & 445.1609 & 0.8 \\
\hline Oxytetracycline & $\mathrm{C}_{22} \mathrm{H}_{2} 4 \mathrm{~N}_{2} \mathrm{O}_{9}$ & 461.1555 & 461.1559 & 1.0 \\
\hline Chlortetracycline & $\mathrm{C}_{22} \mathrm{H}_{23} \mathrm{ClN}_{2} \mathrm{O}_{8}$ & 479.1216 & 479.1221 & 1.1 \\
\hline Doxycycline & $\mathrm{C}_{22} \mathrm{H}_{24} \mathrm{~N}_{2} \mathrm{O}_{8}$ & 445.1605 & 445.1609 & 0.8 \\
\hline Meclocycline & $\mathrm{C}_{22} \mathrm{H}_{21} \mathrm{ClN}_{2} \mathrm{O}_{8}$ & 477.1059 & 477.1063 & 0.8 \\
\hline Sulfamethoxazole & $\mathrm{C}_{10} \mathrm{H}_{11} \mathrm{~N}_{3} \mathrm{O}_{3} \mathrm{~S}$ & 254.0594 & 254.0595 & 0.4 \\
\hline Trimethoprim & $\mathrm{C}_{14} \mathrm{H}_{18} \mathrm{~N}_{4} \mathrm{O}_{3}$ & 291.1452 & 291.1453 & 0.5 \\
\hline Sulfadiazine & $\mathrm{C}_{10} \mathrm{H}_{10} \mathrm{~N}_{4} \mathrm{O}_{2} \mathrm{~S}$ & 251.0597 & 251.0599 & 0.7 \\
\hline Sulfamethazine & $\mathrm{C}_{12} \mathrm{H}_{14} \mathrm{~N}_{4} \mathrm{O}_{2} \mathrm{~S}$ & 279.0910 & 279.0912 & 0.6 \\
\hline Sulfathiazole & $\mathrm{C}_{9} \mathrm{H}_{9} \mathrm{~N}_{3} \mathrm{O}_{2} \mathrm{~S}_{2}$ & 256.0209 & 256.0210 & 0.4 \\
\hline Sulfamerazine & $\mathrm{C}_{11} \mathrm{H}_{12} \mathrm{~N}_{4} \mathrm{O}_{2} \mathrm{~S}$ & 265.0754 & 265.0756 & 0.9 \\
\hline Sulfamethizole & $\mathrm{C}_{9} \mathrm{H}_{10} \mathrm{~N}_{4} \mathrm{O}_{2} \mathrm{~S}_{2}$ & 271.0318 & 271.0319 & 0.4 \\
\hline Sulfachlorpyridazine & $\mathrm{C}_{10} \mathrm{H}_{9} \mathrm{ClN}_{4} \mathrm{O}_{2} \mathrm{~S}$ & 285.0208 & 285.0209 & 0.5 \\
\hline Sulfadimethoxine & $\mathrm{C}_{12} \mathrm{H}_{14} \mathrm{~N}_{4} \mathrm{O}_{4} \mathrm{~S}$ & 311.0809 & 311.0809 & 0.2 \\
\hline
\end{tabular}




\subsubsection{Tentative identification of potential metabolites and transformation products in reclaimed water}

After inputting the elemental composition and ionization mode for the parent antibiotics into MetWorks software, XICs for the parent drug along with their metabolites were generated from original data file based on exact mass modifications. For the accurate

detection of mass peaks mass tolerance was set at $5 \mathrm{ppm}$. Tentatively identified antibiotics are shown in Table 17. In general, the metabolites are more water soluble than the corresponding parent drugs, with exception of acetylated transformation products, therefore, while chromatographic separation, earlier retention time is a positive indication for tentative identification of metabolites. Knowing the chromatographic behavior is also useful for the detection of isomeric forms that can't be distinguished by mass spectrometry alone (Ferrer and Thurman, 2012). In this study tetracycline isomers have same exact mass and the potential to follow similar MS/MS fragmentation pattern. However, they show difference in chromatographic retention time. 
Table 17. Antibiotics and corresponding tentatively identified metabolites

\begin{tabular}{llll}
\hline & $\begin{array}{l}\text { Accurate } \\
\text { Mass } \\
(\mathrm{m} / \mathrm{z})\end{array}$ & Transformation products & $\begin{array}{l}\text { Accurate } \\
\text { Mass } \\
(\mathrm{m} / \mathrm{z})\end{array}$ \\
\hline Parent molicule & 285.0208 & Acetyl sulfachlorpyridazine & 327.0300 \\
Sulfachlorpyridazine & 279.0910 & Acetyl sulfamethazine & 321.1019 \\
sulfamethoxine & 254.0594 & Acetyl sulfamethoxazole & 296.0700 \\
Doxycycline & 445.1605 & N-desmethyl doxycycline & 431.1440 \\
Chlortetracycline & 479.1216 & N-desmethylchlortetracycline & 465.1050 \\
Chlortetracycline & 479.1216 & didesmethylchlortetracycline & 451.0903 \\
Ciprofloxacin & 332.1405 & Ciprofloxacin N-oxide & 348.1340 \\
Nalidixic acid & 233.0921 & Nalidixic acid N-oxide & 249.0860 \\
Nalidixic acid & 233.0921 & Nalidixic acid glucuronate & 409.1240 \\
& & Anhydroerythromycin & \\
Erythromycin & 734.4685 & Desmethyl- & 716.4587 \\
Erythromycin & 734.4685 & anhydroerythromycin & 702.4437 \\
Ofloxacin & 362.1511 & Desmethyl ofloxacin & 348.1340 \\
\hline
\end{tabular}

After the detailed examination of XICs for all potential metabolites in reclaimed water, three transformation products / metabolites were identified, two for erythromycin (anhydroerythromycin, desmethyl-anhydroerythromycin), and one for sulfamethoxazole (acetyl-sulfamethoxazole). In two of the erythromycin transformation products, anhydroerythromycin was the frequently detected antibiotic in environmental waters, whereas the other desmethyl-anhydroerythromycin was detected for the first time.

Regarding erythromycin, an interesting observation reported in scientific literature is that, erythromycin can easily be degraded under experimental conditions $(\mathrm{pH}<7)$, to anhydroerythromycin (Diaz-Cruz and Barcelo, 2006) by losing one water molecule. Even the same was observed in present study, and discussed in earlier chapter. However, this degradation was observed in extracted spiked samples at neutral $\mathrm{pH}$ as well (Hirsch et al., 1999), revealing that the dehydration process takes place in the natural aquatic 
environment. Therefore it is difficult to distinguish that the observed transformation was naturally happened or under experimental setup conditions. Hence for the later part of this study, anhydroerythromycin was taken granted as parent molecule and no more discussed as transformation product.

The chromatographic behavior of anhydroerythromycin and its metabolite, desmethylanydroerythromycin in reclaimed water showes that the desmethylated- form eluting first at the retention time, $6.14 \mathrm{~min}$, and the parent anhydroerythromycin later at $6.24 \mathrm{~min}$ (Figure. 21). For sulfamethoxazole and its metabolite, acetyl-sulfamethoxazole, the parent molecule elutes first at $9.51 \mathrm{~min}$, and the corresponding metabolite later at 9.65 min (Figure. 22), which can be explained by the hydrophobic nature of the acetylated metabolite. Similar type of behavior was also observed for other closely related antibiotics with respect to their metabolites (Gobel et al., 2004; Ferrer and Thurman, 2012; Wang, 2013). This was the first positive sign observed in the process of confirming their identity. 


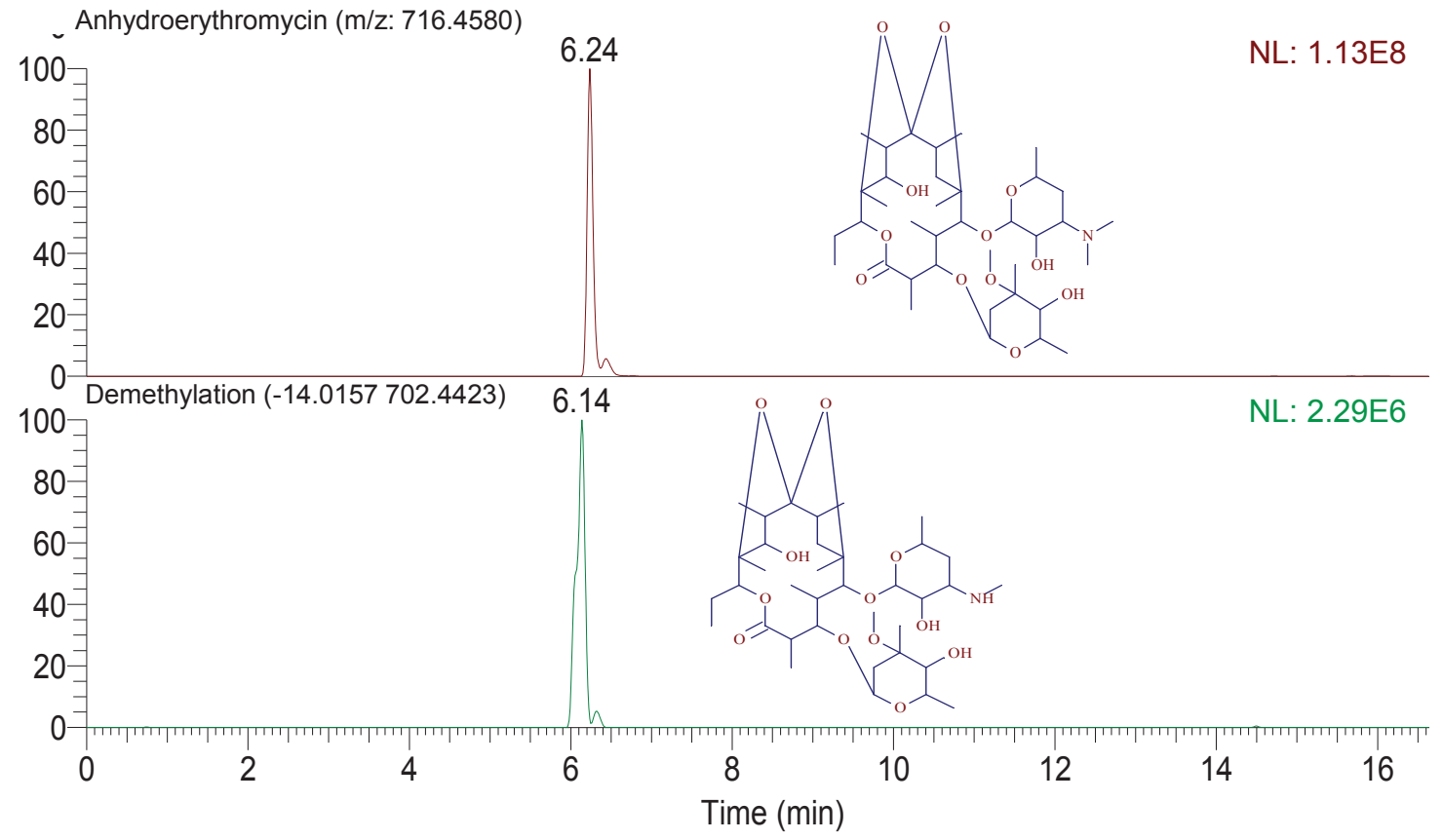

Figure 21. Extracted ion chromatograms of anhydroerythromycin and its metabolite desmethyl-anhydroerythromycin in reclaimed water (Peak settings of mass tolerance 5 ppm, and mass precision 4 decimal places)

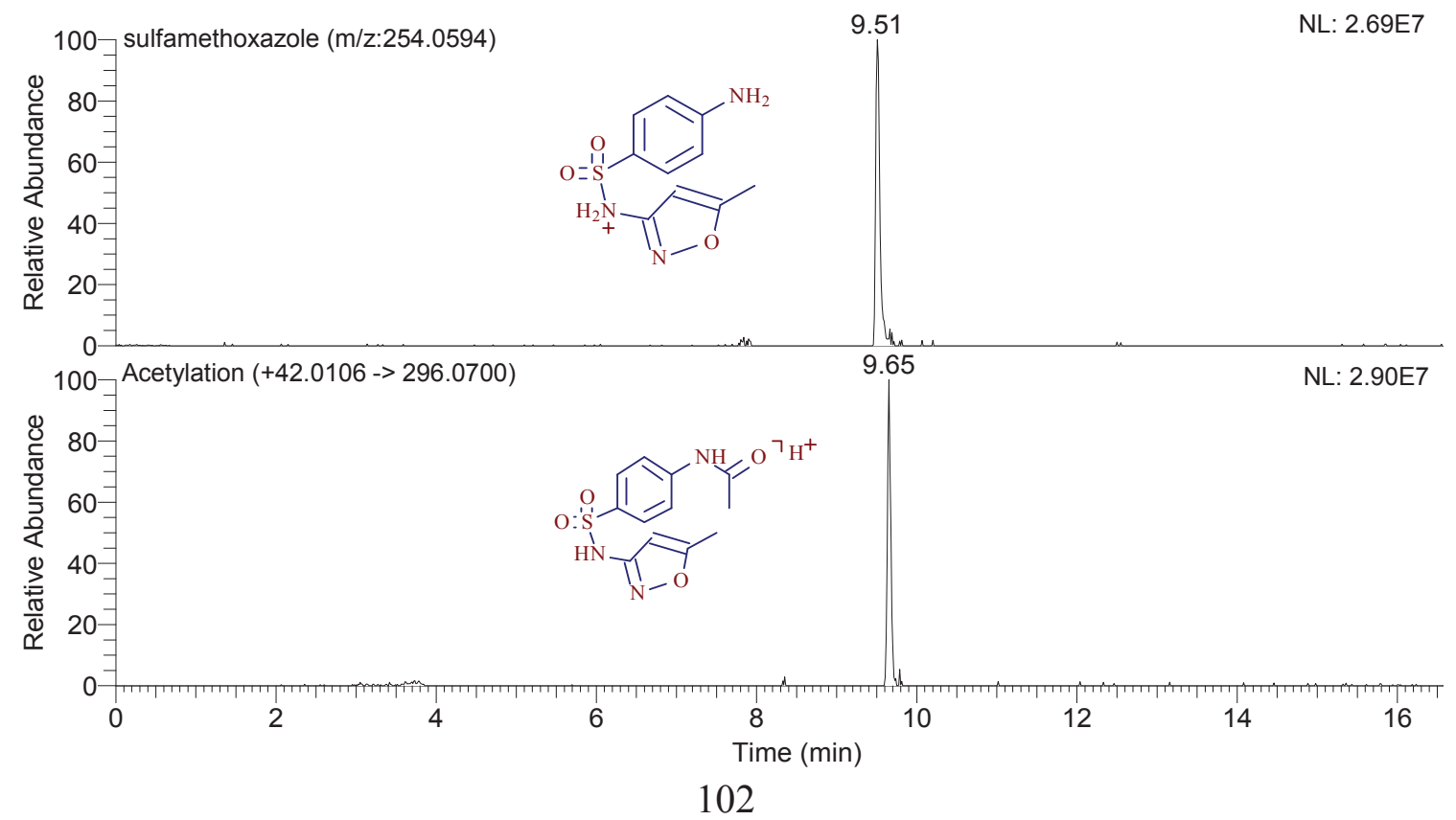


Figure 22. Extracted ion chromatograms of sulfamethoxazole and its metabolite acetylsulfamethoxazole in reclaimed water (Peak detection settings of mass tolerance $5 \mathrm{ppm}$, and mass precision 4 decimal places)

The high resolution mass spectrometry data revealing that the accurate mass of anhydroerythromycin was observed at $\mathrm{m} / \mathrm{z} 716.4587$, which is $-0.9 \mathrm{ppm}$ from its exact mass at $\mathrm{m} / \mathrm{z} 716.4580$, even the standard spiked sample also eluted at the same retention time with the same measured accurate mass, confirming the positive identity for erythromycin in reclaimed water. At the same time, the accurate mass of sulfamethoxazole was observed at $\mathrm{m} / \mathrm{z} 254.0595$, with a mass accuracy of $0.4 \mathrm{ppm}$, from its exact mass of $\mathrm{m} / \mathrm{z}$ 254.0594. The retention time was also matched the same with its standard spiked sample, confirming the positive identity for sulfamethoxazole in reclaimed water. Additional confirmation was made by comparing MS/MS spectra of reclaimed water sample with that of standard.

The accurate mass for anhydroerythromycin metabolite, desmethyl-anhydroerythromycin was measured at m/z 702.4437 with mass accuracy $2.0 \mathrm{ppm}$ from its exact mass, $\mathrm{m} / \mathrm{z}$ 702.4423, calculated based on the elemental composition of the metabolite. This corresponds to the loss of methyl group (14 Da) from its parent, anhydroerythromycin. Similarly the accurate mass of sulfamethoxazole metabolite, acetyl-sulfamethoxazole was measured at 296.0700, with mass accuracy of $0.0 \mathrm{ppm}$ from its exact mass, $\mathrm{m} / \mathrm{z} 296.0700$, correspond to the addition of acetyl group (42 Da) to sulfamethoxazole. As the metabolite standards were not readily available while conducting this experiment, an alternative approach to confirm their identity followed was, comparing the fragmentation pattern 
between the parent drug and the transformation product, knowing that they both share the same "back bone" in their molecular structures, same approach was also reported in literature (Thurman and Ferrer, 2012).

\subsubsection{Identification of Desmethyl-anhydroerythromycin}

The high resolution data-dependent MS/MS spectrum of $\mathrm{m} / \mathrm{z} 716.4587$, in reclaimed water at retention time 6.24 min was shown in Figure 23b, which was nearly identical with MS/MS spectrum of erythromycin standard spiked sample. The three most abundant fragment ions $158 \mathrm{Da}, 116 \mathrm{Da}$ and $98 \mathrm{Da}$ were following the same relative abundance in both the spectra, clearly implying that the ion $\mathrm{m} / \mathrm{z} 716.4587$ was anhydroerythromycin. The structures of most abundant fragments were predicted by inputting parent molecule anhydroerythromycin molecular structure in to MF software, where MF generated the possible structures based on the fragmentation rules built into it. All the major fragments observed in MS/MS spectra matched with the MF predicted fragmentation ions, and were shown in red colour. All the labeled fragmentation ions were within 5 ppm accuracy to the proposed structures, and were shown in Figure 23b. Therefore, confirming that the ion $\mathrm{m} / \mathrm{z} 716.4587$ was anhydroerythromycin.

The MS/MS spectrum of ion $\mathrm{m} / \mathrm{z} 702.4437$ at retention time 6.14 min was shown in Figure 23c, matches with exact mass of proposed desmethyl-anhydroerythromycin, with mass accuracy of $2.0 \mathrm{ppm}$. The most abundant fragment ions $144 \mathrm{Da}$, was $14 \mathrm{Da}$ less than $158 \mathrm{Da}$, the most abundant fragment ion for standard, revealing that the mass loss was corresponding to methyl group with an accuracy of $1.4 \mathrm{ppm}$. The nominal masses of 
other fragment ions, $233 \mathrm{Da}$ and $83 \mathrm{Da}$, were in good agreement with the MS/MS fragments of anhydroerythromycin standard showing that for sure they both have the similar structural features. The structures for the labeled fragment ions were predicted using MF software and the mass accuracies were within $5 \mathrm{ppm}$ to that of observed MS/MS fragments (Figure 24). 

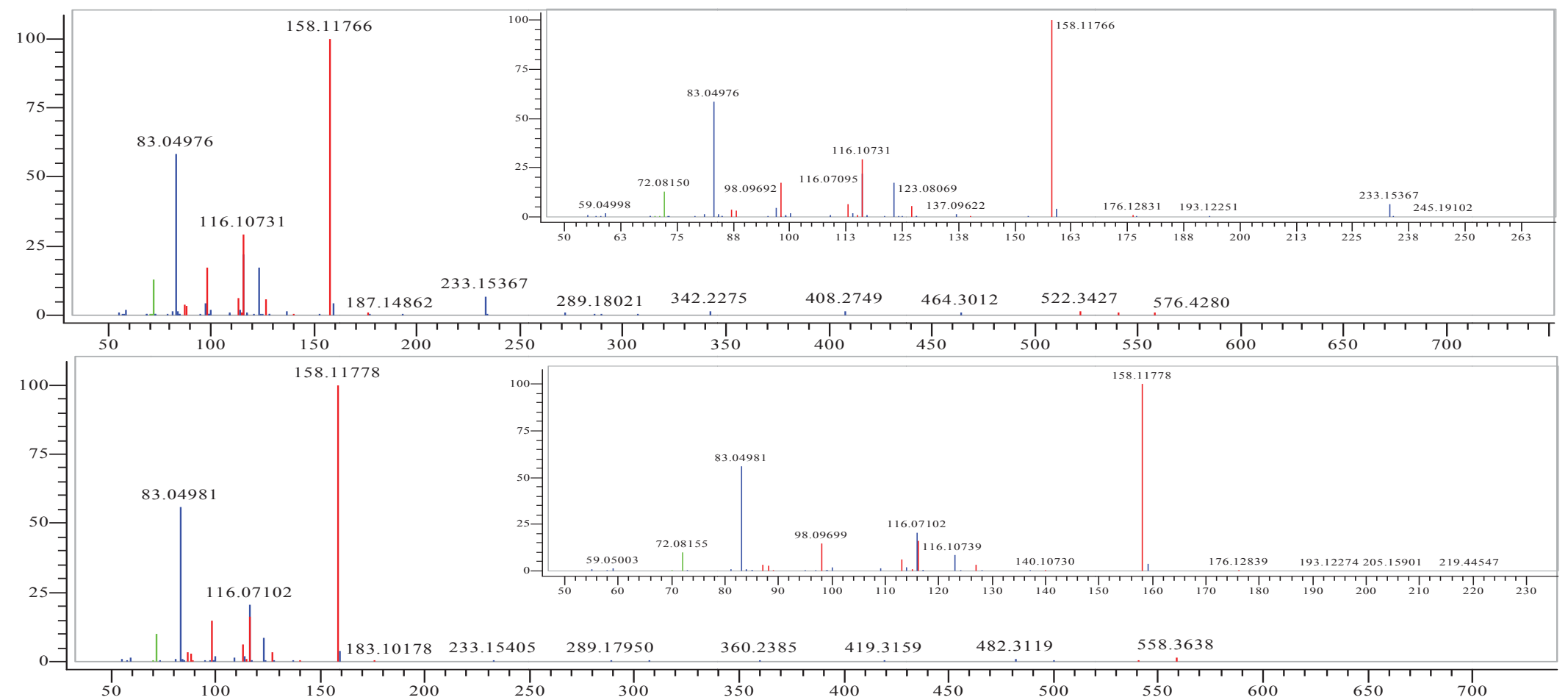


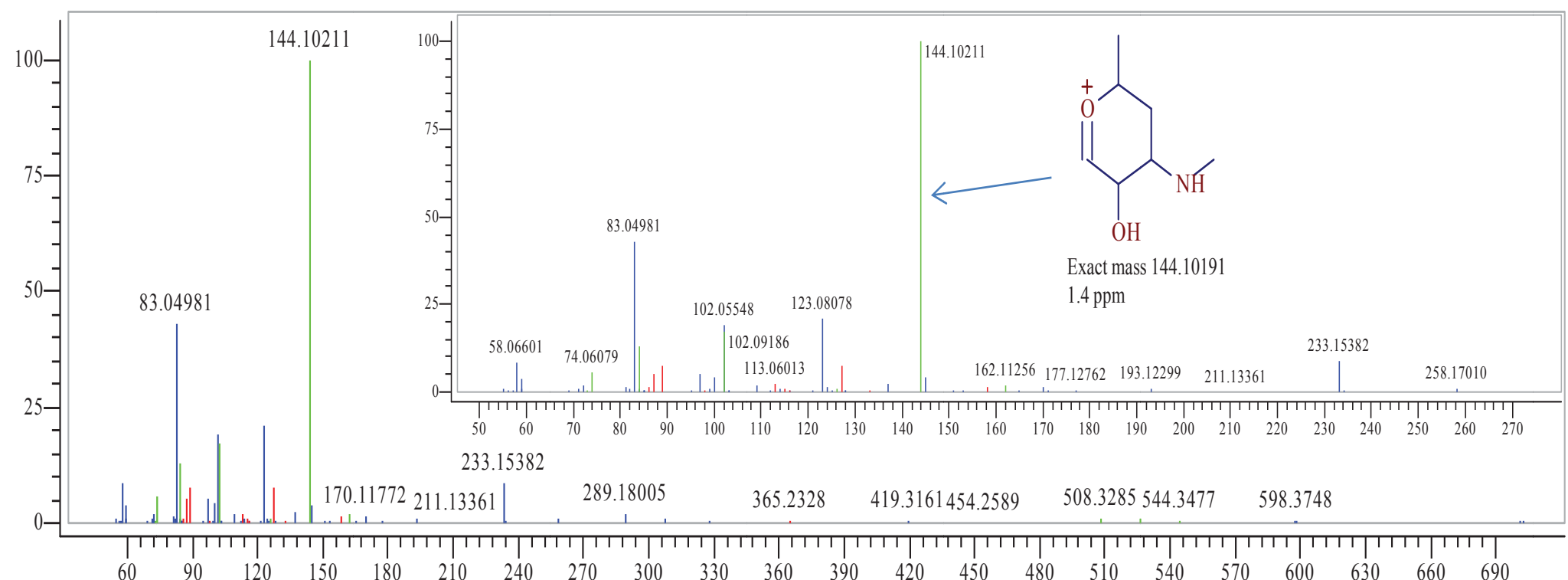

$23 c$

Figure 23. High resolution MS/MS spectra and major fragments for a) erythromycin standard, b) anhydroerythromycin in reclaimed water, and c) desmethyl-anhydroerythromycin in reclaimed water. 


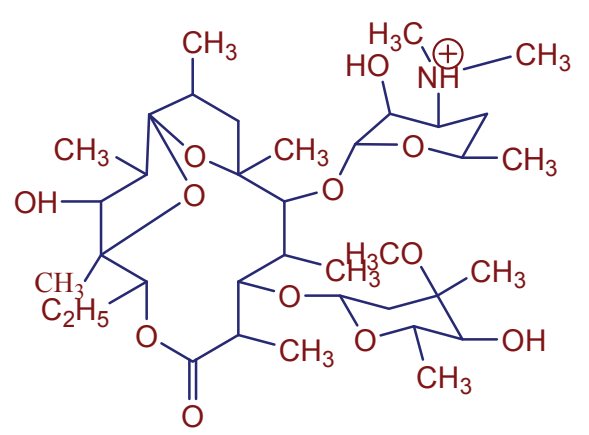

Anhydro erytrhomycin

$$
\mathrm{C}_{37} \mathrm{H}_{66} \mathrm{NO}_{12}{ }^{+}
$$

Exact Mass: 716.458

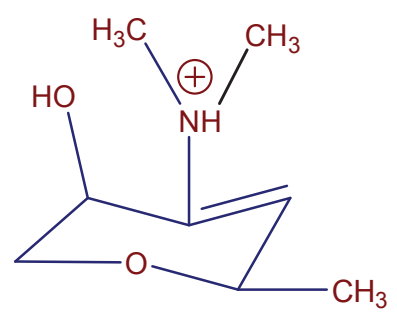

$\mathrm{C}_{8} \mathrm{H}_{16} \mathrm{NO}_{2}^{+}$

Exact Mass: 158.1176

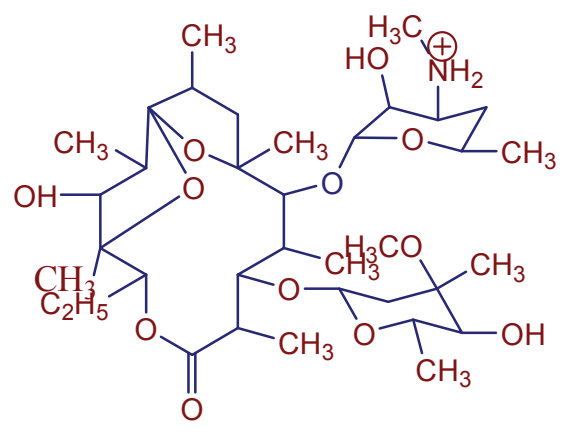

desmethyl anhdro erythromycin

$$
\mathrm{C}_{36} \mathrm{H}_{64} \mathrm{NO}_{12}{ }^{+}
$$

Exact Mass: 702.4423

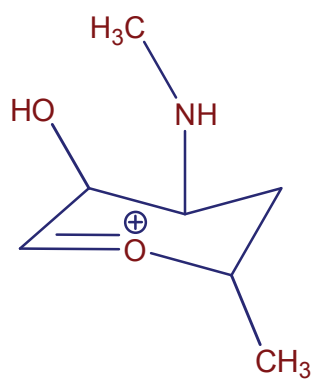

$$
\mathrm{C}_{7} \mathrm{H}_{14} \mathrm{NO}_{2}^{+}
$$

Exact Mass: 144.1019

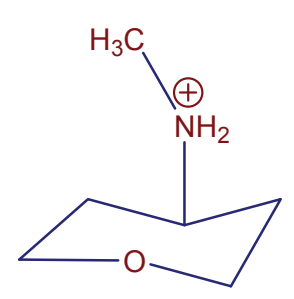

$\mathrm{C}_{6} \mathrm{H}_{14} \mathrm{NO}^{+}$
Exact Mass: 116.107

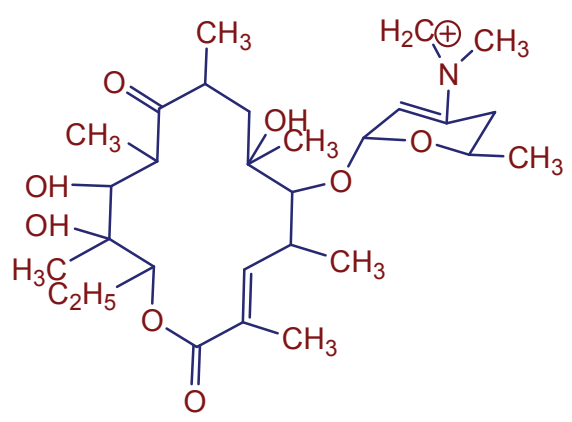

$$
\mathrm{C}_{29} \mathrm{H}_{50} \mathrm{NO}_{8}^{+}
$$

Exact Mass: 540.3531<smiles>C[C+]C=CN(C)C</smiles>

$\mathrm{C}_{6} \mathrm{H}_{12} \mathrm{~N}^{+}$

Exact Mass: 98.0964

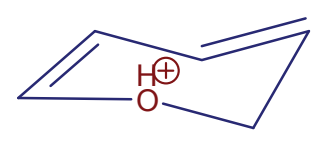

$\mathrm{C}_{5} \mathrm{H}_{7} \mathrm{O}^{+}$
Exact Mass: 83.0491

Figure 24. Major MS/MS fragments for erythromycin and its metabolites. 


\subsubsection{Identification of acetyl-sulfamethoxazole}

The high resolution MS/MS spectrum of ion $\mathrm{m} / \mathrm{z} 254.0595$ in reclaimed water at retention time 9.51 min was almost similar to that of sulfamethoxazole standard as shown in Figure. 25. The three major fragment ions $156 \mathrm{Da}, 108 \mathrm{Da}$ and $99 \mathrm{Da}$ observed were following the same relative abundance pattern in both the samples and standard, and were also in good agreement with previously reported studies (Sacher et al., 2001; Panditi et al., 2013; Wang, 2013). The structures for the major fragments were predicted using MF software based on the fragmentation rules built into it. All the labeled fragmentation ions were within 5 ppm accuracy to the proposed structures. The MS/MS spectrum of ion m/z 296.0700 at retention time 9.59 min was shown in Figure 25, matches with exact mass of acetyl-sulfamethoxazole, with mass accuracy of $0.0 \mathrm{ppm}$. The three major fragment ions $198 \mathrm{Da}, 134 \mathrm{Da}$ and $108 \mathrm{Da}$ were in good agreement with those reported in

previous studies (Gobel et al., 2004; Wang, 2013). And these fragments matched within 5 ppm to the predicted structures using MF software. The detailed fragmentation pathway was described previously by Wang from the same research group (Wang, 2013). The proposed structures for the fragment ions $134 \mathrm{Da}$ and $198 \mathrm{Da}$ contain acetyl groups evidently showing that these ions were forming from the fragmentation of acetyl-sulfamethoxazole. Therefore, the ion $\mathrm{m} / \mathrm{z} 296.0700$ was once again confirmed as acetyl-sulfamethoxazole. 


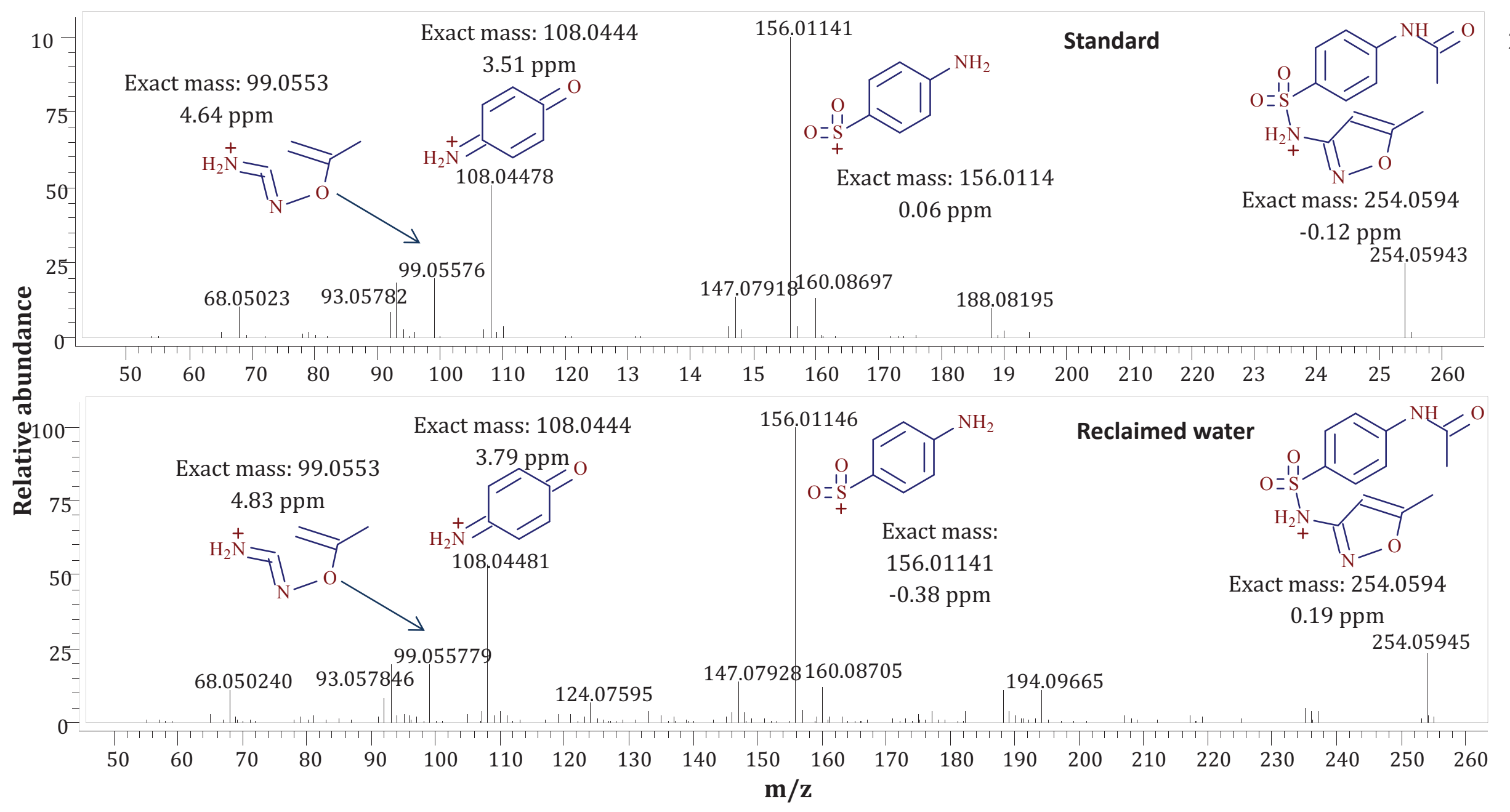




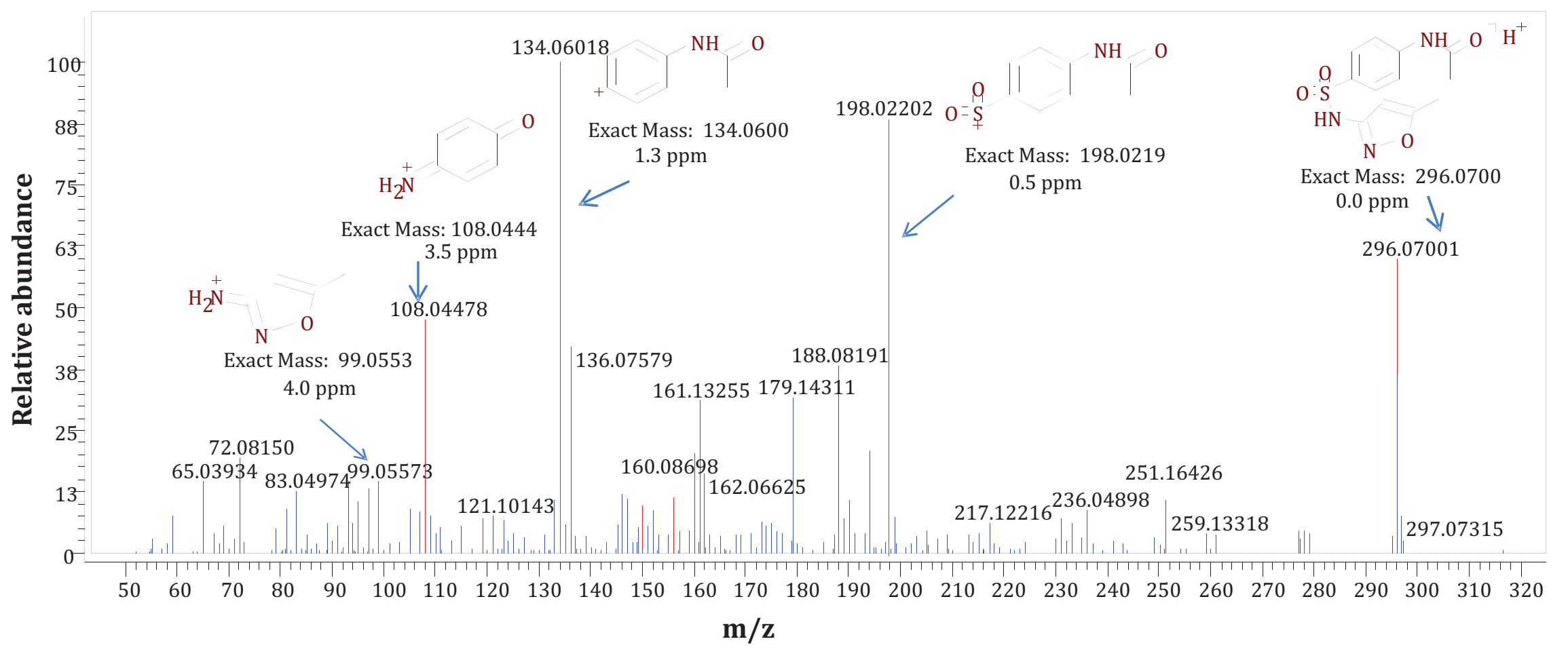

$25 c$

Figure 25. High resolution MS/MS spectra and major fragments for a) sulfamethoxazole standard, b) sulfamethoxazole in reclaimed water, and c) acetyl-sulfamethoxazole in reclaimed water. 


\subsubsection{Determination of erythromycin, sulfamethoxazole and their metabolites in reclaimed water}

Reclaimed water samples were collected and processed through off-line SPE as described earlier in this chapter. Calibration solutions were prepared by spiking standard solutions of sulfamethoxazole and erythromycin to $4 \mathrm{~mL}$ methanol, dried under gentle stream of nitrogen, then $50 \mu \mathrm{L}$ of internal standards mixture containing sulfamethoxazole-d4 and erythromycin- ${ }^{13} \mathrm{C}$-d 3 were added and reconstituted to $250 \mu \mathrm{L}$ with LC-MS grade water. Matrix spike samples were prepared by spiking second highest calibration solution to reclaimed water and extracted the same way as regular reclaimed waters.

Seven reclaimed water samples were collected over a period of one week from reclaimed water sprinklers at Florida International University Biscayne Bay Campus, North Miami, FL., for the quantitation purposes. Quantitation was performed in MS full scan mode (resolution 70,000) using the peak area of extracted ion chromatogram of the base peak ion by setting the mass tolerance at $5 \mathrm{ppm}$ and mass precision up to four decimal places. Concentrations of metabolites, desmethyl-anhydroerythromycin and acetylsulfamethoxazole were tentatively determined based on the response factors obtained for their respective standards. This quantification was performed assuming that structural similarities and closeness in chromatographic retention times of parent antibiotics and their metabolites make them to ionize equally in mass spectrometer, regardless of potential matrix effects. Therefore, retention times and mass precision of parent ions detected were used for their determination. 
Only two metabolites along with their parent drugs were consistently detected in reclaimed water suggesting that these are the only two types of antibiotic metabolites out of many metabolites for the selected antibiotics, that can survive intact through waste water treatment process, or alternatively as a matter of fact, there might be many metabolites for single parent drug therefore the concentration of individual metabolites may be very low, in order to trigger MS/MS fragmentation ion scan, hence not detected. The mean concentration of anhydroerythromycin and desmethyl-anhydroerythromycin were calculated as $519 \pm 493 \mathrm{ng} / \mathrm{L}$ and $76 \pm 57 \mathrm{ng} / \mathrm{L}$, respectively (Figure. 26); the metabolite represented $13 \%$, on the basis of mole fraction, of the total erythromycin detected in reclaimed water. At the same time the mean concentration of the other antibiotic, sulfamethoxazole and its metabolite acetyl-sulfamethoxazole were calculated as $552 \pm 348 \mathrm{ng} / \mathrm{L}$ and $362 \pm 92 \mathrm{ng} / \mathrm{L}$, respectively (Figure. 27) and the mole fraction of the metabolite represent $36 \%$, of the cumulative sulfamethoxazole concentration. The other metabolite, sulfamethoxazole glucucuronide was not detected in present study, though it was reported previously from the same research group (Wang, 2013). The possible explanation would be that the glucuronide conjugates were unstable in waste water treatment processes and either could be back transformed as reported previously or used as energy source for microbes (Bonvin, 2012). The preliminary results were showing that some of the metabolites do survive in waste water treatment and can potentially contaminate the other environmental aquatic compartments as well. Once they reach the environment, similar to the parent antibiotics, some of these metabolites were bio-active and can pose risk to untargeted species. 


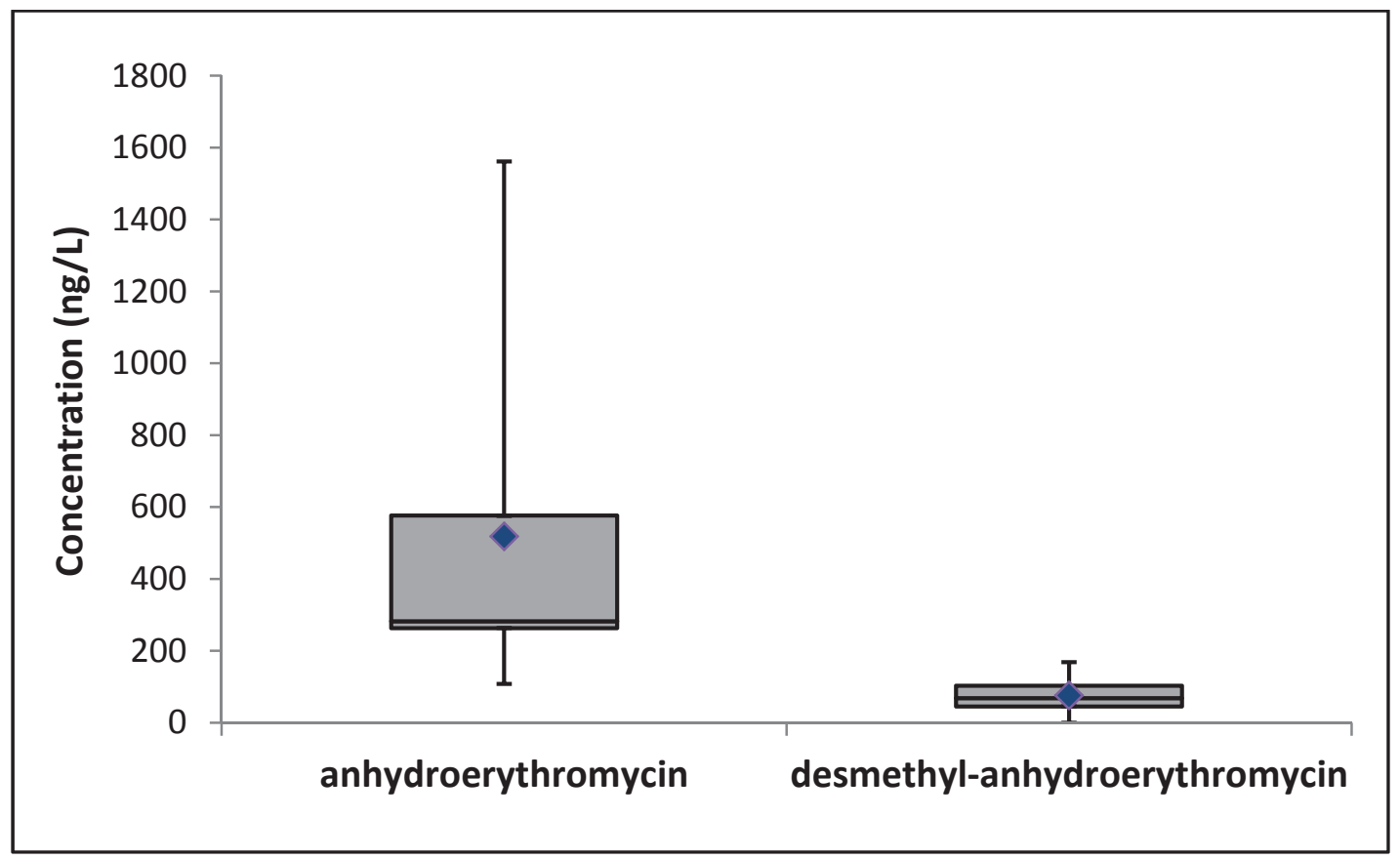

Figure 26. Occurrence of erythromycin and its metabolite desmethyl-erythromycin in reclaimed water (both were measured as anhydro- forms)

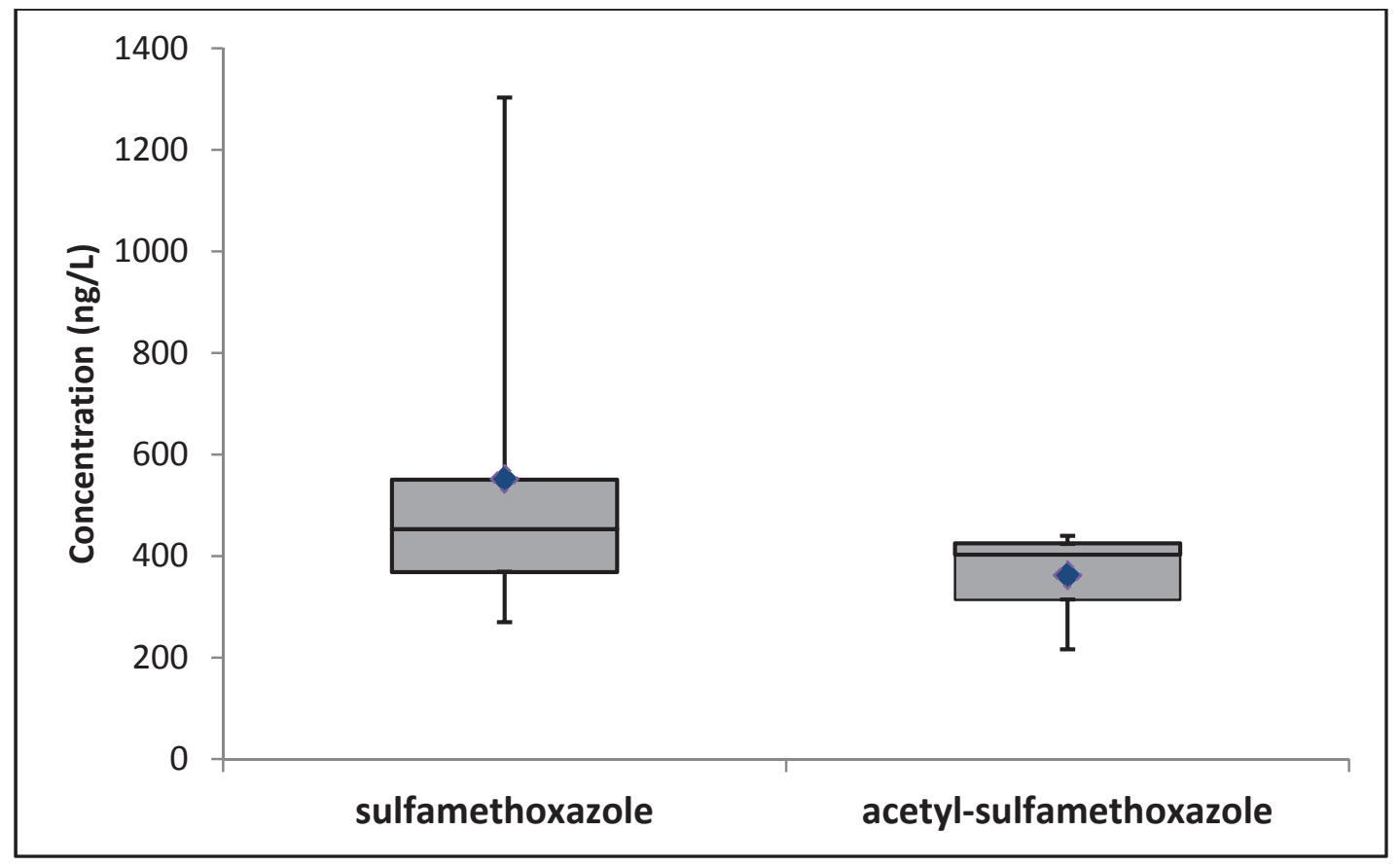


Figure 27. Occurrence of sulfamethoxazole and its metabolite acetyl-sulfamethoxazole in reclaimed water

\subsection{Conclusion}

High resolution mass spectrometry in combination with metabolic profiling software was successfully applied for identifying the metabolites/ transformation products in reclaimed water. The present study illustrated the use of combination of characteristic ions, MS/MS fragmentation pattern, relative abundance and spectral matching for the positive confirmation of compounds in the condition of no availability of standards. Erythromycin and its bio-active metabolite desmethyl-erythromycin (both observed as anhydro- forms), and sulfamethoxazole and its bio-active metabolite acetyl-sulfamethoxazole were found in reclaimed water. In two of the metabolites determined Desmethyl-erythromycin was identified for the first time in reclaimed waters. Moreover, these identities can help in comprehensive risk and fate assessment of both parent erythromycin, sulfamethoxazole and their respective metabolites in aquatic ecosystems. 
CHAPTER 7

Environmental risk assessment of antibiotic residues in reclaimed and surface

waters 


\subsection{Introduction}

Antibiotics by their nature are biologically active molecules designed to control disease spreading microorganisms in humans and animals. As described previously, antibiotics reach the domestic sewage systems and landfills through several sources. Many of these substances are not completely mineralized or eliminated in conventional waste water treatment processes applied in WWTPs (Heberer et al., 2002; Batt et al., 2006; Deblonde et al., 2011)and as a result of insufficient removal, antibiotics are finally reaching to surface waters, ground waters, sediments and even to drinking waters (Meyer et al., 1999; Kolpin et al., 2002; Ye et al., 2007; Tamtam et al., 2008; Kummerer, 2009; Panditi et al., 2013). Though the environmental concentrations detected were in $\mathrm{ng} / \mathrm{L}$ to low $\mu \mathrm{g} / \mathrm{L}$, still they can pose risk to some of the sensitive, non-targeted species (Migliore. L, 1993; Halling-Sorensen et al., 2000; Wollenberger et al., 2000; Halling-Sorensen et al., 2002; Kummerer, 2009; Gonzalez-Pleiter et al., 2013). Some of the antibiotics may have same mechanism of action due to their common physico-chemical behavior; especially antibiotics come from same chemical family; in such cases organisms will be at increased risk as a result of additive effects (Kummerer, 2009; Gonzalez-Pleiter et al., 2013). Synergistic effects are also possible due to two or more compounds existing together at the same time, the well-known example is sulfamethoxazole in combination with trimethoprim. In addition, they can also pose risk indirectly by proliferating resistant bacterial strains (Kummerer and Henninger, 2003). As reported previously,, sufficiently 
low concentrations of antibiotics could alter community structures that form the basis of food chain (Wollenberger et al., 2000; Kummerer, 2009). Therefore, it is important to evaluate the ecological risk associated with occurrence of antibiotics in the aquatic environment.

Ecological risk assessment is a process that evaluates likelihood that adverse ecological effects may occur or are occurring as a result of exposure to environmental pollutants or stressors (USEPA, 1998). The United States, Food and Drug Administration (FDA) and European Medicines Evaluation Agency (EMEA) described the general principles and guidelines for environmental risk assessment (ERA) for new and existing chemicals, employing similar tiered system. Both the agencies explained the ERA based on the comparison between predicted environmental concentrations (PEC) and worst-case predicted no effect concentrations (PNEC) estimated from standard toxicity assays (EC, 1996; FDA, 1998). Based on EMEA guidelines the PECs in waters are calculated using the following equation (Halling-Sorensen et al., 2000).

$$
\mathrm{PEC} \text { in water }=\frac{\mathrm{Ax}(100-\mathrm{R})}{365 \times \mathrm{P} \times \mathrm{V} \times \mathrm{D} \times 100} \quad \ldots \ldots \ldots \ldots \ldots \ldots \ldots(\text { Equation } 4)
$$

Where $\mathrm{A}$ is the annual consumption ( $\mathrm{kg} / \mathrm{year}), \mathrm{R}$ is the percentage removal in sewage treatment (set to zero when worst-case conditions are assessed or biodegradation in STP is missing), $\mathrm{P}$ is the population size, $\mathrm{V}$ is the volume of waste water per capita per day and $\mathrm{D}$ is the dilution factor in the environment. 
Overestimation of most PECs according to these approaches are evident, as they don't include metabolic transformation and natural degradation processes (Hernando et al., 2006). However significant improvements in risk assessment were undertaken recently by introducing assessment factors and using real time exposure data of three or four different species, to reduce the effect of uncertainties and to make the system more reliable (Bound and Voulvoulis, 2004). Environmental risk assessments are commonly based on two types of exposure studies; one is short-term 'acute ecotoxicological studies' and second is long-term 'chronic toxicity screening'. Regulatory concepts of ERA are commonly based on acute toxicological studies conducted in variety of sensitive species ( $\mathrm{EC}_{50}$ values), by applying assessment factors and evaluating environmental behavior (Hernando et al., 2006). On the other hand, the chronic toxicological screening tests of different variety and appear to be practically tough to achieve for all the drugs selected and may induce deficiencies in screening, as they may not be stable for longer durations (Lange and Dietrich, 2002). Considering the above facts, the toxicity data obtained from the acute ecotoxicity studies with application of risk quotients (RQ) derived from measured environmental concentrations instead of PECs and assessment factors would ensure a more concerted effort in environmental risk assessment.

The aim of the present study was to preliminarily characterize the environmental risk associated with detected antibiotics in reclaimed waters and surface waters by comparing the measured environmental concentrations (MEC) obtained from this study, with available literature on measured effective concentrations $\left(\mathrm{EC}_{50}\right.$ value) obtained from ecotoxicity data. 


\subsection{Toxicity studies}

Most of the selected antibiotics were detected in reclaimed water and surface waters. The maximum and mean concentration of antibiotics in reclaimed and surface waters, data presented in the earlier chapters were used in this part for risk assessment.

Three different organism types (algae, bacteria and invertebrate) commonly used in toxicity studies that represent food chain were selected. Acute toxicological data $\left(\mathrm{EC}_{50}\right.$ value) for all the three organism types in water were compiled from literature (shown in Table 18), and were used to calculate worst-case predicted no effect concentrations for each antibiotic in all the three taxonomic groups. Efforts been made to pool the $\mathrm{EC}_{50}$ value for all the antibiotics from single species in a given taxonomic group. However, if the information is not available, then the $\mathrm{EC}_{50}$ values obtained from similar species in the same taxonomic group were chosen, assuming that the given antibiotic will have similar mechanism of action and same degree of effect on all the species in single taxonomic group. To account for intra- and inter-species variability standard assessment factor was applied to mean effective concentration. Though, synergistic or antagonistic effects due to combined existence of antibiotics were possible, to aggravate or suppress the possible ecological risk, because of the lack of sufficient combined exposure data (EC50 values) for the selected antibiotics this was not considered in the present study. 
Table 18. Antibiotics detected in reclaimed water and their toxicology data from literature

\begin{tabular}{|c|c|c|c|c|c|c|c|}
\hline \multirow[b]{2}{*}{ Antibiotic } & \multicolumn{4}{|c|}{ EC50 (mg/L) } & \multicolumn{3}{|c|}{ Test Organism } \\
\hline & Algae $^{a}$ & Bacteria $^{b}$ & $\begin{array}{l}\text { Inverte } \\
\text { brate }^{c}\end{array}$ & References & Algae $^{a}$ & Bacteria $^{b}$ & Invertebrate $^{c}$ \\
\hline Naldixic acid & NA & 0.206 & NA & $\begin{array}{l}\text { b (Backhaus and Grimme, } \\
\text { 1999) }\end{array}$ & & Vibrio fischeri & \\
\hline Erythromycin & 0.35 & 0.022 & 22.45 & $\begin{array}{l}\text { a,b (Gonzalez-Pleiter et al., } \\
\text { 2013) c (Isidori et al., } \\
\text { 2005) }\end{array}$ & $\begin{array}{l}\text { Pseudokirckneriella } \\
\text { subcapitata }\end{array}$ & $\begin{array}{l}\text { Anabaena sp. } \\
\text { CPB4337 }\end{array}$ & Daphnia magna \\
\hline Sulfadiazine & 2.19 & 0.135 & NA & $\begin{array}{l}\text { a (Eguchi et al., 2004) b } \\
\text { (Lützhøft et al., 1999) }\end{array}$ & $\begin{array}{l}\text { Selenastrum } \\
\text { capricornutum }\end{array}$ & $\begin{array}{l}\text { Microcystis } \\
\text { aeruginosa }\end{array}$ & \\
\hline Clarithromycin & $0.002^{*}$ & 100 & 25.72 & $\begin{array}{l}\text { b,c (Isidori et al., 2005) a } \\
\text { (Zhang et al., 2013) }\end{array}$ & P. subcapitata & Vibrio fischeri & Daphnia magna \\
\hline Trimethoprim & 110 & 17.8 & 92 & $\begin{array}{l}\text { a,b (Halling-Sorensen et } \\
\text { al., 2000) c(Park and Choi, } \\
\text { 2008) }\end{array}$ & $\begin{array}{l}\text { Selenastrum } \\
\text { capricornutum }\end{array}$ & $\begin{array}{l}\text { activated } \\
\text { sludge }\end{array}$ & Daphnia magna \\
\hline Sulfamethoxazole & 146 & 84 & 123.1 & $\begin{array}{l}\text { a,b (Ferrari et al., 2004) } \\
\text { c(Park and Choi, 2008) }\end{array}$ & $\begin{array}{l}\text { Pseudokirchneriell } \\
\text { a subcapitata }\end{array}$ & Vibrio fischeri & Daphnia magna \\
\hline Sulfamerazine & NA & NA & 1.056 & c (Bartlett et al., 2013) & & & Hyalella azteca \\
\hline Azithromycin & NA & NA & 120 & c (Zhang et al., 2013) & & & Daphnia magna \\
\hline Norfloxacin & 80 & 0.29 & 1449 & $\begin{array}{l}\text { a (Gonzalez-Pleiter et al., } \\
\text { 2013)b (Ando et al., 2007) } \\
\text { c (Vazquez-Roig et al., } \\
\text { 2012) }\end{array}$ & $\begin{array}{l}\text { Pseudokirchneriell } \\
\text { a subcapitata }\end{array}$ & $\begin{array}{l}\text { Anabaena } \\
\text { flos-aquae } \\
\text { ATCC } 29413\end{array}$ & Daphnia magna \\
\hline Sulfachlorpyridazine & NA & 26.4 & 233.5 & b, c (Kim et al., 2007) & & Vibrio fischeri & Daphnia magna \\
\hline
\end{tabular}




\begin{tabular}{|c|c|c|c|c|c|c|c|}
\hline \multirow[b]{2}{*}{ Antibiotic } & \multicolumn{4}{|c|}{$\mathrm{EC} 50(\mathrm{mg} / \mathrm{L})$} & \multicolumn{3}{|c|}{ Test Organism } \\
\hline & Algae $^{a}$ & Bacteria $^{b}$ & $\begin{array}{l}\text { Invertebra } \\
\text { te }^{c}\end{array}$ & References & Algae $^{a}$ & Bacteria $^{b}$ & Invertebrate $^{c}$ \\
\hline Ofloxacin & 4.74 & 0.021 & 3.13 & $\begin{array}{l}\text { a (Ferrari et al., 2004) } \\
\text { b(Robinson et al., 2005) c } \\
\text { (Vazquez-Roig et al., } \\
\text { 2012) }\end{array}$ & $\begin{array}{l}\text { Pseudokirchneriella } \\
\text { subcapitata }\end{array}$ & $\begin{array}{l}\text { Microcystis } \\
\text { aeruginosa }\end{array}$ & C. dubia \\
\hline Ciprofloxacin & 2.97 & 0.005 & 991 & $\begin{array}{l}\text { a,b (Halling-Sorensen et } \\
\text { al., 2000) c (Vazquez-Roig } \\
\text { et al., 2012) }\end{array}$ & $\begin{array}{l}\text { Selenastrum } \\
\text { capricornutum }\end{array}$ & $\begin{array}{l}\text { Microcystis } \\
\text { aeruginosa }\end{array}$ & Daphnia magna \\
\hline Spiramycin & 2.3 & 58.5 & NA & $\begin{array}{l}\text { a (Halling-Sorensen, } \\
\text { 2000) b (Liu et al., 2012) }\end{array}$ & $\begin{array}{l}\text { Selenastrum } \\
\text { capricornutum }\end{array}$ & $\begin{array}{l}\text { Microcystis } \\
\text { aeruginosa }\end{array}$ & \\
\hline Tylosin & 0.411 & 0.034 & NA & $\begin{array}{l}\text { a (Eguchi et al., 2004) b } \\
\text { (Halling-Sorensen, 2000) }\end{array}$ & $\begin{array}{l}\text { Selenastrum } \\
\text { capricornutum }\end{array}$ & $\begin{array}{l}\text { Microcystis } \\
\text { aeruginosa }\end{array}$ & \\
\hline Oxytetracycline & 0.885 & 0.39 & 22.64 & $\begin{array}{l}\text { a (Munch Christensen et } \\
\text { al., 2006)b (Ando et al., } \\
\text { 2007) c (Isidori et al., } \\
\text { 2005) }\end{array}$ & $\begin{array}{l}\text { Pseudokirchneriella } \\
\text { subcapitata }\end{array}$ & $\begin{array}{l}\text { Anabaena } \\
\text { flos-aquae } \\
\text { ATCC } 29413\end{array}$ & Daphnia magna \\
\hline Roxithromycin & NA & NA & 7.1 & c(Choi et al., 2008) & & & Daphnia magna \\
\hline Doxycycline & NA & NA & NA & & & & \\
\hline Chlortetracycline & NA & & 225 & c. (Park and Choi, 2008) & & & Daphnia magna \\
\hline Enrofloxacin & 3.1 & 0.049 & 56.7 & $\begin{array}{l}\text { a,b (Robinson et al., } 2005 \\
\text { c (Park and Choi, 2008) }\end{array}$ & $\begin{array}{l}\text { Pseudokirchneriella } \\
\text { subcapitata }\end{array}$ & $\begin{array}{l}\text { Microcystis } \\
\text { aeruginosa }\end{array}$ & Daphnia magna \\
\hline
\end{tabular}

Note: Pseudokirckneriella subcapitata was formerly known as Selenastrum capricornutum; * EC50 value obtained from chronic exposure toxicity data 


\subsubsection{Risk Quotient approach}

Risk quotient (RQ) is the basic principle internationally accepted and adopted in the development of environmental risk assessment guidelines (Halling-Sorensen et al., 2000; Hernando et al., 2006). This approach in the present study is the estimation of incidence of the adverse effect occurring in aquatic compartments as a result of an antibiotic at measured environmental concentration. In acute toxicity studies, assessment of whether an antibiotic pose risk to organisms in the environment is done by comparing PEC or MEC with its PNEC to organism, expressed as RQ. Where PNEC represents the worstcase no effect concentration of antibiotic, predicted or derived from acute toxicity data (EC $\mathrm{E}_{50}$ values) by applying a standard assessment factor of 1000 (EC, 2003; Hernando et al., 2006; Gonzalez-Pleiter et al., 2013). Assessment factor was applied to account for intra- and inter-species variability in sensitivity.

$$
\begin{gathered}
\text { PNEC in water }=\frac{\mathrm{EC}_{50} \text { or } \mathrm{LC}_{50}}{1000} \ldots \ldots \ldots \ldots \ldots \text { (Equation 5) } \\
\mathrm{RQ}=\frac{\mathrm{MEC}}{\mathrm{PNEC}} \ldots \ldots \ldots \ldots \ldots \ldots(\text { Equation } 6)
\end{gathered}
$$

RQ equals or exceeds to one, suggests that an ecological risk is expected for the given antibiotic. 


\subsection{Results and Discussion-Risk assessment}

As shown in Tables 19 \& 20 (Figure. 28), PNECs and RQs were calculated for all antibiotics in three selected taxonomic groups based on measured mean environmental concentrations both in reclaimed and surface waters. PNECs were also calculated for highest antibiotic concentrations observed, to represent the least probable highest suspected risk (Table $21 \& 22$, Figure. 29). Results were interpreted based on RQ ratios following the common criteria used in risk assessment studies (EC, 1996; Hernando et al., 2006), where the RQ values ranged from 0.01 through 0.1 were marked as "low risk", 0.1 through 1 were marked as "medium risk" and equal to or exceeding 1 were marked as "high risk".

The risk quotients obtained for individual antibiotics using mean measured concentrations in reclaimed water (Table 19) showed that erythromycin, clarithromycin, ofloxacin and ciprofloxacin exceeded the RQ value one, in at least one of the three taxonomic groups. This result indicates that the measured concentrations in reclaimed water were relatively high and suspected to induce high ecological risk on representative species of the food chain. Many research studies from different parts of the world also reported similar type of results for erythromycin (Isidori et al., 2005; Hernando et al., 2006; Gonzalez-Pleiter et al., 2013), clarithromycin (Isidori et al., 2005), and ciprofloxacin (Halling-Sorensen et al., 2000) indicating the potential environmental impact of these antibiotic residues. Adding to this, erythromycin has been placed in USEPA environmental contaminant candidate list III for further evaluation (USEPA, 
2009). Worst case exposure concentrations (Table 21) (maximum antibiotic concentrations detected in reclaimed water) were showing that, in addition to the above mentioned antibiotics, naldixic acid, sulfadiazine, and tylosin were also suspected to pose potential ecological risk. However, as these concentrations may get diluted when released to other aquatic compartments, the possible hazard may not be the same as suspected.

In order to get more clarity in environmental risk associated with antibiotic exposure, surface water concentrations were used. Surface water results using mean measured concentrations (Table 20) were showing that, for erythromycin, clarithromycin and ciprofloxacin, the respective RQ values were not as high as in reclaimed water but still above one, indicating that they do pose the same level (high) of ecological risk as reclaimed water. Additionally tylosin was also observed as high risk posing antibiotic. Ofloxacin, observed as high risk in reclaimed water, turned as medium risk in surface water due to their low environmental concentrations.

The overall results were showing that the taxonomic group, bacteria were at much higher risk followed by algae. Algae were particularly sensitive to macrolide antibiotics clarithromycin, erythromycin and tylosin. Invertebrates were not under risk for any of the selected antibiotics, at least to the chosen animal model if not for all. 
Table 19. PNEC and risk quotients for antibiotics in reclaimed waters using mean antibiotic concentration detected

\begin{tabular}{|c|c|c|c|c|c|c|c|}
\hline \multirow{2}{*}{ Antibiotic } & \multirow{2}{*}{$\begin{array}{c}\mathrm{MEC}(\mathrm{ng} / \mathrm{L})_{-} \\
\text {mean }\end{array}$} & \multicolumn{3}{|c|}{$\operatorname{PNEC}(\mathrm{AF}=1000)$} & \multicolumn{3}{|c|}{ Risk Quotient } \\
\hline & & Algae & Bacteria & Invertebrate & Algae & Bacteria & Invertebrate \\
\hline Naldixic acid & 176 & - & 0.000206 & - & - & 0.85 & - \\
\hline Erythromycin & 135 & 0.00035 & 0.000022 & 0.02245 & 0.39 & 6.14 & 0.01 \\
\hline Sulfadiazine & 128 & 0.00219 & 0.000135 & - & 0.06 & 0.95 & - \\
\hline Clarithromycin & 123 & 0.000002 & 0.1 & 0.02572 & 61.5 & 0.00 & 0.00 \\
\hline Trimethoprim & 118 & 0.11 & 0.0178 & 0.092 & 0.00 & 0.01 & 0.00 \\
\hline Sulfamethoxazole & 112 & $2.68 \mathrm{E}-05$ & 0.084 & 0.1231 & 0.00 & 0.00 & 0.00 \\
\hline Sulfamerazine & 94.8 & - & - & 0.001056 & - & - & 0.09 \\
\hline Azithromycin & 89.7 & - & - & 0.12 & - & - & 0.00 \\
\hline Norfloxacin & 71.3 & 0.08 & 0.00029 & 1.449 & 0.00 & 0.25 & 0.00 \\
\hline Ofloxacin & 68.8 & 0.00474 & 0.000021 & 0.00313 & 0.01 & 3.28 & 0.02 \\
\hline Sulfachlorpyridazine & 58.9 & - & 0.0264 & 0.2335 & - & 0.00 & 0.00 \\
\hline Ciprofloxacin & 41.6 & 0.00297 & 0.000005 & 0.991 & 0.01 & 8.32 & 0.00 \\
\hline Spiramycin & 37.3 & 0.0023 & 0.0585 & - & 0.02 & 0.00 & - \\
\hline Tylosin & 22.3 & 0.000411 & 0.000034 & - & 0.05 & 0.66 & - \\
\hline Oxytetracycline & 21.1 & 0.000885 & 0.00039 & 0.02264 & 0.02 & 0.05 & 0.00 \\
\hline Roxithromycin & 17.9 & - & - & 0.0071 & - & - & 0.00 \\
\hline Doxycycline & 17.7 & - & - & - & - & - & \\
\hline Chlortetracycline & 16.9 & - & - & 0.225 & - & - & 0.00 \\
\hline Enrofloxacin & 16.7 & 0.0031 & 0.000049 & 0.0567 & 0.01 & 0.34 & 0.00 \\
\hline
\end{tabular}


Table 20. PNEC and risk quotients for antibiotics in surface waters using mean antibiotic concentration detected

\begin{tabular}{|lc|ccc|ccc|}
\hline \multirow{2}{*}{ Antibiotic } & MEC $(\mathrm{ng} / \mathrm{L})$ & \multicolumn{3}{c|}{ PNEC (AF=1000) } & \multicolumn{3}{c|}{ Risk Quotient } \\
\cline { 3 - 8 } & mean & Algae & Bacteria & Invertibrate & Algae & Bacteria & Invertibrate \\
\hline Naldixic acid & 14 & - & 0.000206 & - & - & 0.07 & - \\
Erythromycin & 44 & 0.00035 & 0.000022 & 0.02245 & 0.12 & 1.98 & 0.00 \\
Sulfadiazine & 44 & 0.00219 & 0.000135 & - & 0.02 & - & - \\
Clarithromycin & 7 & 0.000002 & 0.1 & 0.02572 & 3.71 & 0.00 & 0.00 \\
Trimethoprim & 33 & 0.11 & 0.0178 & 0.092 & 0.00 & 0.00 & 0.00 \\
Sulfamethoxazole & 14 & $2.68 \mathrm{E}-05$ & 0.084 & 0.1231 & 0.00 & 0.00 & 0.00 \\
Sulfamerazine & 17 & - & - & 0.001056 & - & - & 0.02 \\
Azithromycin & 29 & - & - & 0.12 & - & - & 0.00 \\
Norfloxacin & 24 & 0.08 & 0.00029 & 1.449 & 0.00 & 0.08 & 0.00 \\
Ofloxacin & 12 & 0.00474 & 0.000021 & 0.00313 & 0.00 & 0.58 & 0.00 \\
Sulfachlorpyridazine & 10 & - & 0.0264 & 0.2335 & - & 0.00 & 0.00 \\
Ciprofloxacin & 34 & 0.00297 & 0.000005 & 0.991 & 0.01 & $\mathbf{6 . 8 4}$ & 0.00 \\
Spiramycin & 36 & 0.0023 & 0.0585 & - & - & 0.00 & - \\
Tylosin & 74 & 0.000411 & 0.000034 & - & - & 2.19 & - \\
Oxytetracycline & 17 & 0.000885 & 0.00039 & 0.02264 & 0.02 & 0.04 & 0.00 \\
Roxithromycin & 15 & - & - & 0.0071 & - & - & 0.00 \\
Chlortetracycline & 32 & - & - & 0.225 & - & - & 0.00 \\
Enrofloxacin & 6 & 0.0031 & 0.000049 & 0.0567 & 0.00 & 0.12 & 0.00 \\
Lincomycin & 9 & - & 0.1 & - & - & 0.00 & - \\
Amoxicillin & 29 & 1.5 & 0.0563 & 1 & 0.00 & 0.00 & 0.00 \\
Danofloxacin & 43 & - & - & - & - & - & - \\
Tetracycline & 12 & 0.00331 & 0.0000251 & - & 0.00 & 0.47 & - \\
Sulfadimethoxine & 21 & 0.0023 & 0.47 & 0.248 & 0.01 & 0.00 & 0.00 \\
\hline
\end{tabular}



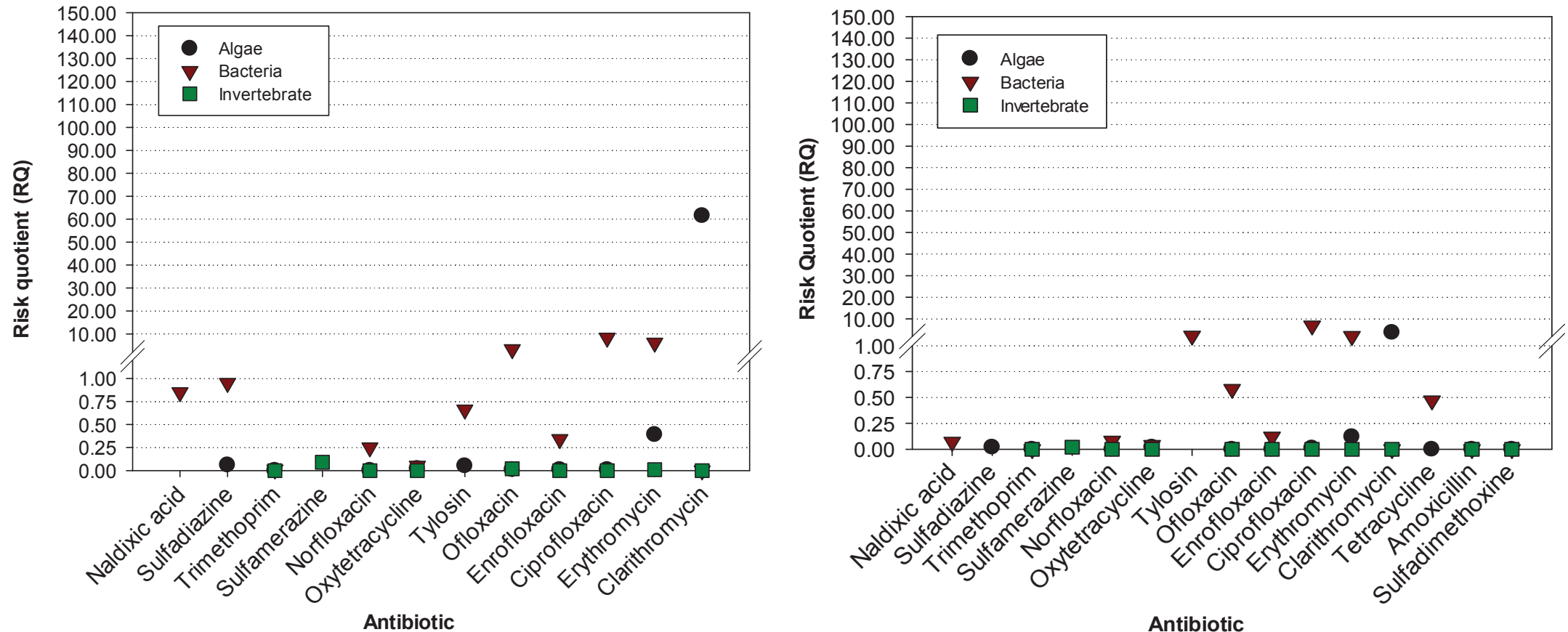

Figure 28. Risk quotients for antibiotics using mean antibiotic concentration detected in reclaimed waters (left) and in surface waters (right). Note that absence of a symbol in the graph indicates lack of ecotoxicological data for the specific antibiotic in the given taxonomic group. 
Table 21. PNEC and risk quotients for antibiotics in reclaimed waters using maximum antibiotic concentration detected

\begin{tabular}{|c|c|c|c|c|c|c|c|}
\hline \multirow{2}{*}{ Antibiotic } & \multirow{2}{*}{$\begin{array}{c}\mathrm{MEC}(\mathrm{ng} / \mathrm{L}) \\
\max \end{array}$} & \multicolumn{3}{|c|}{$\operatorname{PNEC}(\mathrm{AF}=1000)$} & \multicolumn{3}{|c|}{ Risk Quotient } \\
\hline & & Algae & Bacteria & Invertebrate & Algae & Bacteria & Invertebrate \\
\hline Naldixic acid & 453 & - & 0.000206 & - & - & 2.20 & - \\
\hline Erythromycin & 414 & 0.00035 & 0.000022 & 0.02245 & 1.18 & 18.8 & 0.02 \\
\hline Sulfadiazine & 276 & 0.00219 & 0.000135 & - & 0.13 & 2.04 & - \\
\hline Clarithromycin & 284 & 0.000002 & 0.1 & 0.02572 & 142 & 0.00 & 0.01 \\
\hline Trimethoprim & 605 & 0.11 & 0.0178 & 0.092 & 0.01 & 0.03 & 0.01 \\
\hline Sulfamethoxazole & 341 & $2.68 \mathrm{E}-05$ & 0.084 & 0.1231 & 0.00 & 0.00 & 0.00 \\
\hline Sulfamerazine & 100 & - & - & 0.001056 & - & - & 0.09 \\
\hline Azithromycin & 180 & - & - & 0.12 & - & - & 0.00 \\
\hline Norfloxacin & 71.3 & 0.08 & 0.00029 & 1.449 & 0.00 & 0.25 & 0.00 \\
\hline Ofloxacin & 127 & 0.00474 & 0.000021 & 0.00313 & 0.03 & 6.05 & 0.04 \\
\hline Sulfachlorpyridazine & 66.9 & - & 0.0264 & 0.2335 & - & 0.00 & 0.00 \\
\hline Ciprofloxacin & 68 & 0.00297 & 0.000005 & 0.991 & 0.02 & 13.6 & 0.00 \\
\hline Spiramycin & 73.7 & 0.0023 & 0.0585 & - & 0.03 & 0.00 & - \\
\hline Tylosin & 36.3 & 0.000411 & 0.000034 & - & 0.09 & 1.07 & - \\
\hline Oxytetracycline & 21.1 & 0.000885 & 0.00039 & 0.02264 & 0.02 & 0.05 & 0.00 \\
\hline Roxithromycin & 25.1 & - & - & 0.0071 & - & - & 0.00 \\
\hline Doxycycline & 17.7 & - & - & - & - & - & - \\
\hline Chlortetracycline & 16.9 & - & - & 0.225 & - & - & 0.00 \\
\hline Enrofloxacin & 21.9 & 0.0031 & 0.000049 & 0.0567 & 0.01 & 0.45 & 0.00 \\
\hline
\end{tabular}


Table 22. PNEC and risk quotients for antibiotics in surface waters using maximum antibiotic concentration detected

\begin{tabular}{|lc|ccc|ccc|}
\hline \multirow{2}{*}{ Antibiotic } & MEC $(\mathrm{ng} / \mathrm{L})$ & \multicolumn{3}{c|}{ PNEC (AF=1000) } & \multicolumn{3}{c|}{ Risk Quotient } \\
\cline { 3 - 8 } & $\max$ & Algae & Bacteria & Invertebrate & Algae & Bacteria & Invertebrate \\
\hline Naldixic acid & 14 & - & 0.000206 & - & - & 0.07 & - \\
Erythromycin & 199 & 0.00035 & 0.000022 & 0.02245 & 0.57 & 9.06 & 0.01 \\
Sulfadiazine & 139 & 0.00219 & 0.000135 & - & 0.06 & - & - \\
Clarithromycin & 8 & 0.000002 & 0.1 & 0.02572 & 3.99 & 0.00 & 0.00 \\
Trimethoprim & 129 & 0.11 & 0.0178 & 0.092 & 0.00 & 0.01 & 0.00 \\
Sulfamethoxazole & 25 & $2.68 \mathrm{E}-05$ & 0.084 & 0.1231 & 0.00 & 0.00 & 0.00 \\
Sulfamerazine & 18 & - & - & 0.001056 & - & - & 0.02 \\
Azithromycin & 61 & - & - & 0.12 & - & - & 0.00 \\
Norfloxacin & 36 & 0.08 & 0.00029 & 1.449 & 0.00 & 0.12 & 0.00 \\
Ofloxacin & 14 & 0.00474 & 0.000021 & 0.00313 & 0.00 & 0.64 & 0.00 \\
Sulfachlorpyridazine & 13 & - & 0.0264 & 0.2335 & - & 0.00 & 0.00 \\
Ciprofloxacin & 61 & 0.00297 & 0.000005 & 0.991 & 0.02 & $\mathbf{1 2 . 2}$ & 0.00 \\
Spiramycin & 61 & 0.0023 & 0.0585 & - & - & 0.00 & - \\
Tylosin & 152 & 0.000411 & 0.000034 & - & - & 4.48 & - \\
Oxytetracycline & 43 & 0.000885 & 0.00039 & 0.02264 & 0.05 & 0.11 & 0.00 \\
Roxithromycin & 23 & - & - & 0.0071 & - & - & 0.00 \\
Chlortetracycline & 48 & - & - & 0.225 & - & - & 0.00 \\
Enrofloxacin & 8 & 0.0031 & 0.000049 & 0.0567 & 0.00 & 0.16 & 0.00 \\
Lincomycin & 12 & - & 0.1 & - & - & 0.00 & - \\
Amoxicillin & 32 & 1.5 & 0.0563 & 1 & 0.00 & 0.00 & 0.00 \\
Danofloxacin & 43 & - & - & - & - & - & - \\
Tetracycline & 18 & 0.00331 & 0.0000251 & - & 0.01 & 0.71 & - \\
Sulfadimethoxine & 35 & 0.0023 & 0.47 & 0.248 & 0.02 & 0.00 & 0.00 \\
\hline
\end{tabular}



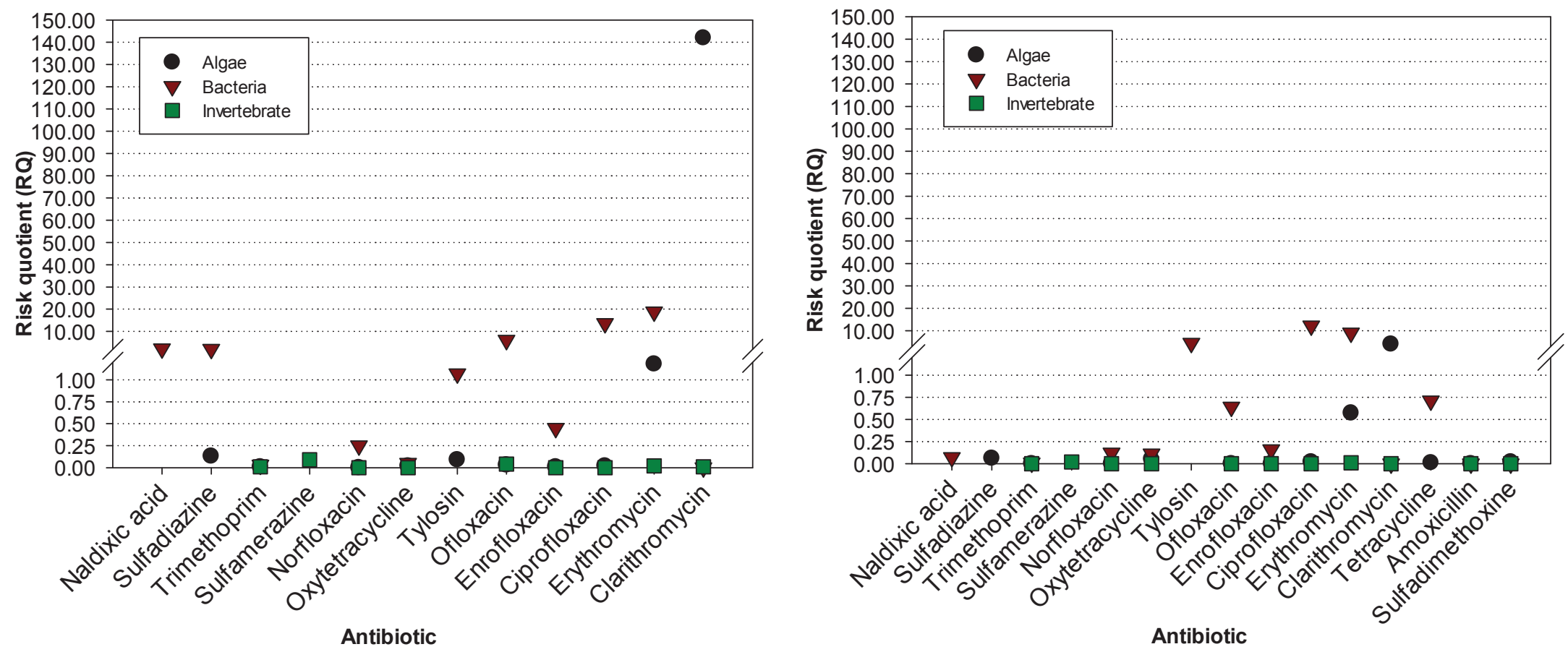

Figure 29. Risk quotients for antibiotics using maximum antibiotic concentration detected in reclaimed waters (left) and in surface waters (right). Note that absence of a symbol in the graph indicates lack of ecotoxicological data for the specific antibiotic in the given taxonomic group. 


\subsection{Conclusions}

In this study, all the antibiotics detected in reclaimed and surface waters were investigated to assess their potential risk to the aquatic organisms. The surface water antibiotic concentrations that represented the real time exposure conditions revealed that the macrolide antibiotics erythromycin, clarithromycin and tylosin along with quinolone antibiotic, ciprofloxacin were suspected to induce high toxicity to algae and bacteria. Preliminary results showing that, among the antibiotic groups tested, macrolides posed the highest ecological threat, suggesting that they may need to be further evaluated with, long-term exposure studies considering bioaccumulation factors and more number of species selected. 


\section{CONCLUSION}

An automated on-line Solid phase extraction (SPE) liquid chromatography in combination with tandem mass spectrometry (LC-MS/MS) method was developed for the quantitation of multiple classes of antibiotics in natural waters. The direct coupling of an online SPE to LC-MS/MS was achieved using column switching technique. High sensitivity in the low ng/L range was accomplished by using large volume injections with $10-\mathrm{mL}$ of the sample. This coupling technique increased the sample throughput with a total run time of $20 \mathrm{~min}$. The target analytes were detected in a triple quadrupole equipped with HESI source operated in the positive mode with two selected reaction monitoring (SRM) transitions per antibiotic for positive identity. Quantification was performed by the internal standard approach using isotopically labeled standards, to correct for matrix effects and any losses in the online extraction step. The method yielded MDLs in the range of 1.2-9.7 (except for danofloxacin), 2.2-15, 5.5-63 ng/L in deionized water, surface water and reclaimed waters, respectively and hence has the potential to measure analytes at their environmental concentrations. The method accuracy in spiked river and reclaimed samples ranged from $50-150 \%$ for the studied antibiotics. Furthermore, the method was validated in terms of precision, accuracy and linearity. The chosen approach is suitable for both research and monitoring applications.

The method was applied to reclaimed waters $(n=56$, collected from sprinklers in FIU BBC campus), surface waters $(n=43)$, ground waters $(n=8)$ and drinking waters $(n=54)$ collected from South Florida. In reclaimed waters, nalidixic acid, erythromycin, clarithromycin and azithromycin were detected in all the samples tested (26.9-453.2 
$\mathrm{ng} / \mathrm{L}$ ). Other most frequently detected antibiotics are trimethoprim, sulfamethoxazole and ofloxacin (19.3-604.9 $\mathrm{ng} / \mathrm{L})$. Occurrence of antibiotics in reclaimed water suggests that antibiotics can't be completely removed by traditional wastewater treatment process. Based on the levels detected mass loads of antibiotics released into the environment were estimated.

Surface water analysis showed that most of the canals tested were free of antibiotic residues. Among the ones tested positive for the occurrence of antibiotics, highest concentrations were found in Miami River canal (reaching up to $580 \mathrm{ng} / \mathrm{L}$ ) and reasons could be of anthropogenic origin, drainage overflows and/or landfill leachates. Black Creek canal was also found to contain antibiotic residues at relatively higher concentrations (up to $124 \mathrm{ng} / \mathrm{L}$ ) and it might be due to its close proximity to a sewage treatment plant and landfill.

Occurrence of antibiotics in both reclaimed and surface waters have prompted to check ground and drinking waters as the major ground water source Biscayne aquifer lies very close to the surface and easily prone to contamination. The number of ground water samples analyzed $(\mathrm{n}=8)$, and sampling locations may not be large enough to represent the whole Miami Dade ground water quality. However, the preliminary results showed that there were no traces of antibiotics detected in ground waters tested or may be the levels were lower than the method detection limits. Drinking water samples were collected $(\mathrm{n}=54)$ through student sampling and the analysis results showed the presence of erythromycin in $82 \%$ of the samples (n.d-66 ng/L). However, no traces of erythromycin were detected in the next set of samples collected using a stringent protocol $(\mathrm{n}=5)$. 
The non-detection of antibiotics in some of the samples indicates that their concentrations were reduced to levels below method detection limits or that parent molecule has been transformed into metabolites. Benchtop Q-Exactive orbitrap mass spectrometer was used to identify the possible metabolites of antibiotics in reclaimed waters. A phase 1 metabolite of erythromycin was tentatively identified in full scan based on accurate mass measurement. Using extracted ion chromatogram (XIC), high resolution data-dependent MS/MS spectra and metabolic profiling software the metabolite was identified as desmethyl anhydro erythromycin with $\mathrm{m} / \mathrm{z}$ 702.4423. The proposed structure was confirmed based on MS/MS fragmentation information and published literature. With the knowledge that erythromycin and anhydroerythromycin previously detected in environmental waters, this was the first known report on desmethylated erythromycin metabolite in reclaimed waters.

Finally, all the antibiotics detected in reclaimed and surface waters were investigated to assess the potential risk to the aquatic organisms. The surface water antibiotic concentrations that represented the real time exposure conditions revealed that the macrolide antibiotics, erythromycin, clarithromycin and tylosin along with quinolone antibiotic, ciprofloxacin were suspected to induce high toxicity to algae and bacteria. Preliminary results showing that, among the antibiotic groups tested, macrolides posed the highest ecological threat, and therefore, they may need to be further evaluated with, long-term exposure studies considering bioaccumulation factors and more number of species selected. 


\section{REFERENCES}

Ando, T., Nagase, H., Eguchi, K., Hirooka, T., Nakamura, T., Miyamoto, K., Hirata, K., 2007. A novel method using cyanobacteria for ecotoxicity test of veterinary antimicrobial agents. Environmental Toxicology and Chemistry 26, 601-606.

Anquandah, G.A.K., Sharma, V.K., Knight, D.A., Batchu, S.R., Gardinali, P.R., 2011. Oxidation of Trimethoprim by Ferrate(VI): Kinetics, Products, and Antibacterial Activity. Environmental Science \& Technology 45, 10575-10581.

Backhaus, T., Grimme, L.H., 1999. The toxicity of antibiotic agents to the luminescent bacterium Vibrio fischeri. Chemosphere 38, 3291-3301.

Bakkali, M., 2013. Could DNA uptake be a side effect of bacterial adhesion and twitching motility? Archives of Microbiology 195, 279-289.

Balakrishnan, V.K., Terry, K.A., Toito, J., 2006. Determination of sulfonamide antibiotics in wastewater: A comparison of solid phase microextraction and solid phase extraction methods. Journal of Chromatography A 1131, 1-10.

Barbosa, T.M., Levy, S.B., 2000. The impact of antibiotic use on resistance development and persistence. Drug Resistance Updates 3, 303-311.

Barlett, D., 2012. Integrated water quality assessment for Florida: 2012 305(b) Report and 303(d) List Update. Florida Department of Environmental Protection, Division of Environmental Assessment and RestorationTallahassee, Florida, http://www.dep.state.fl.us/water/docs/2012_integrated_report.pdf. Accessed on 4/20/2013.

Bartlett, A.J., Balakrishnan, V.K., Toito, J., Brown, L.R., 2013. Toxicity of four sulfonamide antibiotics to the freshwater amphipod Hyalella azteca. Environmental Toxicology and Chemistry 32, 866-875.

Batchu, S.R., 2013. Photo Degradation of Contaminants of Emerging concern (CECs) under Simulated Solar Radiation:Implications for their Environmental Fate. Chemistry. FIU, FIU Electronic Theses and Dissertations.Paper 859. http://digitalcommons.fiu.edu/etd/859.

Batt, A.L., Aga, D.S., 2005. Simultaneous analysis of multiple classes of antibiotics by ion trap LC/MS/MS for assessing surface water and groundwater contamination. Analytical Chemistry 77, 2940-2947. 
Batt, A.L., Bruce, I.B., Aga, D.S., 2006. Evaluating the vulnerability of surface waters to antibiotic contamination from varying wastewater treatment plant discharges. Environmental Pollution 142, 295-302.

Bedner, M., Maccrehan, W.A., 2006. Transformation of acetaminophen by chlorination produces the toxicants 1,4-benzoquinone and N-acetyl-p-benzoquinone imine. Environmental Science \& Technology 40, 516-522.

Berger, K., Petersen, B., Buningpfaue, H., 1986. Persistence of drugs occuring in liquid manure in the food-chain. Archiv Fur Lebensmittelhygiene 37, 99-102.

Bloetscher, F., Englehardt, J.D., Chin, D.A., Rose, J.B., Tchobanoglous, G., Amy, V.P., Gokgoz, S., 2005. Comparative assessment of municipal wastewater disposal methods in Southeast Florida. Water Environment Research 77, 480-490.

Boleda, M.R., Galceran, M.T., Ventura, F., 2013. Validation and uncertainty estimation of a multiresidue method for pharmaceuticals in surface and treated waters by liquid chromatography-tandem mass spectrometry. Journal of Chromatography A 1286, 146158.

Bonvin, F., 2012. Direct Photolysis of Human Metabolites of the Antibiotic Sulfamethoxazole: Evidence for Abiotic Back-Transformation. in: Julien Omlin, R.R., W. Bernd Schweizer, Peter J. Alaimo, Timothy J. Strathmann, Kristopher McNeill, Tamar Kohn (Ed.), environmental science and technology.

Bonvin, F., Omlin, J., Rutler, R., Schweizer, W.B., Alaimo, P.J., Strathmann, T.J., McNeill, K., Kohn, T., 2012. Direct Photolysis of Human Metabolites of the Antibiotic Sulfamethoxazole: Evidence for Abiotic Back-Transformation. Environmental Science \& Technology 47, 6746-6755.

Bound, J.P., Voulvoulis, N., 2004. Pharmaceuticals in the aquatic environment - a comparison of risk assessment strategies. Chemosphere 56, 1143-1155.

Boxall, A.B.A., 2004. The environmental side effects of medication - How are human and veterinary medicines in soils and water bodies affecting human and environmental health? Embo Reports 5, 1110-1116.

Boxall, A.B.A., Fogg, L.A., Blackwell, P.A., Blackwell, P., Kay, P., Pemberton, E.J., Croxford, A., 2004. Veterinary Medicines in the Environment. Reviews of Environmental Contamination and Toxicology. Springer New York, pp. 1-91.

Caliman, F.A., Gavrilescu, M., 2009. Pharmaceuticals, Personal Care Products and Endocrine Disrupting Agents in the Environment - A Review. Clean-Soil Air Water 37, 277-303. 
Celiz, M.D., Tso, J., Aga, D.S., 2009. Pharmaceutical metabolites in the environment: Analytical challenges and ecological risks. Environmental Toxicology and Chemistry 28, 2473-2484.

Chang, X.S., Meyer, M.T., Liu, X.Y., Zhao, Q., Chen, H., Chen, J.A., Qiu, Z.Q., Yang, L., Cao, J., Shu, W.Q., 2010. Determination of antibiotics in sewage from hospitals, nursery and slaughter house, wastewater treatment plant and source water in Chongqing region of Three Gorge Reservoir in China. Environmental Pollution 158, 1444-1450.

Choi, K., Kim, Y., Jung, J., Kim, M.-H., Kim, C.-S., Kim, N.-H., Park, J., 2008. Occurrences and ecological risks of roxithromycin, trimethoprim, and chloramphenicol in the Han River, Korea. Environmental Toxicology and Chemistry 27, 711-719.

CMPD, 2010. Water supply facilities work plan. City of Miami planning department, Florida. http://egov.ci.miami.fl.us/Legistarweb/Attachments/54744.pdf.

Cunningham, v., 2008. Special characteristics of pharmaceuticals related to environmental fate. springer, Berlin Heidelberg.

CVM, 2010. 2009 summary report on antimicrobials sold or distributed for use in foodproducing animals. http://www.fda.gov/downloads/ForIndustry/UserFees/AnimalDrugUserFeeActADUFA/U CM231851.pdf. Accessed on: 4/1/2013.

Danielson, P.B., 2002. The cytochrome P450 superfamily: Biochemistry, evolution and drug metabolism in humans. Current Drug Metabolism 3, 561-597.

Dantas, R.F., Contreras, S., Sans, C., Esplugas, S., 2008. Sulfamethoxazole abatement by means of ozonation. Journal of Hazardous Materials 150, 790-794.

Daughton, C.G., Ternes, T.A., 1999. Pharmaceuticals and personal care products in the environment: Agents of subtle change? Environmental Health Perspectives 107, 907-938.

Davies, J., Davies, D., 2010. Origins and Evolution of Antibiotic Resistance. Microbiology and Molecular Biology Reviews 74, 417-433.

Davis, J.G., Truman, C.C., Kim, S.C., Ascough, J.C., Carlson, K., 2006. Antibiotic transport via runoff and soil loss. Journal of Environmental Quality 35, 2250-2260.

Deblonde, T., Cossu-Leguille, C., Hartemann, P., 2011. Emerging pollutants in wastewater: A review of the literature. International Journal of Hygiene and Environmental Health 214, 442-448. 
Diaz-Cruz, M.S., Barcelo, D., 2006. Determination of antimicrobial residues and metabolites in the aquatic environment by liquid chromatography tandem mass spectrometry. Analytical and Bioanalytical Chemistry 386, 973-985.

Ding, C., He, J., 2010. Effect of antibiotics in the environment on microbial populations. Applied Microbiology and Biotechnology 87, 925-941.

Ding, J., Ren, N., Chen, L., Ding, L., 2009. On-line coupling of solid-phase extraction to liquid chromatography-tandem mass spectrometry for the determination of macrolide antibiotics in environmental water. Analytica Chimica Acta 634, 215-221.

Dinh, Q., Alliot, F., Moreau-Guigon, E., Eurin, J., Chevreuil, M., Labadie, P., 2011. Measurement of trace levels of antibiotics in river water using on-line enrichment and triple-quadrupole LC-MS/MS. Talanta 85, 1238-1245.

EC, 1996. Technical Guidance Documents in Support of the Commission Directive 93/667/EEC on risk assessment for new notified substances and commission regulations (EC) 1488/94 on risk substances, European Chemical Bureau, Ispra, Italy, 19th April 1996, part 1, 2 and 3.

EC, 2003. European Commission. Technical guidance document on risk assessment. EUR 20418 EN/2. Italy: Joint Research Centre, European Commission.

Eguchi, K., Nagase, H., Ozawa, M., Endoh, Y.S., Goto, K., Hirata, K., Miyamoto, K., Yoshimura, H., 2004. Evaluation of antimicrobial agents for veterinary use in the ecotoxicity test using microalgae. Chemosphere 57, 1733-1738.

EPA, 2013. Water treatment process., http://water.epa.gov/learn/kids/drinkingwater/watertreatmentplant_index.cfm. Accessed on $4 / 20 / 2013$.

EPA, U., 2009. Contaminant Candidate List 3 - CCL in drinking waters.

FDA, 1998. Guidance for industry-Environmental assessment of human drugs and biological applications, FDA, CDER/CBER, CMC 6, rev. 1, 1998.

Feitosa-Felizzola, J., Temime, B., Chiron, S., 2007. Evaluating on-line solid-phase extraction coupled to liquid chromatography-ion trap mass spectrometry for reliable quantification and confirmation of several classes of antibiotics in urban wastewaters. Journal of Chromatography A 1164, 95-104.

Ferrari, B., Mons, R., Vollat, B., Fraysse, B., Paxeus, N., Lo Giudice, R., Pollio, A., Garric, J., 2004. Environmental risk assessment of six human pharmaceuticals: Are the current environmental risk assessment procedures sufficient for the protection of the aquatic environment? Environmental Toxicology and Chemistry 23, 1344-1354. 
Ferrer, I., Thurman, E.M., 2012. Analysis of 100 pharmaceuticals and their degradates in water samples by liquid chromatography/quadrupole time-of-flight mass spectrometry. Journal of Chromatography A 1259, 148-157.

Fleming, A., 2001. On the antibacterial action of cultures of a penicillium, with special reference to their use in the isolation of B. influenzae. Bulletin of the World Health Organization 79, 780-790.

Gao, L.H., Shi, Y.L., Li, W.H., Niu, H.Y., Liu, J.M., Cai, Y.Q., 2012. Occurrence of antibiotics in eight sewage treatment plants in Beijing, China. Chemosphere 86, 665-671.

Garcia-Ac, A., Segura, P.A., Viglino, L., Furtos, A., Gagnon, C., Prevost, M., Sauve, S., 2009. On-line solid-phase extraction of large-volume injections coupled to liquid chromatography-tandem mass spectrometry for the quantitation and confirmation of 14 selected trace organic contaminants in drinking and surface water. Journal of Chromatography A 1216, 8518-8527.

Garcia-Galan, M.J., Garrido, T., Fraile, J., Ginebreda, A., Diaz-Cruz, M.S., Barcelo, D., 2011. Application of fully automated online solid phase extraction-liquid chromatography-electrospray-tandem mass spectrometry for the determination of sulfonamides and their acetylated metabolites in groundwater. Analytical and Bioanalytical Chemistry 399, 795-806.

Garcia-Galan, M.J., Silvia Diaz-Cruz, M., Barcelo, D., 2010. Determination of 19 sulfonamides in environmental water samples by automated on-line solid-phase extraction-liquid chromatography-tandem mass spectrometry (SPE-LC-MS/MS). Talanta 81, 355-366.

Gardinali, P.R., Zhao, X., 2002. Ultra Trace Determination of Caffeine in Natural Waters by LC-APCI-MS. Environment International 28, 521-528.

Gardinali, P.R., Zhao, X., 2002. Ultra Trace Determination of Caffeine in Natural Waters by LC-APCI-MS. Environment International 28, 521-528.

Gartiser, S., Urich, E., Alexy, R., Kummerer, K., 2007. Ultimate biodegradation and elimination of antibiotics in inherent tests. Chemosphere 67, 604-613.

Gobel, A., McArdell, C.S., Suter, M.J.F., Giger, W., 2004. Trace determination of macrolide and sulfonamide antimicrobials, a human sulfonamide metabolite, and trimethoprim in wastewater using liquid chromatography coupled to electrospray tandem mass spectrometry. Analytical Chemistry 76, 4756-4764.

Gonzalez-Pleiter, M., Gonzalo, S., Rodea-Palomares, I., Leganes, F., Rosal, R., Boltes, K., Marco, E., Fernandez-Pinas, F., 2013. Toxicity of five antibiotics and their mixtures 
towards photosynthetic aquatic organisms: Implications for environmental risk assessment. Water Research 47, 2050-2064.

Gros, M., Petrovic, M., Barcelo, D., 2009. Tracing Pharmaceutical Residues of Different Therapeutic Classes in Environmental Waters by Using Liquid Chromatography/Quadrupole-Linear Ion Trap Mass Spectrometry and Automated Library Searching. Analytical Chemistry 81, 898-912.

Gu, J., Weng, Y., Zhang, Q.Y., Cui, H.D., Behr, M., Wu, L., Yang, W.Z., Zhang, L., Ding, X.X., 2003. Liver-specific deletion of the NADPH-cytochrome P450 reductase gene - Impact on plasma cholesterol homeostasis and the function and regulation of microsomal cytochrome P450 and heme oxygenase. Journal of Biological Chemistry 278, 25895-25901.

Guengerich, F.P., 2001. Common and uncommon cytochrome P450 reactions related to metabolism and chemical toxicity. Chemical Research in Toxicology 14, 611-650.

Guengerich, F.P., 2011. Mechanisms of Drug Toxicity and Relevance to Pharmaceutical Development. Drug Metabolism and Pharmacokinetics 26, 3-14.

Gulkowska, A., Leung, H.W., So, M.K., Taniyasu, S., Yamashita, N., Yeunq, L.W.Y., Richardson, B.J., Lei, A.P., Giesy, J.P., Lam, P.K.S., 2008. Removal of antibiotics from wastewater by sewage treatment facilities in Hong Kong and Shenzhen, China. Water Research 42, 395-403.

Hadjipour, N., 2011. Histopathological Comparison of Gentamycin and Amikacin Nephrotoxicity in Rabbits. Journal of Animal and Veterinary Advances 10, 1003-1006.

Halling-Sorensen, B., 2000. Algal toxicity of antibacterial agents used in intensive farming. Chemosphere 40, 731-739.

Halling-Sorensen, B., Lutzhoft, H.C.H., Andersen, H.R., Ingerslev, F., 2000. Environmental risk assessment of antibiotics: comparison of mecillinam, trimethoprim and ciprofloxacin. Journal of Antimicrobial Chemotherapy 46, 53-58.

Halling-Sorensen, B., Nielsen, S.N., Lanzky, P.F., Ingerslev, F., Lutzhoft, H.C.H., Jorgensen, S.E., 1998. Occurrence, fate and effects of pharmaceutical substances in the environment - A review. Chemosphere 36, 357-394.

Halling-Sorensen, B., Sengelov, G., Tjornelund, J., 2002. Toxicity of tetracyclines and tetracycline degradation products to environmentally relevant bacteria, including selected tetracycline-resistant bacteria. Archives of Environmental Contamination and Toxicology 42, 263-271. 
Hao, C., Clement, R., Yang, P., 2007. Liquid chromatography-tandem mass spectrometry of bioactive pharmaceutical compounds in the aquatic environment - a decade's activities. Analytical and Bioanalytical Chemistry 387, 1247-1257.

Heberer, T., Reddersen, K., Mechlinski, A., 2002. From municipal sewage to drinking water: fate and removal of pharmaceutical residues in the aquatic environment in urban areas. Water Science and Technology 46, 81-88.

Hernandez, F., Sancho, J.V., Ibanez, M., Abad, E., Portoles, T., Mattioli, L., 2012. Current use of high-resolution mass spectrometry in the environmental sciences. Analytical and Bioanalytical Chemistry 403, 1251-1264.

Hernandez, F., Sancho, J.V., Ibanez, M., Guerrero, C., 2007. Antibiotic residue determination in environmental waters by LC-MS. Trac-Trends in Analytical Chemistry $26,466-485$.

Hernando, M.D., Mezcua, M., Fernandez-Alba, A.R., Barcelo, D., 2006. Environmental risk assessment of pharmaceutical residues in wastewater effluents, surface waters and sediments. Talanta $69,334-342$.

Hirsch, R., Ternes, T., Haberer, K., Kratz, K.L., 1999. Occurrence of antibiotics in the aquatic environment. Science of the Total Environment 225, 109-118.

Holcapek, M., Kolarova, L., Nobilis, M., 2008. High-performance liquid chromatography-tandem mass spectrometry in the identification and determination of phase I and phase II drug metabolites. Analytical and Bioanalytical Chemistry 391, 5978.

Holzel, C.S., Schwaiger, K., Harms, K., Kuchenhoff, H., Kunz, A., Meyer, K., Muller, C., Bauer, J., 2010. Sewage sludge and liquid pig manure as possible sources of antibiotic resistant bacteria. Environmental Research 110, 318-326.

Homem, V., Santos, L., 2011. Degradation and removal methods of antibiotics from aqueous matrices - A review. Journal of Environmental Management 92, 2304-2347.

Huovinen, P., 2001. Resistance to trimethoprim-sulfamethoxazole. Clinical Infectious Diseases 32, 1608-1614.

Isidori, M., Lavorgna, M., Nardelli, A., Pascarella, L., Parrella, A., 2005. Toxic and genotoxic evaluation of six antibiotics on non-target organisms. Science of The Total Environment 346, 87-98.

Jiang, L., Hu, X.L., Yin, D.Q., Zhang, H.C., Yu, Z.Y., 2011. Occurrence, distribution and seasonal variation of antibiotics in the Huangpu River, Shanghai, China. Chemosphere $82,822-828$. 
Karthikeyan, K.G., Meyer, M.T., 2006. Occurrence of antibiotics in wastewater treatment facilities in Wisconsin, USA. Science of the Total Environment 361, 196-207.

Kasprzyk-Hordern, B., Dinsdale, R.M., Guwy, A.J., 2008. Multiresidue methods for the analysis of pharmaceuticals, personal care products and illicit drugs in surface water and wastewater by solid-phase extraction and ultra performance liquid chromatographyelectrospray tandem mass spectrometry. Analytical and Bioanalytical Chemistry 391, 1293-308.

Kawaguchi, M., Nonaka, K., Masuma, R., Tomoda, H., 2013. New method for isolating antibiotic-producing fungi. Journal of Antibiotics 66, 17-21.

Khetan, S.K., Collins, T.J., 2007. Human pharmaceuticals in the aquatic environment: A challenge to green chemistry. Chemical Reviews 107, 2319-2364.

Kim, S.-C., Carlson, K., 2007. Quantification of human and veterinary antibiotics in water and sediment using SPE/LC/MS/MS. Analytical and Bioanalytical Chemistry 387, 1301-1315.

Kim, Y., Choi, K., Jung, J., Park, S., Kim, P.-G., Park, J., 2007. Aquatic toxicity of acetaminophen, carbamazepine, cimetidine, diltiazem and six major sulfonamides, and their potential ecological risks in Korea. Environment International 33, 370-375.

Kim, Y.H., Heinze, T.M., Beger, R., Pothuluri, J.V., Cerniglia, C.E., 2004. A kinetic study on the degradation of erythromycin A in aqueous solution. International Journal of Pharmaceutics 271, 63-76.

Kleywegt, S., Pileggi, V., Yang, P., Hao, C., Zhao, X., Rocks, C., Thach, S., Cheung, P., Whitehead, B., 2011. Pharmaceuticals, hormones and bisphenol A in untreated source and finished drinking water in Ontario, Canada - Occurrence and treatment efficiency. Science of The Total Environment 409, 1481-1488.

Koch, D.E., Bhandari, A., Close, L., Hunter, R.P., 2005. Azithromycin extraction from municipal wastewater and quantitation using liquid chromatography/mass spectrometry. Journal of Chromatography A 1074, 17-22.

Kolpin, D., 2013. Emerging contaminants in the environment. http://toxics.usgs.gov/regional/emc/. Accessed on 4/25/2013.

Kolpin, D.W., Furlong, E.T., Meyer, M.T., Thurman, E.M., Zaugg, S.D., Barber, L.B., Buxton, H.T., 2002. Pharmaceuticals, hormones, and other organic wastewater contaminants in US streams, 1999-2000: A national reconnaissance. Environmental Science \& Technology 36, 1202-1211. 
Kummerer, K., 2004. Resistance in the environment. Journal of Antimicrobial Chemotherapy 54, 311-320.

Kummerer, K., 2009. Antibiotics in the aquatic environment - A review - Part I. Chemosphere 75, 417-434.

Kummerer, K., Henninger, A., 2003. Promoting resistance by the emission of antibiotics from hospitals and households into effluent. Clinical Microbiology and Infection 9, 12031214.

Lange, R., Dietrich, D., 2002. Environmental risk assessment of pharmaceutical drug substances - conceptual considerations. Toxicology Letters 131, 97-104.

Larsson, D.G.J., de Pedro, C., Paxeus, N., 2007. Effluent from drug manufactures contains extremely high levels of pharmaceuticals. Journal of Hazardous Materials 148, 751-755.

Levine, A.D., Asano, T., 2004. Recovering sustainable water from wastewater. Environmental Science \& Technology 38, 201A-208A.

Levy, S.B., 1997. Antibiotic resistance: An ecological imbalance. Antibiotic Resistance: Origins, Evolution, Selection and Spread 207, 1-9.

Lillenberg, M., Yurchenko, S., Kipper, K., Herodes, K., Pihl, V., Lohmus, R., Ivask, M., Kuu, A., Kutti, S., Litvin, S.V., Nei, L., 2010. Presence of fluoroquinolones and sulfonamides in urban sewage sludge and their degradation as a result of composting. International Journal of Environmental Science and Technology 7, 307-312.

Lim, H.-K., Chen, J., Sensenhauser, C., Cook, K., Subrahmanyam, V., 2007. Metabolite identification by data-dependent accurate mass spectrometric analysis at resolving power of 60,000 in external calibration mode using an LTQ/Orbitrap. Rapid Communications in Mass Spectrometry 21, 1821-1832.

Lindberg, R.H., Olofsson, U., Rendahl, P., Johansson, M.I., Tysklind, M., Andersson, B.A.V., 2006. Behavior of fluoroquinolones and trimethoprim during mechanical, chemical, and active sludge treatment of sewage water and digestion of sludge. Environmental Science \& Technology 40, 1042-1048.

Lindsey, M.E., Meyer, M., Thurman, E.M., 2001. Analysis of trace levels of sulfonamide and tetracycline antimicrobials, in groundwater and surface water using solid-phase extraction and liquid chromatography/mass spectrometry. Analytical Chemistry 73, 46404646.

Liska, D.J., 1998. The Detoxification Enzyme Systems. Altern Med Rev, pp. 187-198. 
Liu, Y., Gao, B., Yue, Q., Guan, Y., Wang, Y., Huang, L., 2012. Influences of two antibiotic contaminants on the production, release and toxicity of microcystins. Ecotoxicology and Environmental Safety 77, 79-87.

Lopes, R.P., Augusti, D.V., Oliveira, A.G.M., Oliveira, F.A.S., Vargas, E.A., Augusti, R., 2011. Development and validation of a methodology to qualitatively screening veterinary drugs in porcine muscle via an innovative extraction/clean-up procedure and LC-MS/MS analysis. Food Additives and Contaminants Part a-Chemistry Analysis Control Exposure \& Risk Assessment 28, 1667-1676.

Lopez-Serna, R., Perez, S., Ginebreda, A., Petrovic, M., Barcelo, D., 2010. Fully automated determination of 74 pharmaceuticals in environmental and waste waters by online solid phase extraction-liquid chromatography-electrospray-tandem mass spectrometry. Talanta $83,410-424$.

Lützhøft, H.C.H., Halling-Sørensen, B., Jørgensen, S.E., 1999. Algal Toxicity of Antibacterial Agents Applied in Danish Fish Farming. Archives of Environmental Contamination and Toxicology 36, 1-6.

Macri, A., Stazi, A.V., Didelupis, G.D., 1988. Acute toxicity of furazolidone on Artmesalina, Daphnia-magna, and Culex-pipiens-molestus larvae. Ecotoxicology and Environmental Safety 16, 90-94.

MAF, 2010. Antibiotic Sales and Use Overview 2004 - 2009. ISBN 978-0-478-38448-2, Wellington, USA.

Mallet, C.R., Lu, Z.L., Mazzeo, J.R., 2004. A study of ion suppression effects in electrospray ionization from mobile phase additives and solid-phase extracts. Rapid Communications in Mass Spectrometry 18, 49-58.

Martinez, J.L., 2008. Antibiotics and antibiotic resistance genes in natural environments. Science 321, 365-367.

Masters, P.A., O'Bryan, T.A., Zurlo, J., Miller, D.Q., Joshi, N., 2003. Trimethoprimsulfamethoxazole revisited. Archives of Internal Medicine 163, 402-410.

McArdell, C.S., Molnar, E., Suter, M.J.F., Giger, W., 2003. Occurrence and fate of macrolide antibiotics in wastewater treatment plants and in the Glatt Valley Watershed, Switzerland. Environmental Science \& Technology 37, 5479-5486.

McClure, E.L., Wong, C.S., 2007. Solid phase microextraction of macrolide, trimethoprim, and sulfonamide antibiotics in wastewaters. Journal of Chromatography A $1169,53-62$. 
MDWASD, 2007a. Alternative water supply plan and reuse feasibility plan annual progress report http://www.miamidade.gov/water/library/reports/water-use-permitalternative-supply-reuse-2007.pdf. Accessed on 10/1/2012.

MDWASD, 2007b. MDWASD reuse feasibility update., http://www.miamidade.gov/water/library/reports/reuse-feasibility-summary.pdf.

Accessed on 6/10/2013.

Meyer, M.R., Maurer, H.H., 2012. Current applications of high-resolution mass spectrometry in drug metabolism studies. Analytical and Bioanalytical Chemistry 403, 1221-1231.

Meyer, M.T., Bumgarner, J., Daughtridge, J., Kolpin, D., Thurman, E., Hostetler, K., 1999. Occurrence of antibiotics in liquid waste at confined animal feeding operations and in surface and ground water. Tagung US Geological Surrey Effect of Animal Feeding Operations on Hydrologie Resources and the Environment. 20th meeting of the Society of Environmental Toxicology and Chemistry, Philadelphia, 14-18 November, pp 13-14.

MiamiDade, Biscayne Aquifer. http://www.miamidade.gov/water/biscayne-aquifer.asp. Accessed on 4/1/2013.

MiamiDade, Water supply \& Treatment. http://www.miamidade.gov/water/water-supplytreatment.asp. Accessed on 4/1/2013.

MiamiDade, 2013. About reclaimed water. http://www.miamidade.gov/water/reclaimedwater-about.asp.Accessed on 4/1/2013.

Migliore. L, G.B., A. Grassitellis and G. Dojmi di Delupis, 1993 Toxicity and bioaccumulation of sulphadimethoxinein Artemia (Crustacea, Anostraca). Int. J. Salt Lake Res, pp. 141-152

MRC, 2002. Miami River Basin Water Quality Improvement Report based on Upper Wagner Creek Pilot Program. http://www.miamirivercommission.org/PDF/stormwater.pdf. Accessed on 10/12/2012.

Munch Christensen, A., Ingerslev, F., Baun, A., 2006. Ecotoxicity of mixtures of antibiotics used in aquacultures. Environmental Toxicology and Chemistry 25, 22082215.

Murphy, P.J., 2001. Xenobiotic metabolism: A look from the past to the future. Drug Metabolism and Disposition 29, 779-780.

Nakata, H., Kannan, K., Jones, P.D., Giesy, J.P., 2005. Determination of fluoroquinolone antibiotics in wastewater effluents by liquid chromatography-mass spectrometry and fluorescence detection. Chemosphere 58, 759-766. 
Osenga, W., 2013. Antibiotics in the environment. http://courses.washington.edu/uwtjoe/issues/2004_02/2004_01_06.pdf. Accessed on 4/10/2013.

Panditi, V., Batchu, S., Gardinali, P., 2013. Online solid-phase extraction-liquid chromatography-electrospray-tandem mass spectrometry determination of multiple classes of antibiotics in environmental and treated waters. Analytical and Bioanalytical Chemistry, 1-12.

Park, S., Choi, K., 2008. Hazard assessment of commonly used agricultural antibiotics on aquatic ecosystems. Ecotoxicology 17, 526-538.

Petrovic, M., Hernando, M.D., Diaz-Cruz, M.S., Barcelo, D., 2005. Liquid chromatography-tandem mass spectrometry for the analysis of pharmaceutical residues in environmental samples: a review. Journal of Chromatography A 1067, 1-14.

Pham, T., 2012. Drug use review. http://www.fda.gov/downloads/Drugs/DrugSafety/InformationbyDrugClass/UCM319435 .pdf. Accessed on:4/1/2013.

Pozo, O.J., Guerrero, C., Sancho, J.V., Ibanez, M., Pitarch, E., Hogendoorn, E., Hernandez, F., 2006. Efficient approach for the reliable quantification and confirmation of antibiotics in water using on-line solid-phase extraction liquid chromatography/tandem mass spectrometry. Journal of Chromatography A 1103, 83-93.

Purdom, C.E., Hardiman, P.A., Bye, V.V.J., Eno, N.C., Tyler, C.R., Sumpter, J.P., 1994. Estrogenic Effects of Effluents from Sewage Treatment Works. Chemistry and Ecology $8,275-285$.

Qian, Q., Li, S.-L., Sun, E., Zhang, K.-R., Tan, X.-B., Wei, Y.-J., Fan, H.-W., Cui, L., Jia, X.-B., 2012. Metabolite profiles of icariin in rat plasma by ultra-fast liquid chromatography coupled to triple-quadrupole/time-of-flight mass spectrometry. Journal of Pharmaceutical and Biomedical Analysis 66, 392-398.

Ramirez, C.E., Batchu, S.R., Gardinali, P.R., 2013. High sensitivity Liquid Chromatography Tandem Mass Spectrometric (LC-MS/MS) methods for the analysis of dioctyl sulfosuccinate (DOSS) in different stages of an oil spill response monitoring effort. Analytical and Bioanalytical Chemistry 405, 4167-4175.

Rao, R.N., Venkateswarlu, N., Narsimha, R., 2008. Determination of antibiotics in aquatic environment by solid-phase extraction followed by liquid chromatographyelectrospray ionization mass spectrometry. Journal of Chromatography A 1187, 151-164. 
Richardson, S.D., 2006. Environmental mass spectrometry: Emerging contaminants and current issues. Analytical Chemistry 78, 4021-4045.

Robinson, A.A., Belden, J.B., Lydy, M.J., 2005. Toxicity of fluoroquinolone antibiotics to aquatic organisms. Environmental Toxicology and Chemistry 24, 423-430.

Sacher, F., Lang, F.T., Brauch, H.J., Blankenhorn, I., 2001. Pharmaceuticals in groundwaters - Analytical methods and results of a monitoring program in BadenWurttemberg, Germany. Journal of Chromatography A 938, 199-210.

Sanchez, A.R., Rogers, R.S., Sheridan, P.J., 2004. Tetracycline and other tetracyclinederivative staining of the teeth and oral cavity. International Journal of Dermatology 43, 709-715.

Segura, P.A., Gagnon, C., Sauve, S., 2007a. A fully automated on-line preconcentration and liquid chromatography-tandem mass spectrometry method for the analysis of antiinfectives in wastewaters. Analytica Chimica Acta 604, 147-157.

Segura, P.A., Garcia-Ac, A., Lajeunesse, A., Ghosh, D., Gagnon, C., Sauve, S., $2007 b$. Determination of six anti-infectives in wastewater using tandem solidphase extraction and liquid chromatography-tandem mass spectrometry. Journal of Environmental Monitoring 9, 307-313.

Seifrtova, M., Novakova, L., Lino, C., Pena, A., Solich, P., 2009. An overview of analytical methodologies for the determination of antibiotics in environmental waters. Analytica Chimica Acta 649, 158-179.

Sorensen, L.K., Elbaek, T.H., 2004. Simultaneous determination of trimethoprim, sulfadiazine, florfenicol and oxolinic acid in surface water by liquid chromatography tandem mass spectrometry. Chromatographia 60, 287-291.

Stackelberg, P.E., Furlong, E.T., Meyer, M.T., Zaugg, S.D., Henderson, A.K., Reissman, D.B., 2004. Persistence of pharmaceutical compounds and other organic wastewater contaminants in a conventional drinking-watertreatment plant. Science of the Total Environment 329, 99-113.

Stockwell, V.O., Duffy, B., 2012. Use of antibiotics in plant agriculture. Revue Scientifique Et Technique-Office International Des Epizooties 31, 199-210.

Stolker, A.A.M., Niesing, W., Hogendoorn, E.A., Versteegh, J.F.M., Fuchs, R., Brinkman, U.A.T., 2004. Liquid chromatography with triple-quadrupole or quadrupoletime of flight mass spectrometry for screening and confirmation of residues of pharmaceuticals in water. Analytical and Bioanalytical Chemistry 378, 955-963. 
Stoob, K., Singer, H.P., Goetz, C.W., Ruff, M., Mueller, S.R., 2005. Fully automated online solid phase extraction coupled directly to liquid chromatography-tandem mass spectrometry - Quantification of sulfonamide antibiotics, neutral and acidic pesticides at low concentrations in surface waters. Journal of Chromatography A 1097, 138-147.

Struhs, D.B., 2003. Water Reuse for Florida: Strategies for the effective use of reclaimed water. http://www.dep.state.fl.us/water/reuse/docs/valued resource_FinalReport.pdf. Accessed on 4/15/2013.

Tamtam, F., Mercier, F., Le Bot, B., Eurin, J., Dinh, Q.T., Clement, M., Chevreuil, M., 2008. Occurrence and fate of antibiotics in the Seine River in various hydrological conditions. Science of the Total Environment 393, 84-95.

Tang, H.P.-o., Ho, C., Lai, S.S.-1., 2006. High-throughput screening for multi-class veterinary drug residues in animal muscle using liquid chromatography/tandem mass spectrometry with on-line solid-phase extraction. Rapid Communications in Mass Spectrometry 20, 2565-2572.

Templeton, M.R., Graham, N., Voulvoulis, N., 2009. Emerging chemical contaminants in water and wastewater INTRODUCTION. Philosophical Transactions of the Royal Society a-Mathematical Physical and Engineering Sciences 367, 3873-3875.

Ternes, T.A., 2001. Analytical methods for the determination of pharmaceuticals in aqueous environmental samples. Trac-Trends in Analytical Chemistry 20, 419-434.

Thurman, E.M., Ferrer, I., 2012. Liquid chromatography/quadrupole-time-of-flight mass spectrometry with metabolic profiling of human urine as a tool for environmental analysis of dextromethorphan. Journal of Chromatography A 1259, 158-166.

Trenholm, R.A., Vanderford, B.J., Drewes, J.E., Snyder, S.A., 2008. Determination of household chemicals using gas chromatography and liquid chromatography with tandem mass spectrometry. Journal of Chromatography A 1190, 253-262.

UCS, Union of Concerned Scientists, 2001. Hogging It: Estimates of Antimicrobial Abuse in Livestock. Press Release, 8 January, Cambridge, MA.

UN, 2003. World Population Prospects: The 2002 Revision-Highlights; United Nations Population Division, Department of Economic and Social Affairs. United Nations Population Division,Department of Economic and Social Affairs, http://www.un.org/en/development/desa/population/. Accessed on 4/10/2013.

USCB, 2012. State \& County QuickFacts. http:/quickfacts.census.gov/qfd/states/12/12086.html. Accessed on 10/1/2012. 
USEPA, 1998. Guidelines for Ecological Risk Assessment EPA/630/R-95/002F. USEPA, Washington,DC, USA. http://www.epa.gov/raf/publications/pdfs/ECOTXTBX.PDF. Accessed on 5/15/2013.

USEPA, 2009. Contaminant Candidate List 3 - CCL in drinking waters., http://water.epa.gov/scitech/drinkingwater/dws/ccl/ccl3.cfm Accessed on 10/1/2012.

USEPA, 2010. Definition and procedures for the determination of the method detection limit. Revision 1.11. edition. Guidelines establishing test procedures for the analysis of pollutants. Appendix B, part 136. Definition and procedures for the determination of the method detection limit. U.S. Code of Federal Regulations, Title 40. Revision 1.11.

Vazquez-Roig, P., Andreu, V., Blasco, C., Pico, Y., 2012. Risk assessment on the presence of pharmaceuticals in sediments, soils and waters of the Pego-Oliva Marshlands (Valencia, eastern Spain). Science of the Total Environment 440, 24-32.

Vieno, N.M., Tuhkanen, T., Kronberg, L., 2006. Analysis of neutral and basic pharmaceuticals in sewage treatment plants and in recipient rivers using solid phase extraction and liquid chromatography-tandem mass spectrometry detection. Journal of Chromatography A 1134, 101-111.

Vione, D., Feitosa-Felizzola, J., Minero, C., Chiron, S., 2009. Phototransformation of selected human-used macrolides in surface water: Kinetics, model predictions and degradation pathways. Water Research 43, 1959-1967.

Wang, C., 2012. Assessment of the Occurrence and Potential Effects of Pharmaceuticals and Personal Care Products inSouth Florida Waters and Sediments. Chemistry and Biochemistry. Florida International University, FIU Electronic Theses and Dissertations.Paper 689. http://digitalcommons.fiu.edu/etd/689.

Wang, J., 2013. Assessment of the Occurrence and Potential Risks of Pharmaceuticals and their Metabolites in Fish and Water UsingLiquid Chromatography Mass Spectrometry. Chemistry and Biochemistry. FIU, FIU Electronic Theses and Dissertations.Paper 835. http://digitalcommons.fiu.edu/etd/835

Wang, J., Gardinali, P.R., 2012. Analysis of selected pharmaceuticals in fish and the fresh water bodies directly affected by reclaimed water using liquid chromatographytandem mass spectrometry. Analytical and Bioanalytical Chemistry 404, 2711-2720.

Watkinson, A.J., Murby, E.J., Kolpin, D.W., Costanzo, S.D., 2009. The occurrence of antibiotics in an urban watershed: From wastewater to drinking water. Science of the Total Environment 407, 2711-2723.

williams, R.T., 1947. Detoxification Mechanisms. John Wiley and Sons, Inc, New York. 
Wollenberger, L., Halling-Sorensen, B., Kusk, K.O., 2000. Acute and chronic toxicity of veterinary antibiotics to Daphnia magna. Chemosphere 40, 723-730.

Yang, S.W., Cha, J.M., Carlson, K., 2005. Simultaneous extraction and analysis of 11 tetracycline and sulfonamide antibiotics in influent and effluent domestic wastewater by solid-phase extraction and liquid chromatography-electro spray ionization tandem mass spectrometry. Journal of Chromatography A 1097.

Ye, Z., Weinberg, H.S., Meyer, M.T., 2007. Trace analysis of trimethoprim and sulfonamide, macrolide, quinolone, and tetracycline antibiotics in chlorinated drinking water using liquid chromatography electrospray tandem mass spectrometry. Analytical Chemistry 79.

Zhang, R., Tang, J., Li, J., Zheng, Q., Liu, D., Chen, Y., Zou, Y., Chen, X., Luo, C., Zhang, G., 2013. Antibiotics in the offshore waters of the Bohai Sea and the Yellow Sea in China: Occurrence, distribution and ecological risks. Environmental Pollution 174, 7177.

Zhang, Y., Steinman, M.A., Kaplan, C.M., 2012. Geographic Variation in Outpatient Antibiotic Prescribing Among Older Adults. Archives of Internal Medicine 172, 14651471.

Zuccato, E., Castiglioni, S., Fanelli, R., 2005. Identification of the pharmaceuticals for human use contaminating the Italian aquatic environment. Journal of Hazardous Materials 122, 205-209. 
VITA

\section{Venkata Reddy Panditi}

$1999-2003$

Bachelor of Pharmacy

M L College of Pharmacy

Singarayakonda, India

2004-2006

Master of Pharmacy, Pharmaceutical Analysis

Andhra University

Visakhapatnam, India

2007-present

Doctoral Candidate

Florida International University

Miami, Florida

Teaching \& Research Assistant

Florida International University

Miami, Florida

\section{PUBLICATIONS AND PRESENTATIONS}

Venkata R. Panditi, Sudha Rani Batchu, Piero R. Gardinali. Online solid phase extraction-liquid chromatography-electrospray-tandem mass spectrometry determination of multiple classes of antibiotics in environmental and treated waters. Analytical and Bioanalytical Chemistry. 405(18), 5953-5964, 2013.

Anquandah, G.A.K, Sharma, V.K, Venkata R. Panditi, Gardinali, P.R, Kim, H, Oturan, M.A. Ferrate (VI) oxidation of propranolol: Kinetics and products. Chemosphere. 91, 105-109, 2013.

Sudha Rani Batchu, Natalia Quinete, Venkata R. Panditi, Piero R. Gardinali. Online solid phase extraction liquid chromatography tandem mass spectrometric (SPE-LCMS/MS) method for the determination of Sucralose in reclaimed waters and its photodegradation in natural waters from South Florida (In review, Chemistry Central Journal)

Sudha Rani Batchu, Venkata R. Panditi, Piero R. Gardinali. Photodegradation of antibiotics in simulated solar radiation: Implications for their environmental fate (In review, Science of the Total Environment) 
Sudha Rani Batchu, Venkata R. Panditi, Piero R. Gardinali. Photodegradation of sulfonamide antibiotics in simulated and natural sunlight: Implications for their environmental fate (In review, Journal of Environmental Science and Health- Part B Pesticides, Food Contaminants, and Agricultural Wastes)

Sudha Rani Batchu, Natalia Quinete, Venkata Reddy Panditi and Piero R. Gardinali. Online solid phase extraction liquid chromatography tandem mass spectrometry (SPELC-MS/MS) method for the determination of Sucralose in reclaimed and drinking waters and its photo degradation in natural waters from South Florida. $9^{\text {th }}$ Annual workshop on LC-MS/MS Applications in Environmental Analysis and Food Safety. May $6^{\text {th }}-9^{\text {th }}, 2013$, CCIW, Burlington, Ontario, Canada.

Venkata R. Panditi and Piero R. Gardinali; An on-line SPE/LC-MS/MS method for the determination of multiple classes of antibiotics in environmental and reclaimed waters. SETC North America, 33rd Annual Meeting, 11-15, November, 2012, Long Beach, CA, USA.

Venkata Reddy Panditi and Piero Gardinali, An on-line preconcentration and liquid chromatography tandem mass spectrometry method for the determination of multiple classes of antibiotics in reclaimed waters', $7^{\text {th }}$ Annual LC/MS/MS work shop, June $13^{\text {th }}$ 2011, Buffalo, NY, USA. (Received Best poster award)

Sudha Rani Batchu, V. Panditi, J. Wang, and P. Gardinali. Photodegradation of a macrolide antibiotic roxithromycin by simulated solar radiation. Southeast SETAC Chapter Regional Meeting, University of Florida, May $30^{\text {th }}-$ June $1^{\text {st }}, 2008$, Gainesville, FL, USA. 